\title{
POSICIONAMENTO DE CAMINHÕES AUTÔNOMOS PARA COLHEITA DE CANA-DE-AÇÚCAR: UMA ABORDAGEM BASEADA EM VISÃO COMPUTACIONAL
}

Dissertação de Mestrado apresentada ao Centro Universitário FEI, como parte dos requisitos necessários para obtenção do título de Mestre em Engenharia Elétrica. Orientado pelo Prof. Dr. Reinaldo Augusto da Costa Bianchi.

São Bernardo do Campo 
de Araujo Fernandes, Érico.

POSICIONAMENTO DE CAMINHÕES AUTÔNOMOS PARA

COLHEITA DE CANA-DE-AÇÚCAR: UMA ABORDAGEM

BASEADA EM VISÃO COMPUTACIONAL / Érico de Araujo

Fernandes. São Bernardo do Campo, 2020.

85 f. : il.

Dissertação - Centro Universitário FEI.

Orientador: Prof. Dr. Reinaldo Augusto da Costa Bianchi.

1. Redes Neurais Artificiais. 2. Visão Computacional. 3.

Processamento de Imagem. 4. Caminhão Autônomo. I. Augusto da Costa Bianchi, Reinaldo, orient. II. Título.

Elaborada pelo sistema de geração automática de ficha catalográfica da FEI com os dados fornecidos pelo(a) autor(a). 
centro

Título do Trabalho: Posicionamento de caminhões autônomos para colheita de cana de açúcar: uma abordagem baseada em visão computacional.

Área de Concentração: Inteligência Artificial Aplicada à Automação e Robótica

Orientador: Prof. Dr. Reinaldo Augusto da Costa Bianchi

Data da realização da defesa: 26/06/2020

ORIGINAL ASSINADA

Avaliação da Banca Examinadora:

São Bernardo do Campo, / / /

\section{MEMBROS DA BANCA EXAMINADORA}

Prof. Dr. Reinaldo Augusto da Costa Bianchi

Prof. Dr. Plinio Thomaz Aquino Junior

Prof. Dr. Alexandre da Silva Simões
Ass.:

Ass. :

Ass.:

A Banca Julgadora acima-assinada atribuiu ao aluno o seguinte resultado:

APROVADO $\square$

REPROVADO

\section{VERSÃO FINAL DA DISSERTACÃ̃O}

APROVO A VERSÃo FINAL DA DISSERTAÇÃo EM QUE FORAM INCLUÍDAS AS RECOMENDAÇÕES DA BANCA EXAMINADORA
Aprovação do Coordenador do Programa de Pós-graduação

Prof. Dr. Carlos Eduardo Thomaz 
Dedico este trabalho à minha esposa, filhos e meus pais, pelo apoio e aquiescência nos momentos de minha ausência. 


\section{AGRADECIMENTOS}

Agradeço ao meu orientador Prof. Dr. Reinaldo Bianchi pela dedicação e inspiração para tornar este trabalho realidade. Ofereceu um apoio fundamental para que eu conseguisse transpassar os desafios impostos. Desafios estes, que emergem diante de alguém que estava mais de 15 anos longe do mundo acadêmico, e ainda decide iniciar o aprendizado de um novo ramo do conhecimento.

Agradeço, também, meu colega de classe e amigo Lucas Ribeiro, que me apoiou nos momentos mais complexos no decorrer de toda a minha jornada de aprendizado. Sem seu apoio, certamente não estaria redigindo estas palavras hoje.

Meus agradecimentos ao meu colega Jonas Henrique R. de Oliveira, que não mediu esforços para me ajudar no desenvolvimento e aplicação da rede neural artificial. Grande profissional que adentra ao mercado Brasileiro.

À Mercedes-Benz do Brasil Ltda. e seu Board of Management ofereço meu sincero agradecimento por todo apoio oferecido, reconhecimento de meu esforço e inspiração para execução deste trabalho. 
"Eu acredito no cavalo. O automóvel é um fenômeno temporário."

Guilherme II - Imperador alemão e Rei da Prússia de 1888 até sua abdicação em 1918. 


\section{RESUMO}

Diante da constante evolução tecnológica e consolidação como preponderante agente do Produto Interno Bruto brasileiro, o agronegócio alcançou um espaço importante na sociedade brasileira e tem como relevante protagonista, a cana-de-açúcar, que é grande fonte de energia renovável, além de ser foco constante de evoluções tecnológicas em seu ciclo produtivo. Este trabalho tem como finalidade apresentar um sistema para posicionamento de caminhões autônomos no processo de colheita de cana-de-açúcar, conforme linhas de plantio pré-estabelecidas a fim de aumentar a produtividade na colheita da cana-de-açúcar. Pois com a manutenção do caminhão corretamente posicionado na pista traçada anteriormente durante o plantio, não há ocorrência de atropelamento do broto da cana-de-açúcar durante o processo de colheita, mantendo assim broto desta intacto e pronto para próxima brotação e subsequente colheita. Quanto mais vezes puder se fazer a colheita sem um novo plantio, ou seja, apenas se valendo do broto remanescente da colheita anterior, maior a produtividade no ciclo desta monocultura. Para este trabalho, após a devida aplicação de técnicas de calibração de câmeras, foi levantado um banco de imagens com mais de 24 horas de filmagens que foram convertidas em um banco com mais de 25 mil imagens referentes ao processo de colheita de cana-de-açúcar durante a manhã, tarde e noite. Foram avaliadas 2 hipóteses para atendimento do objetivo deste trabalho com a aplicação Filtro Sobel, Transformada de Hough e Rede Neural Convolucional MobileNet. A hipótese com aplicação da Rede Neural artificial MobileNet apresentou melhor resultado ao determinar as linhas de plantio com Precisão de $57,22 \%$ e Revocação de $28,84 \%$.

Palavras-Chave: Redes Neurais Artificiais, Visão Computacional, Processamento de Imagem, Caminhão Autônomo. 


\begin{abstract}
Due to the constant technological evolution and consolidation as a preponderant agent of the Brazilian Gross Domestic Product, agribusiness has reached an important space in Brazilian society and its main protagonist is sugarcane, which is a great source of renewable energy and constant focus of technological developments in its production cycle. This work aims to present a system for positioning of autonomous trucks in the sugarcane harvesting process, according to pre-established planting lines to increase productivity in the sugarcane harvesting. By keeping the truck correctly positioned on the track previously traced during planting, there is no occurrence of trampling of the sugarcane sprout during the harvesting process, thus leaving this sprout intact and ready for the next sprouting and subsequent harvest. The more times it is possible to harvest without a new planting, by using the remaining bud from the previous harvest, the greater the productivity in the cycle of this monoculture. For this work, after the proper application of camera calibration techniques, an image bank was built with more than 24 hours of footage that were converted into a bank with more than 25 thousand images referring to the sugarcane harvesting process in the morning, afternoon and night. Two hypotheses were evaluated to achieve the objective of this work with the application Sobel Filter, Hough Transform and MobileNet Convolutional Artificial Neural Network.The hypothesis with application of the Artificial Neural Network MobileNet showed the best result when determining the planting lines with Precision of $57,22 \%$ and Recall of $28,84 \%$.
\end{abstract}

Keywords: Artificial Neural Networks, Computer Vision, Image Processing, Autonomous Truck. 


\section{LISTA DE ILUSTRAÇÕES}

Figura 1 - Posicionamento da câmera no espaço 3D 15

Figura 2 - Rotação de objeto nos eixos 3D 16

Figura 3 - Correlação de imagens com mundo real 17

Figura 4 - Exemplo de aplicação do Filtro Sobel no eixo x e y 21

Figura 5 - Espaço Hough 23

$\begin{array}{ll}\text { Figura } 6 \text { - Perceptron } & 27\end{array}$

Figura 7 - Rede Neural Multicamada $\quad 34$

Figura 8 - Rede Neural Convolucional de 2 camadas 36

Figura 9 - Arquitetura para metodologia de detecção de objeto 39

Figura 10 - Algoritmo para localização 2D - 3D - RANSAC 41

Figura 11 - Imagem tratada para encontrar profundidade 43

Figura 12 - Reconhecimento de linhas no solo 44

Figura 13 - Arquitetura LSTM 45

Figura 14 - Hipótese $1 \quad 48$

Figura 15 - Hipótese $2 \quad 49$

Figura 16 - Caminhão marca Mercedes-Benz Axor 3131 mod. 8x4 50

Figura 17 - Demonstração de recorte de imagem em quadrantes - "Crop" 52

Figura 18 - Recorte (Crop) do quadrante 0,2 descrito na Figura 17, anteriormente 52

Figura 19 - Aplicação do Filtro Sobel na imagem da Figura 18

Figura 20 - Histograma e concentração de pixels $\quad 54$

Figura 21 - Cálculo da média de pixels - Pista 55

Figura 22 - Exemplo de linha de plantio não perpendicular ao sentido de marcha 56

Figura 23 - Exemplo marcação de imagem para treinamento da Rede Neural 57

Figura 24 - Curva de Aprendizado MobileNet 58

Figura 25 - Exemplo reconhecimento de imagem classificação pista plantio 59

Figura 26 - Curva de Precisão $\quad 60$

Figura 27 - Curva de Revocação 


\section{LISTA DE TABELAS}

Tabela 1 - Arquitetura MobileNet padrão

Tabela 2 - Pesquisa de trabalhos correlatos 


\section{SUMÁRIO}

1 INTRODUÇÃO 12

2 REVISÃO TEÓRICA $\quad 15$

2.1 CALIBRAÇÃO DE CAMERAS 15

2.2 DETECTORES DE BORDAS 18

2.3 TRANSFORMADA DE HOUGH 21

2.4 REDES NEURAIS ARTIFICIAIS 25

2.5 APRENDIZADO PROFUNDO 30

3 TRABALHOS CORRELATOS

$4 \quad$ PROPOSTA $\quad 47$

5 EXPERIMENTOS E RESULTADOS

6 DISCUSSÃO

7 CONCLUSÃO $\quad 65$

$\begin{array}{ll}\text { REFERENCIAS } & 67\end{array}$

APÊNDICE A - CONCEITO CAMINHÃO AUTONOMO 70

APÊNDICE B - CONTROLE PROPORCIONAL 72

APÊNDICE C - PESQUISA DE TRABALHOS CORRELATOS 74

APÊNDICE D - APRENDIZADO DE MÁQUINA 80 


\section{INTRODUÇÃO}

Conforme a Confederação de Agricultura e Pecuária do Brasil (CNA, 2020), no ano de 2019 o PIB do agronegócio cresceu 3,81\% e atingiu 21,4\% de participação no PIB nacional. Com os subsequentes relatos de safra recorde e o ambiente externo propício para exportação.

O agronegócio no Brasil tem como um de seus grandes protagonistas a cana-deaçúcar, que é grande fonte de energia renovável e foco constante de evoluções tecnológicas tanto em seu ciclo produtivo, quanto na vasta utilização de seus subprodutos.

Um marco relevante relacionado ao ciclo produtivo da cana-de-açúcar é a legislação referente à colheita denominada "Lei da Queima da Cana" (Lei no 11.241/2002). Esta legislação trata da queima controlada da cana-de-açúcar e de sua gradual eliminação.

A legislação prevê planos diferenciados para áreas mecanizáveis (maiores que 150 hectares e declividade menor ou igual a 12\%). Neste caso, o prazo para eliminação gradativa das queimadas foi de $20 \%$ em 2003, 30\% em 2006, 50\% em 2011, 80\% em 2016 e $100 \%$ até 2021.

A partir deste marco regulatório, foram empregados esforços e investimentos para mecanização da referida colheita e desenvolvimento de tecnologias para aumento da produtividade.

Para buscar o aumento da produtividade na colheita da cana-de-açúcar a partir de sua mecanização e consequente supressão de queimadas, empregam-se muitos esforços a alcançar o maior número de colheitas (safras) pelo menor número de plantios. Busca-se plantar a cana-de-açúcar e preservar o seu broto durante a colheita de forma que ele se mantenha intacto para a próxima brotação e para que a cana-de-açúcar volte a crescer sem que seja necessário um novo processo de plantio.

Para manutenção da integridade do broto da cana-de-açúcar durante a colheita, é necessário que não haja dano na região do solo onde ele se encontra plantado. Para tanto, os equipamentos utilizados no processo de colheita são projetados e construídos a fim de evitar este dano.

O principal equipamento aplicado ao processo de colheita é a máquina colheitadeira que automaticamente corta a parte inferior da cana, faz a limpeza das folhas, corta a cana em 
pedaços menores e os deposita em um veículo de carga que acompanha a máquina colheitadeira no circuito de colheita. O veículo de carga que acompanha a máquina colheitadeira é denominado veículo escravo e pode ser um caminhão.

Adiciona-se o adjetivo autônomo à máquina colheitadeira e ao caminhão escravo que não necessitam de intervenção humana para seu controle durante o processo de colheita.

A SAE (Associação de Engenheiros Automotivos, sigla em inglês) classifica veículos que não necessitam de intervenção humana como autônomos e os divide em 5 níveis. Do nível 1, quando há uma grande intervenção humana e o veículo tem apenas dispositivos de suporte para sua condução, ao nível 5, quando não há nenhuma necessidade de intervenção humana e o veículo, por meio de tecnologia embarcada, decide e executa todas as ações necessárias. ${ }^{1}$

O objetivo deste trabalho é apresentar um sistema para correto posicionamento cartográfico conforme linhas de plantio pré-estabelecidas, de caminhões escravos autônomos na colheita de cana-de-açúcar.

Para tanto, este sistema faz uso de conceitos de Visão Computacional, Processamento de Imagem e Redes Neurais Artificiais.

Para este trabalho, após a devida aplicação de técnicas de calibração de câmeras aplicadas fisicamente no caminhão escravo autônomo, foi levantado um banco de imagens com mais de 24 horas de filmagens que foram convertidas em um banco com mais de 25 mil imagens referentes ao processo de colheita de cana-de-açúcar durante a manhã, tarde e noite.

Foram avaliadas 2 hipóteses para atendimento do objetivo deste trabalho.

A primeira hipótese foi baseada numa abordagem apenas com ferramentas tradicionais de Visão Computacional. Aplicou-se primeiramente o Filtro Sobel para redução de ruído e então a Transformada de Hough para identificação das linhas de plantio.

A aplicação de visão computacional tradicional foi considerada neste trabalho em função de apresentar baixo custo computacional, ser mais rápida e de depender de hardware mais simples para sua execução em campo.

${ }^{1}$ Maiores informações sobre veículos autônomos podem ser observadas no Apêndice A deste trabalho 
Porém esta hipótese não logrou êxito frente ao objetivo determinado. A grande quantidade de ruído proveniente de uma imagem de um processo de colheita de cana-deaçúcar não permitiu que a Transformada de Hough encontrasse e determinasse a correta posição das linhas de plantio.

O ruído contido nas imagens é proveniente do próprio contexto em que esta inserido a coleta de imagens, devido a complexidade imposta a imagens provenientes de áreas de colheita de cana-de-açúcar como o grande volume de transição de texturas no solo e plantação de cana-de-açúcar, além da própria sujeira recuperada na imagem em função da movimentação de máquinas.

A segunda hipótese constituía na aplicação da Rede Neural artificial MobileNet. Para o treinamento, fizeram-se marcações manuais para identificação da pista de plantio em mais de 630 imagens. Esta hipótese atingiu o objetivo deste trabalho ao determinar as linhas de plantio conforme o banco de imagens supracitado e iteração em 227 épocas com Precisão de $57,22 \%$ e Revocação de $28,84 \%$.

Como o sistema proposto por este trabalho refere-se o processo de colheita de canade-açúcar, exclui-se sua a aplicação onde não existem condições idênticas. Como exemplo, mas não se limitando a este, todo o transporte fora da plantação, ou conhecido mercadologicamente como "Rodoviário Misto" (On Road, em inglês).

Também não faz parte do escopo deste trabalho desenvolver ou apresentar qualquer alternativa para dispositivos de segurança ativa que atuem de forma a frear ou manobrar o caminhão em caso de obstáculos. A manobra do caminhão necessária para reiniciar o processo de colheita, feita ao final da área plantada, também não é parte do escopo deste trabalho.

O restante deste trabalho é organizado da seguinte maneira: O Capítulo 2 apresenta a Revisão Teórica, o Capítulo 3 elenca Trabalhos Correlatos, o Capítulo 4 descreve a Proposta, o Capítulo 5 oferece Experimentos e Resultados, o Capítulo 7 refere-se a Discussão, o Capítulo 8 apresenta a Conclusão e o Capítulo 9, a Referência Bibliográfica. 


\section{REVISÃO TEÓRICA}

\subsection{CALIBRAÇÃO DE CÂMERAS}

A primeira etapa para um adequado processamento de imagens é a calibração de câmeras no mundo 3D.

O método consiste em encontrar um mapeamento entre pontos característicos de um padrão conhecido e pontos correspondentes no plano da imagem e assim, por meio de processos geométricos, encontrar-se um conjunto de parâmetros que descrevem o posicionamento da câmera no espaço 3D e também as características projetivas que afetam a luz durante a formação da imagem. De posse deste conjunto de parâmetros é possível fazer o processo inverso para estimar características da cena com base nas imagens.

Figura 1 - Posicionamento da câmera no espaço 3D



Fonte: Gonzalez, 2007

Para este exemplo na Figura 1, a câmera foi transladada em $Z_{0}$ metros e rotacionada em $\alpha$ graus, sendo $\alpha$ o ângulo formado pelos eixos $\mathrm{Z}$ e z. Além de ter sido rotacionada em $\beta$ graus, sendo $\beta$ o ângulo formado pelos eixos $\mathrm{X}$ e $\mathrm{x}$. 
O primeiro conceito abordado referente-se a translação que permite movimentar um objeto de um ponto a outro em qualquer ou em todos os eixos 3D e é representada conforme a Equação 2.1.1, ou de forma matricial conforme Equação 2.1.2.

$v^{*}=T \cdot v$

$$
\left[\begin{array}{c}
X^{*} \\
Y^{*} \\
Z^{*} \\
1
\end{array}\right]=\left[\begin{array}{cccc}
1 & 0 & 0 & X_{0} \\
0 & 1 & 0 & Y_{0} \\
0 & 0 & 1 & Z_{0} \\
0 & 0 & 0 & 1
\end{array}\right]\left[\begin{array}{c}
X \\
Y \\
Z \\
1
\end{array}\right]
$$

Quanto a conceito de rotação, pode-se simplesmente entender como a possibilidade de rotacionar um determinado objeto em um determinado ângulo nos eixos 3D, pictoricamente representado na Figura 2 e nas Equações 2.1.3, 2.1.4 e 2.1.5.

Figura 2 - Rotação de objeto nos eixos 3D



Fonte: Gonzalez, 2007

$$
\begin{aligned}
& \text { Rotação eixo } \mathrm{Z}=R_{\theta}=\left[\begin{array}{cccc}
\cos \theta & \sin \theta & 0 & 0 \\
-\sin \theta & \cos \theta & 0 & 0 \\
0 & 0 & 1 & 0 \\
0 & 0 & 0 & 1
\end{array}\right] \\
& \text { Rotação eixo } \mathrm{X}=R_{\theta}=\left[\begin{array}{cccc}
1 & 0 & 0 & 0 \\
0 & \cos \alpha & \sin \alpha & 0 \\
0 & -\sin \alpha & \cos \alpha & 0 \\
0 & 0 & 0 & 1
\end{array}\right] \\
& \text { Rotação eixo } \mathrm{Y}=R_{\theta}=\left[\begin{array}{cccc}
\cos \beta & 0 & -\sin \beta & 0 \\
0 & 1 & 0 & 0 \\
\sin \beta & 0 & \cos \beta & 0 \\
0 & 0 & 0 & 1
\end{array}\right]
\end{aligned}
$$


Com os modelos de rotação e translação pode-se aplicar os princípios de concatenação e transformação inversa de forma que resulte também em uma matriz $A_{v}$ com dimensão 4 x 4, sendo a gerada pela multiplicação dos eixos rotacionados e transladados, da seguinte forma: $v^{*}=R_{\theta}\left(S\left(T_{v}\right)\right)=A_{v}$

A transformação em perspectiva é um princípio geométrico importantíssimo para calibração de câmeras em função de sua capacidade de correlacionar captações de imagens com suas respectivas matrizes mundo real, como apresentado na Figura 3 e Equações 2.1.6 e 2.1.7.

Figura 3 - Correlação de imagens com mundo real



Fonte: Gonzalez, 2007

$$
\begin{aligned}
& \frac{x}{\lambda}=-\frac{X}{Z-\lambda}=\frac{X}{\lambda-Z} \\
& \frac{y}{\lambda}=-\frac{Y}{Z-\lambda}=\frac{Y}{\lambda-Z}
\end{aligned}
$$

A partir dos conceitos da transformação em perspectiva, de coordenadas homogêneas $W_{h}$ (também provenientes das coordenadas artesianas, porém multiplicadas por uma constante k) e de uma matriz de transformação em perspectiva definida como $P=\left[\begin{array}{cccc}1 & 0 & 0 & 0 \\ 0 & 1 & 0 & 0 \\ 0 & 0 & 1 & 0 \\ 0 & 0 & -1 / \lambda & 1\end{array}\right]$, pode se evoluir para uma matriz de transformação em perspectiva $c_{h}=P W_{h}$, bem como sua forma inversa $c_{h}=P^{-1} W_{h}$ (GONZALEZ, 2007). 
O fenômeno da ambiguidade colinear que é representado com coordenadas homogêneas em $W_{h}=\left[\begin{array}{c}k x_{0} \\ k y_{0} \\ K z \\ (K z / \lambda)+k\end{array}\right]$ e, também cartesianas em $W=\left[\begin{array}{c}\lambda x_{0} /(\lambda+z) \\ \lambda y_{0} /(\lambda+z) \\ \lambda z /(\lambda+z)\end{array}\right]$ ou como $X=\frac{x_{0}}{\lambda}(\lambda-Z)$ e $Y=\frac{y_{0}}{\lambda}(\lambda-Z)$

\subsection{DETECTORES DE BORDAS}

A detecção de bordas é o método mais usado para segmentação de imagens por meio de variações abruptas de intensidade (GONZALEZ e WOODS, 2011). Existem vários tipos de bordas, considerando a respectiva variação abrupta proveniente do nível de ruído da imagem, podendo variar de um pixel no caso de uma borda em degrau, passando pela denominada borda em rampa, ou até como uma borda como uma conexão de duas imagens de borda em rampa, uma iniciando pela direita e outra pela esquerda.

Para lidar com bordas em uma imagem é possível fazer uma derivada, por exemplo na borda mais comumente encontrada, a borda em rampa. O tamanho, ou magnitude, da primeira derivada pode detectar a presença de uma borda em uma imagem, já a segunda derivada pode trazer um sinal que pode ser usado para determinar se o pixel esta do lado claro ou escuro da borda (GONZALEZ e WOODS, 2011).

Para determinar o tamanho, ou magnitude, da primeira derivada anteriormente citada, deve-se partir da definição da intensidade e a direção da borda da imagem f na posição (x,y). Para tanto a melhor ferramenta é o cálculo de gradiente descrito como um vetor na Equação 2.2.1 abaixo. Então, de posse do vetor de gradiente da imagem $\mathrm{f}$, obtém-se a magnitude conforme a Equação 2.2.2, que é o valor da taxa de variação na direção do vetor gradiente.

$$
\begin{aligned}
& \Delta f=\operatorname{grad}(f)=\left[\begin{array}{l}
g_{x} \\
g_{y}
\end{array}\right]=\left[\begin{array}{l}
\delta f / \delta x \\
\delta f / \delta y
\end{array}\right] \\
& M(x, y)=\operatorname{mag}(\Delta f)=\sqrt{g_{x}^{2}+g_{y}^{2}}
\end{aligned}
$$

A obtenção do gradiente de uma imagem, como demonstrado acima, implica em cálculo de derivadas parciais $\delta f / \delta x$ e $\delta f / \delta y$ nas determinadas posições (x,y) da imagem f. 
Por se tratarem de quantidades digitais, aproximações digitais das referidas derivadas parciais são necessárias. Para tanto, são necessárias as chamadas máscaras de aproximação que partem de unidimensionais a máscaras de tamanho 3 × 3 , que atuam como uma matriz de convolução na área a ser tratada ou filtrada.

Para as máscaras 3 x 3, temos os operadores de Prewitt e Sobel os mais utilizados, onde variam apenas os quocientes da matriz de convolução (GONZALEZ e WOODS, 2011).

Máscara 3 x 3 com operadores Prewit:

\begin{tabular}{|c|c|c|}
\hline-1 & -1 & -1 \\
0 & 0 & 0 \\
\hline 1 & 1 & 1 \\
\hline
\end{tabular}$\quad \quad$\begin{tabular}{llll|}
\hline-1 & 0 & 1 \\
-1 & 0 & 1 \\
-1 & 0 & 1 \\
\hline
\end{tabular}

Máscara 3 x 3 com operadores Sobel:

\begin{tabular}{|c|c|c|c|c|c|c|}
\hline-1 & -2 & -1 \\
\hline 0 & 0 & 0 \\
1 & 2 & 1 \\
\hline-1 & -2 & 0 & 2 \\
\hline-1 & 0 & 1 \\
\hline
\end{tabular}

Resultando então nas equações de gradiente 2.2 .5 e 2.2.6 abaixo:

$$
\begin{aligned}
& g_{x}=\frac{\delta f}{\delta x}=\left(Z_{7}+2 Z_{8}+Z 9\right)-\left(Z_{1}+2 Z_{2}+Z 3\right) \\
& g_{y}=\frac{\delta f}{\delta y}=\left(Z_{3}+2 Z_{6}+Z 9\right)-\left(Z_{1}+2 Z_{4}+Z 7\right)
\end{aligned}
$$

Para uma dada máscara $3 \times 3$ demonstrada abaixo:

\begin{tabular}{|c:c|c|}
\hline $\mathrm{Z1}$ & $\mathrm{Z} 2$ & $\mathrm{Z} 3$ \\
\hline $\mathrm{Z} 4$ & $\mathrm{Z} 5$ & $\mathrm{Z} 6$ \\
\hline $\mathrm{Z7}$ & $\mathrm{Z} 8$ & $\mathrm{Z} 9$ \\
\hline
\end{tabular}

Filtro Sobel, ou Filtro Sobel-Feldman, obteve este nome após seus criadores, Irwin Sobel e Gary Feldman, colegas do Laboratório de Inteligência Artificial de Stanford (SAIL), apresentarem a idéia de um "Operador de Gradiente de Imagem Isotrópico 3x3" em uma palestra no SAIL em 1968 (SOBEL, 2014). 
O Filtro Sobel é aplicado largamente no processamento de imagens no segmento da visão computacional, principalmente com a finalidade de detecção de bordas a partir de seus respectivos algoritmos.

Mais precisamente, consiste num operador que calcula diferenças finitas, dando uma aproximação do gradiente da intensidade dos pixels da imagem. Ou seja, em cada ponto da imagem, o resultado da aplicação do filtro Sobel apresenta o gradiente da intensidade da imagem em cada ponto, dando a direcção da maior variação de claro para escuro e a quantidade desta variação em sua respectiva direção. Desta forma, então, obtém-se uma noção de como varia a luminosidade em cada ponto e com isto consegue-se estimar a presença de uma transição claro-escuro e sua respectiva orientação. Como as variações claroescuro intensas correspondem a fronteiras bem definidas entre objetos, consegue-se fazer a detecção de contornos.

Este filtro também tem como base a convolução da imagem, ou seja, é um operador linear que, a partir de duas funções dadas, resulta numa terceira que mede a soma do produto dessas funções ao longo da região subentendida pela superposição delas em função do deslocamento existente entre elas.

Matematicamente este operador utiliza duas matrizes $3 \times 3$ que são convoluídas com a imagem original para calcular aproximações das derivadas - uma para as variações horizontais e uma para as verticais. Sendo A a imagem inicial, então Gx e Gy serão duas imagens que em cada ponto contêm uma aproximação às derivadas horizontal e vertical de A.

$$
\begin{aligned}
& G x=\left[\begin{array}{ccc}
-1 & 0 & +1 \\
-2 & 0 & +2 \\
-1 & 0 & +1
\end{array}\right] \cdot A x \\
& G y=\left[\begin{array}{ccc}
-1 & -2 & -1 \\
0 & 0 & 0 \\
+1 & +2 & +1
\end{array}\right] \cdot A x
\end{aligned}
$$


Abaixo exemplo de uma imagem processada a partir da aplicação de um Filtro Sobel com uma matriz de convolução conforme descrita nas equações 2.2.7 e 2.2.8.

Figura 4 - Exemplo de aplicação do Filtro Sobel no eixo x e y.


Fonte: Autor

O Filtro Sobel com a aplicação da respectiva máscara apresentam melhor supressão de ruídos do que os operadora de Prewitt, como exemplo de operador 3-D (GONZALES \& WOODS, 2011).

A operação de gradientes por meio de quadrados e raizes gera um custo computacional indesejado, mas pode ser aproximado ao calculasse a magnitude do gradiente somente com valores absolutos, ou $M(x, y) \approx\left|g_{x}\right|+\left|g_{y}\right|$. Porém, desta forma o filtro não será isotrópico, ou seja, invariantes a rotação implicando principalmente em bordas diagonais.

\subsection{TRANSFORMADA DE HOUGH}

No processamento de imagens, comumente enfrenta-se a necessidade de detecção de formas simples, como retas, círculos, etc.

Em função de ruídos e interferência eventualmente encontrados na imagem pode-se incorrer no erro de não detectarem-se pixels ausentes nas retas desejadas, ou também obterem-se desvios espaciais entre as retas desejadas, ou seja, por mais elementar que pareça, a identificação de retas não é trivial.

Tecnicamente, tendo $n$ pontos em uma imagem, para detectarem-se subconjuntos que pertençam a retas, deve-se encontrar primeiro retas formadas por cada par de pontos e, 
posteriormente, encontrar todos os respectivos subconjuntos que estejam próximos as retas traçadas, ou seja, encontrar $n(n-1) 2 \sim n^{2}$ retas e fazer $(n)(n(n-1)) 2 \sim n^{3}$ comparações, conforme Rafael Gonzalez e Richard Woods (GONZALEZ e WOODS, 2011), ou seja, esta é uma atividade computacional proibitiva.

Diante disto, Hough propôs uma alternativa patenteada em 1962 ( U.S. 3.069.654 ) como "Método e Meios para Reconhecer Padrões Complexos". Esta patente refere-se a utilização de uma determinada parametrização para identificação de retas.

A técnica aplicada a Transfromada de Hough é para justamente abordar a necessidade de detecção de retas, círculos, entre outras formas simples, possibilitando a realização de agrupamentos de pontos de borda em potenciais a objetos desejados, executando um procedimento de votação explícito sobre um conjunto de objetos de imagem com parâmetros (SHAPIRO E STOCKMAN, 2001)

Para um ponto $\left(x_{i}, y_{i}\right)$ no plano xy, a equação geral de uma reta de $y_{i}=a x_{i}+b$ e, infinitas retas passando por $\left(x_{i}, y_{i}\right)$, mesmo que para valores diferentes de a e b, pode-se, em princípio, traçar retas do espaço de parâmetros que correspondam a todos os pontos no plano xy por meio da identificação dos pontos onde uma grande quantidade de retas do espaço de parâmetros se intercepta. Porém, a resultante da inclinação da reta pode ser infinita, desta forma então, utiliza-se a representação normal de uma reta em coordenadas polares $\rho=x \cos \theta+y \sin \theta$ onde $\rho$ é a distância da origem até o ponto mais próximo na linha reta, e $\theta$ é o ângulo entre o eixo $x$ e a linha que conecta a origem com o ponto mais próximo (GONZALEZ e WOODS, 2011).

Desta forma, pode-se associar com cada linha da imagem um par $(\rho, \theta)$ em um respectivo plano conhecido como espaço Hough para o conjunto de retas em duas dimensões. Se houver um único ponto no plano, então o conjunto de todas as retas que atravessam esse ponto corresponde a uma curva sinusoidal no plano $(\rho, \theta)$ e, se houverem um conjunto de dois ou mais pontos que formam uma linha reta produzirá sinusóides que cruzam no $(\rho, \theta)$ para aquela linha, desta forma, a detecção de pontos colineares pode ser feita por meio da detecção de curvas simultâneas (GONZALEZ e WOODS, 2011).

Figura 5 - Espaço da Transformada de Hough 


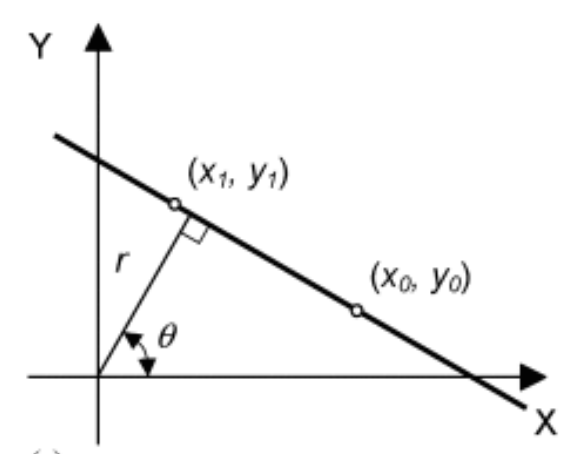

(a)



(b)

Fonte: Gonzalez, 2007

Desta forma, tem-se então, uma reta horizontal quando $\Theta=0^{0}$ e $\rho$ intercede o eixo $x$ na parte positiva, ou uma reta vertical quando $\Theta=90^{\circ} \rho$ intercede o eixo y na parte positiva e assim sucessivamente. Cada senoide representa uma família de retas que passam pelo ponto $(x, y)$ no plano $x y$.

O algoritmo da Transformada de Hough tem como base uma matriz bidimensional a fim de buscar uma linha reta definida por $\rho=x \cos \theta+y \sin \theta$. Esta matriz bidimensional refere-se a quantidade de parâmetros desconhecidos, ou seja, para o par de $\rho$ e $\theta$ de cada pixel em $x$ e $y$ em sua vizinhança, o algoritmo determina se há uma linha reta naquele determinado pixel, e então, calcula os parâmetros $\rho$ e $\theta$. Posteriormente o algoritmo deve procurar os valores mais altos dentro desta matriz bidimensional, por meio dos máximos locais. Ao encontrar estes máximos locais, as retas mais prováveis podem ser delineadas, assim como suas aproximada coordenadas geométricas (SHAPIRO e STOCKMAN, 2001). A maneira mais simples de encontrar estes máximos locais é aplicando algum tipo de limiar, porém dependendo das circunstâncias, outras técnicas podem produzir melhores resultados.

Em suma, o resultado da Transformada de Hough é uma matriz bidimensional, na qual uma dimensão dessa matriz é o ângulo $\theta$ e a outra dimensão é a distância $\rho$. Cada elemento da matriz tem um valor igual à soma dos pixels que estão posicionados na linha representada pelos parâmetros $\rho$ e $\theta$.

Uma melhoria sugerida por O'Gorman e Clowes (O'GORMAN e GLOWES, 1976) é aplicada a fim de detectar linhas levando em consideração o gradiente local da intensidade da imagem. Como a detecção de bordas geralmente envolve o cálculo da magnitude do gradiente de intensidade, a direção do gradiente é normalmente encontrada indiretamente. $\mathrm{Ou}$ seja, se um dado ponto de coordenadas $(x, y)$ estiver de fato em uma linha, então a direção 
local do gradiente obterá o parâmetro $\theta$ correspondente à linha em questão, e o parâmetro $r$ também será obtido (SHAPITO e STOCKMAN, 2001). De forma prática, para reduzir a complexidade computacional, pode-se estimar inicialmente a direção do gradiente em $20^{\circ}$, reduzindo assim o traçado sinusoidal de $180^{\circ}$ para aproximadamente $45^{\circ}$, consequentemente aumentando assim a visibilidade dos picos correspondentes às linhas reais da imagem.

Outra possibilidade proposta (FERNANDES e OLIVEIRA, 2008) sugere uma Transformada de Hough baseada em kernel também com os parâmetros $r$ e $\theta$ que opera em clusters de pixels aproximadamente colineares. Para cada cluster, os votos são lançados usando um kernel Gaussiano elíptico orientado que modela a incerteza associada à linha de melhor ajuste em relação ao cluster correspondente. A abordagem não apenas melhora significativamente o desempenho do esquema de votação, mas também produz uma matriz bidimensional resultante muito mais limpa e uma detecção de linhas mais robusta.

Já Limberger e Oliveira (LIMBERGER e OLIVEIRA, 2015) sugeriram uma técnica determinística baseada em uma rápida estratégia de votação para regiões planas, inspirada na Transformada de Hough baseada em kernel. Esta técnica implica na segmentação de clusters amostras co-planares e lança votos para clusters individuais, ao invés de amostras individuais em um $\theta, \phi, \rho$ como uma matriz de dados esférico usando um kernel gaussiano. Esta abordagem tende a ser mais rápida do que as técnicas não-determinísticas.

Embora a versão da Transformada de Hough se aplique somente à localização de retas, uma transformação semelhante pode ser usada para encontrar qualquer forma que possa ser representada por um conjunto de parâmetros. Um círculo, por exemplo, pode ser transformado em um conjunto de três parâmetros, representando seu centro e raio, de modo que o espaço Hough se torne tridimensional. Elipses e curvas arbitrárias também podem ser encontradas dessa maneira, assim como qualquer forma pode ser facilmente expressa como um conjunto de parâmetros.

A generalização da transformada de Hough para detecção de formas analíticas em espaços de qualquer dimensionalidade foi proposta por Fernandes e Oliveira (FERNANDES e OLIVEIRA, 2012).

Para formas que não podem ser representadas analiticamente em algum espaço $2 \mathrm{D}$, a Transformada Generalizada de Massa (BALLARD, 1981) é usada de forma a permitir que 
um recurso vote em uma determinada posição, orientação e / ou escala do forma usando uma tabela de consulta predefinida.

A Transformada de Hough só é eficiente se um grande número de votos cair na posição correta, de modo que a região possa ser facilmente detectada em meio ao ruído de fundo.

A vantagem computacional da Transformada de Hough é em função da divisão do espaço de parâmetros $\rho \theta$ nas células acumuladoras, sendo que $\left(\rho_{\min }, \rho_{\max }\right)$ e $\left(\theta_{\min }, \theta_{\max }\right)$ são esperados intervalos de valores dos parâmetros de $\theta$ entre $-90^{0}$ e $+90^{0}$, e $\rho$ entre a máxima distância negativa e positiva dos cantos opostos de uma imagem, e valor de acumulador $A(i, j)$ corresponde ás coordenadas do espaço de parâmetros $\left(\rho_{i}, \theta_{j}\right)$ (GONZALEZ e WOODS, 2011).

A assertividade da Transformada de Hough depende da qualidade dos dados de entrada, seu uso em imagens ruidosas é um assunto muito delicado e, geralmente, um estágio de tratamento da imagem deve ser usado antes.

\subsection{REDES NEURAIS ARTIFICIAIS}

Redes Neurais Artificiais (RNAs) são sistemas paralelos distribuídos e compostos por unidades de processamento simples (nós) que calculam determinadas funções matemáticas (BRAGA, LUDEMIR e CARVALHO, 2000).

Estas unidades de processamento simples, ou nós, são interligadas por diversas conexões entre si, em uma ou mais camadas e de forma unidirecional. Tais conexões estão relacionadas a pesos e servem para ponderar, por meio de equações matemáticas, a entrada recebida por cada nó da rede. Este funcionamento é inspirado no funcionamento biológico de um neurônio.

A Rede Neural Artificial mais utilizada é baseada no modelo apresentado por Frank Rosenblatt em 1958, o Perceptron (BRAGA, LUDEMIR e CARVALHO, 2000). 


\subsubsection{PERCEPTRON}

Conforme o trabalho original de McCulloch e Pits (MCCULLOCH e PITS, 1943) e retratado por Antonio Braga, Teresa Ludemir e André Carvalho (BRAGA, LUDEMIR e CARVALHO, 2000), é a reprodução artificial de um neurônio biológico e sua capacidade de processamento de impulsos, ou artificialmente por meio de capacidade computacional, com a propriedade fundamental de executar de funções booleanas. A época acreditava-se um neurônio biológico deveria ser reproduzido por meio de Hardware, porém pouco mais de uma década depois Frank Rosenblatt introduziu o conceito de redes neurais artificiais e do modelo proposto denominado Perceptron, que era uma unidade básica individual (como um próprio neurônio biológico) que conectado a outros, por meio de nós e com a definição de regras de aprendizado, formava-se então o conceito de rede de uma só camada de Perceptrons.

Perceptron é um classificador binário com uma função que mapeia sua entrada x (um vetor de valor real) para um valor de saída $\mathrm{f}$ (x) (um único valor binário), o qual se atribui um vetor de pesos reais w. A multiplicação do vetor peso w pela função entrada x dar-se-a pela soma do produto escalar de $w_{i}$ e $x_{i}$, onde m é o número de entradas para o perceptron e $\mathrm{b}$ é o viés. O desvio desloca o limite de decisão da origem e não depende de nenhum valor de entrada. Esquematicamente, o Perceptron pode ser visto na Figura 6.

O valor de f (x) (0 ou 1) é usado para classificar x como uma instância positiva ou negativa, no caso de um problema de classificação binária. Se b é negativo, então a combinação ponderada de insumos deve produzir um valor positivo maior que $|\mathrm{b}|$ a fim de empurrar o neurônio do classificador sobre o limite 0. Espacialmente, o viés altera a posição (embora não a orientação) do limite de decisão.

Algum tempo depois, o próprio Rosenblatt apresentou o teorema da convergência do perceptron, que mostra que as unidades básicas de perceptrons treinados com algoritmo de aprendizado sempre converge, porém apenas se os problemas em questão fossem linearmente separáveis. O exemplo mais famoso da incapacidade do perceptron de resolver problemas com vetores linearmente não separáveis é o problema booleano-exclusivo. 
Figura 6 - Perceptron



Fonte: Autor

\subsubsection{PERCEPTRON MULTICAMADAS}

Para solução de problemas não linearmente separáveis deve-se aplicar uma rede de Perceptrons Multicamada (MLP, sigla em inglês). Uma MLP consiste em, pelo menos, três camadas de nós: uma camada seria de entrada, outra camada oculta e uma de saída. Exceto pelos nós de entrada, cada nó é um neurônio que usa uma função de ativação não linear.

Porém, tal topologia com mais de uma camada de Perceptrons, cria um outro desafio para treinar tal rede neural, devido a complexidade de análise do erro no caso de aplicação de uma função de ativação tipo limiar, por exemplo. Desta forma, a fim de sobrepujar este desafio, a MLP faz uso de uma técnica de aprendizagem supervisionada chamada retropropagação (backpropagation, em inglês) para o referido treinamento que se baseia em um método de gradiente descendente e de funções de ativação continuas, diferenciáveis, e preferencialmente decrescente. Esta função ativação deve informar os erros cometidos pela rede para as camadas anteriores com a maior precisão possível, para tanto, utiliza-se a função tipo sigmoidal, conforme Antonio Braga, Teresa Ludemir e André Carvalho (BRAGA, LUDEMIR e CARVALHO, 2000). 
As funções de ativação tipo sigmoidal são descritas por:

$$
\begin{aligned}
& y(v i)=\tanh (v i) \\
& y(v i)=\left(1+e^{-v i}\right)^{-1}
\end{aligned}
$$

A primeira é uma tangente hiperbólica que varia de -1 a 1, enquanto a outra é a função logística, que é similar em forma, mas varia de 0 a 1 . Aqui $y_{i}$ retorna com nó (neurônio) e $v_{i}$ é a soma ponderada das conexões de entrada.

A funcionalidade das 3 camadas anteriormente citadas é:

1. Camada de entrada: cada nó traça retas no espaço de padrões de treinamento

2. Primeira camada intermediária: cada nó combina as retas traçadas pelos neurônios da camada anterior, definindo assim regiões convexas, as quais o número de lados é definido pelo número de unidades a ele conectadas.

3. Camada de saída: cada nó forma regiões que são combinações das regiões convexas definidas pelos nós conectados a ele pela camada anterior. Desta forma, os nós definem regiões com formatos abstratos.

Foram feitos diversos estudos para definir qual seria a melhor quantidade de de camadas intermediárias. Concluiu-se que, conforme descrito por Antonio Braga, Teresa Ludemir e André Carvalho (BRAGA, LUDEMIR e CARVALHO, 2000), uma camada intermediária é suficiente para aproximar qualquer função contínua e que duas camadas são suficientes para aproximar qualquer função matemática. Também neste mesmo trabalho, relata-se que o número de nós das camadas intermediárias devem ser definidos de forma empírica e depende de vários fatores, como: número de exemplos de treinamento, quantidade de ruído presente nos exemplos, complexidade da função s ser aprendida e distribuição estatística dos dados de treinamento.

Como citado anteriormente, o método de aprendizado mais conhecido e aplicado é o de retro-propagação, ou mais comumente conhecido pela sua denominação em inglês de backpropagation. É um método de aprendizado supervisionado e uma generalização do método dos mínimos quadrados médios. O aprendizado ocorre no perceptron, alterando os pesos de conexão após o processamento de cada parte dos dados, com base na quantidade de erro no resultado comparado ao resultado esperado. 
O treinamento ocorre um duas fases: forward e backward. A primeira fase é utilizada para definir a saída da rede para um dado padrão de entrada, ja a segunda fase utiliza a saída desejada para ajustar os pesos de suas conexões por meio do método de gradiente.

O erro no nó de saída j pode ser demonstrado por $e_{j}(n)=d_{j}(n)-y_{j}(n)$, onde $d$ é o valor alvo e y é o valor produzido pelo perceptron. Desta forma, como citado anteriormente, os pesos dos nós são ajustados com base em correções que minimizam o erro em toda a saída, dadas por:

$$
E(n)=\frac{1}{2} \sum_{j} e_{j}^{2}(n)
$$

Aplicando, então o método de gradiente descendente, ajuste de cada peso dar-se-á por

$$
\Delta w_{j i}(n)=-\eta \frac{\partial E(n)}{\partial v_{j}(n)} y_{i}(n)
$$

Onde $y_{i}$ é a saída do neurônio anterior e $\eta$ é a taxa de aprendizado, que é selecionada para garantir que os pesos rapidamente convirjam para uma resposta.

Ja a derivada do erro depende do campo $v_{j}$, que conforme Haykin (HAYKIN, 1998) pode ser simplificada por:

$$
-\frac{\partial E(n)}{\partial v_{j}(n)}=e_{j}(n) \phi^{\prime}\left(v_{j}(n)\right)
$$

Onde $\phi$ é a derivada da função de ativação.

A alteração dos pesos dos nós ocultos é mais complexa, porém pode ser simplificada, também conforme Haykin (HAYKIN, 1998), por:

$$
-\frac{\partial E(n)}{\partial v_{j}(n)}=\phi^{\prime}\left(v_{j}(n)\right) \sum_{k}-\frac{\partial E(n)}{\partial v_{k}(n)} w_{k j}(n)
$$

Ou seja, para mudar os pesos das camadas ocultas, os pesos da camada de saída mudam de acordo com a derivada da função de ativação, e assim este algoritmo representa uma retropropagação da função de ativação. 


\subsection{APRENDIZADO PROFUNDO}

Uma solução para problemas com viés mais intuitivo é normalmente plena quando efetuada por um ser humano, porém, métodos de inteligência artificial vem buscando também mimetizar tal tipo de solução intuitiva. Para tanto, desenvolve-se uma solução que permita computadores aprenderem por experimentação e entender o mundo ao seu redor por meio do modelo de hierarquia de conceitos. Com o ganho de conhecimento por meio de experiencias, esta abordagem evita que um operador humano tenha que programar toda e qualquer inteligência que o computador precise. Tal hierarquia de conceitos possibilita que o computador aprenda conceitos complicados, baseado na conjunção de simples conceitos.

Para desenhar esta hierarquia de conceitos, partindo de uma base mais simples até uma mais complexa, verificar-se-a que a forma gráfica seria extensa, ou profunda, com muitas camadas. Desta forma, atribui-se o nome para este tipo de abordagem de Aprendizado Profundo (GOODFELLOW et al, 2016).

O Aprendizado Profundo diz respeito a capacidade de um sistema adquirir sua própria base de conhecimento por meio de algoritmos que extraem padrões de dados brutos e projetam tais resultados atualizando constantemente a referida base de conhecimento.

O Aprendizado Profundo é um modelo de aprendizagem profunda por retroalimentação (feedforward, em inglês). O objetivo de uma rede de aprendizagem por retroalimentação é aproximar algumas funções. Por exemplo, para um classificador, $y=f(x)$ mapeia uma entrada para uma categoria, já uma rede de aprendizagem por retroalimentação define um mapeamento $=\mathrm{f}(\mathrm{x} ; \theta)$ e aprende o valor dos parâmetros que resultam na melhor aproximação da função (GOODFELLOW et al, 2016).

As redes neurais retroalimentadas são representadas pela composição de muitas funções diferentes. O modelo é associado a um gráfico acíclico dirigido descrevendo como as funções são compostas. Por exemplo, podemos ter três funções $f^{1}, f^{2} e f^{3}$, conectadas em uma cadeia, para formar $f(x)=f^{3}\left(f^{1} \cdot f^{2}(x)\right)$, tal estrutura é tipicamente atribuída a uma rede neural e $f^{1}$ é chamada de primeira camada da rede, $f^{2}$ de segunda camada e assim por diante.

O comprimento total da estrutura define a profundidade do modelo, de onde provém a terminologia aprendizagem profunda. 
Para o treinamento da rede neural, define-se uma $f(x)$ de forma a encontrar o resultado correto de saída da função. Os dados de treinamento são exemplos aproximados e ruidosos de do resultado esperado da função avaliados em diferentes pontos de treinamento e, cada amostra de $x$ é acompanhada por um pelo resultado esperado da função $\approx f(x)$. Os exemplos de treinamento especificam diretamente o que a camada de saída deve fazer em cada ponto de $x$. O comportamento das outras camadas não é diretamente especificado pelos dados de treinamento. O algoritmo de aprendizado deve decidir como usar essas camadas para produzir a saída desejada.

Para demonstrar mais concretamente o conceito de uma rede neural com modelo de aprendizado por retroalimentação, seguimos com um exemplo de uma função XOR. Função esta que por muitos anos foi tida como insolúvel para o modelo com Perceptros, e posteriormente tal solução robusta foi encontrada (GOODFELLOW et al, 2016).

A função XOR ("exclusiva ou") é uma operação em dois valores binários, que quando um desses valores binários é igual a 1, a função XOR retorna 1 , caso contrário, ela retorna 0 . A função XOR fornece a função objetivo $y=f^{*}(x)$, e o modelo propõe uma função $y=f(x$; $\theta$ ), e o algoritmo de aprendizado irá adaptar os parâmetros $\theta$ a fim de tornar $\mathrm{f}$ mais semelhante a possível de $f^{*}$. Neste exemplo simples, rede neural deve funcionar corretamente nos quatro pontos de $X=\left\{|0,0|^{T},|0,1|^{T},|1,0|^{T},|1,1|^{T}\right\}$, para tanto, esta rede deve ser treinada ajustando o conjunto de treinamento por meio de um de uma regressão e usar uma função de perda de erro quadrático médio (MSE, sigla em inglês), descrita por:

$$
J(\theta)=\frac{1}{4} \sum_{x \in X}\left(f^{*}(x)-f(x ; \theta)\right)^{2}
$$

Para um modelo linear, $\theta$ consistirá em $w$ e $b$, então resulta em um modelo $f(x, w, b)=x^{T} w+b$. Desta forma, minimizando $J(\theta)$ conforme $w$ e $b$, obtém-se $w=0$ e $b=$ $1 / 2$.

Implementando um modelo de aprendizado retroalimentado simples com duas unidades ocultas, sendo um vetor de unidades ocultas $f^{(1)}(x ; W, c)$ e os valores dessas unidades ocultas são usados como entrada para uma segunda camada. A segunda camada é a camada de saída da rede como um modelo de regressão linear, mas como h ao invés de x. 
Portando, agora, a rede possui duas funções encadeadas, $h=f^{(1)}(x ; W, c)$ e $y=f^{(2)}(h ; w, b)$ ou então $f(x ; W, c, w, b)=f^{(2)}\left(f^{(1)}(x)\right)$.

Entretanto, deve-se usar uma função não-linear para descrever os recursos necessários para tanto deve-se usar uma transformação de onda controlada por parâmetros aprendidos, seguida por uma função não linear fixa chamada de função de ativação. Ou seja, $h=g$ (Wx $+c$ ), onde fornecem-se os pesos de transformação não linear e os respectivos vieses.

Para um modelo de função não linear a transformação ocorre de vetor para vetor, portanto é necessário definir um vetor completo de parâmetros e polarização. A função de ativação seria $y=g(x W: i+c i)$, porém nas redes neurais modernas, a recomenda-se usar a unidade linear retificada (ReLU, sigla em inglês) (Jarrett et al., 2009; Nair e Hinton, 2010; Glorot et al., 2011a), descrita pela função de ativação $g(z)=\max \{0, z\}$.

Além do modelo de aprendizado exemplificado acima, na questão da referida a função XOR, existe o modelo de aprendizado baseado no gradiente que, o qual treinamento é usa do gradiente para descer a função de custo e os algoritmos representam melhorias e refinamentos quanto ao algoritmo estocástico de gradiente descendente (GOODFELLOW et al, 2016).

Outro aspecto importante quanto a redes neurais profundas, é que utilizas-se normalmente uma distribuição $(y \mid x ; \theta)$ e então aplica-se o princípio da máxima verossimilhança, ou seja, usa-se o conceito de entropia entrecruzada entre os dados de treinamento e as previsões do modelo como a função de custo. Pode-se, também, aplicar-se uma forma mais simples, agindo apenas na predição estatística em $x$.

A escolha da função custo é intrinsicamente associada a unidade de saída, ou seja, a escolha de como representar a saída determina então a forma da função de entropia cruzada.

Para as redes neurais profundas, um aspecto também de suma importância refere-se a forma de definir o tipo de unidade oculta a ser usada nas camadas ocultas do modelo. $\mathrm{O}$ design de unidades ocultas é uma área extremamente ativa de pesquisa e ainda não possui muitos princípios teóricos orientadores definitivos, portanto processo de design consiste em tentativa e erro, intuindo que um tipo de unidade oculta pode funcionar bem e, em seguida, treinando uma rede com esse tipo de unidade oculta e avaliando seu desempenho. 
Também, para projeto de redes neurais, é necessário determinar sua arquitetura, a qual refere-se à estrutura geral da rede: quantas unidades ela deve ter e como essas unidades devem ser conectadas umas às outras. A maioria das redes neurais é organizada em grupos de unidades chamadas camadas e essas camadas em uma estrutura de cadeia, com função da entrada da camada posterior conectada a da saída da camada anterior. A primeira camada é dada pela Equação D.1 e a segunda camada pode ser vista na Equação D.2, e logicamente seguem equações para as demais camadas se houverem (GOODFELLOW et al, 2016).

$$
\begin{aligned}
& h^{(1)}=g^{(1)}\left(W^{(1) T} x+b^{(1)}\right) \\
& h^{(2)}=g^{(2)}\left(W^{(2) T} h^{(1)}+b^{(2)}\right)
\end{aligned}
$$

Por fim, para para uma rede neural retroalimentada aceitar uma entrada $x$ e produzir uma saída $y$, a informação avança por meio da rede, e a entrada de $x$ fornece as informações iniciais que se propagam por meio de suas camadas então resulta na saída $y$ e este processo é chamado de propagação para a frente. Já o conceito propagação reversa (Backpropagation, em inglês) (Rumelhart et al., 1986a), permite que a informação do custo flua de trás para frente por meio da rede neural e suas camadas ocultas de forma a determinar o gradiente da função custo, na maioria dos casos.

Em suma, o conceito de propagação reversa limita-se apenas a determinar o gradiente função custo, na maioria dos casos, como $\nabla x f(x, y)$ para uma função $f$, sendo $x$ um conjunto de variáveis cujas derivadas são desejadas, e y um conjunto adicional de variáveis que são entradas para a função $f$, porém sem necessidade de suas derivadas. Ou $\nabla \theta J(\theta)$ mais especificamente referente aos parâmetros da função custo.

Ressalta-se principalmente no conceito de propagação reversa a forma eficiente para calcular as derivadas das funções formadas pela composição de outras funções cujos derivados são conhecidos, descrito na Equação D.3, a ser aplicada também de forma recursiva.

$$
\nabla x^{z}=\sum_{j}\left(\nabla x Y_{j}\right) \delta_{z} / \delta Y_{j}
$$




\subsubsection{REDES NEURAIS CONVOLUCIONAIS}

As redes neurais multicamada exploram a correlação espacial local impondo um padrão de conectividade local entre os neurônios das camadas adjacentes, ou seja, as entradas de unidades ocultas na camada $m$ são de um subconjunto de unidades na camada $m-1$, unidades que possuem campos receptivos espacialmente contíguos, conforme Figura 7 abaixo.

Figura 7 - Rede Neural Multicamada

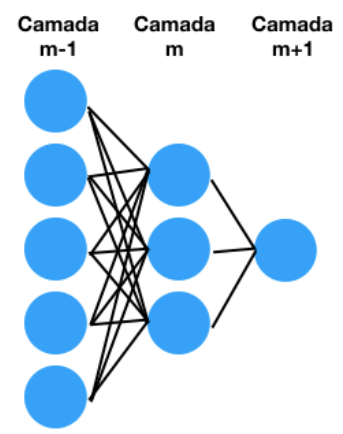

Fonte: Autor

A camada $m$ - 1 é a entrada e a camada m têm campos receptivos de largura 3 no perímetro de entrada, isto significa que obviamente os neurônios de m estão conectados a 3 neurônios adjacentes. A camada $m+1$ têm conectividade idêntica a camada $m$ anterior.

O empilhamento de muitas dessas camadas leva a conexões e filtros não lineares e muito mais abrangentes, neste exemplo da figura acima, a camada oculta $m+1$ pode codificar uma conexão não linear de largura 5 em termos de espaço de pixels. Além disso, cada filtro $h_{i}$ é replicado em todo o campo de atuação e com a mesma parametrização de pesos e fator de aprendizado (conhecido como Bias), formando assim um mapa de recursos.

$\mathrm{Na}$ figura acima, têm-se 3 unidades ocultas pertencentes ao mesmo mapa de características (camada m), nos quais os pesos são compartilhados e limitados para serem idênticos. Neste caso, pode-se aplicar a descida de gradiente para o aprendizado destes parâmetros compartilhados como descrito anteriormente quanto ao modelo de propagação 
reversa, sendo o gradiente de um peso compartilhado a soma dos gradientes dos parâmetros que estão sendo compartilhados.

Replicar as unidades permite que os recursos sejam detectados independentemente de sua posição no campo visual e o compartilhamento de peso com propagação reversa, aumenta a eficiência do aprendizado.

Um mapa de características é obtido pela aplicação repetida de uma função por meio de sub-regiões de toda a imagem, ou seja, por convolução da imagem de entrada com um filtro linear, adicionando um termo de polarização e aplicando uma função não linear. Para o k-ésimo mapa de características em uma dada camada como $h^{k}$, cujos filtros são determinados pelos pesos $W^{k}$ e taxa de aprendizado (bias) $b^{k}$, então o mapa de características $h^{k}$ é obtido por meio da Equação E.1 (para não-linearidades) (LISA Lab, 2018):

$$
h_{i j}^{k}=\tanh \left(\left(W^{k} * x\right)_{i j}+b_{k}\right.
$$

Não obstante da definição de convolução para um sinal 1D na Equação E.2 e 2D na Equação E.3.

$$
\begin{aligned}
& o[n]=f[n]^{*} g[n]=\sum_{u=- \text { infty }}^{\text {infty }} f[u] g[n u]=\sum_{u=- \text { infty }}^{\text {infty }} f[n u] g[u] \\
& o[m, n]=f[m, n]^{*} g[m, n]=\sum_{u=- \text { infty }}^{\text {infty }} \sum_{v=- \text { infty }}^{\text {infty }} f[u, v] g[m u, n v]
\end{aligned}
$$

Cada camada oculta é composta de vários mapas de recursos, $\left\{h^{(k)}, k=0 . . K\right\}$ e seus pesos $W$ são representados em um elemento contendo tensor 4D para cada combinação de: mapa de recursos de destino; mapa de recursos de origem; posição vertical de origem e posição horizontal de origem. Os vieses da taxa de aprendizado b podem ser representados como um vetor contendo um elemento para cada mapa de recursos de destino.

Uma rede neural convolucional (CNN, sigla em inglês) é uma classe de rede neural artificial multicamada de perceptrons retroalimentada para aplicação no processamento e análise de imagens digitais, também lhes é atribuída a denominação rede neural artificial invariante deslocada, em função de sua arquitetura de pesos compartilhados e características de invariância de translação, conforme exemplo na Figura 8. 
Figura 8 - Rede Neural Convolucional de 2 Camadas

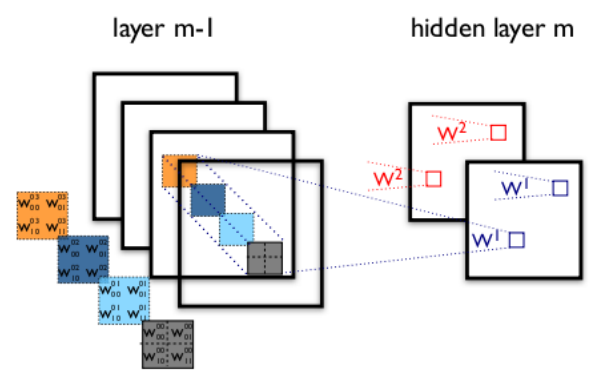

Fonte: Theano Development Team, 2008

A figura acima mostra duas camadas de uma $\mathrm{CNN}$, sendo a primeira com quatro mapas de recursos e oculta m com dois mapas de recursos $\left(h^{0}\right.$ e $\left.h^{1}\right)$, e os pixels em $h^{0}$ e $h^{1}$ grafados como quadrados azuis e vermelhos, os quais são calculados a partir de pixels da camada (m-1) que caem dentro de seu campo receptivo $2 \times 2$ na camada abaixo também representada com retângulos coloridos. Como o perímetro receptivo abrange todos os quatro mapas de recursos de entrada, os pesos $W^{0}$ e $W^{1}$ de $h^{0}$ e $h^{1}$ são tensores de peso 3D e a dimensão principal indexa os mapas de recursos de entrada, enquanto os outros dois se referem às coordenadas de pixel.

\subsubsection{MOBILENETS}

Em quatorze de janeiro do ano de 2017, por meio de seus Engenheiros de Software, Andrew G. Howard, e Menglong Zhu, a Google anunciou a criação das MobileNets (HOWARD, Andrew G., et al, 2017)

O anuncio supracitado baseava-se na linha argumentação de que o aprendizado profundo havia promovido um tremendo progresso no campo da visão computacional nos últimos anos, com redes neurais empurrando repetidamente a fronteira da tecnologia de reconhecimento visual e que o crescente poder computacional dos dispositivos móveis pode permitir o fornecimento de tecnologias massivamente, a qualquer hora, em qualquer lugar. Porém, argumentava ainda o referido anúncio, o reconhecimento visual para aplicativos incorporados e no dispositivo apresenta muitos desafios, pois os modelos deveriam ser executados rapidamente, com alta precisão e em um ambiente com recursos limitados. 
Diante disto, a Google lançou a família de modelos de visão computacional para dispositivos móveis para o TensorFlow, MobileNets. Uma família de modelos projetados para maximizar efetivamente a precisão, ao mesmo tempo em que atentos aos recursos restritos.

As MobileNets são modelos pequenos, de baixa latência e baixa potência, parametrizados para atender às restrições de recursos de vários casos de uso. Eles podem ser construídos para classificação, detecção, incorporação e segmentação semelhantes à forma como outros modelos populares de larga escala.

Diante do supracitado, como estratégia desenvolvida para este trabalho, foi escolhida a família de MobileNets para a detecção e classificação de imagens. Pois tal arquitetura vem a aderir a requisitos de sistemas móveis embarcados e com recursos limitados.

Tal arquitetura emprega convoluções separáveis em profundidade por meio de uma versão fatorada da operação de convolução, a fim de se reduzir expressivamente o tamanho da computação e do modelo. Desta forma, há uma fácil personalização do tamanho do modelo por meio dos hiperparâmetros multiplicadores de largura e resolução (OLIVEIRA et al, 2019).

O hiperparâmetro multiplicador de largura $\alpha \in(0,1)$ altera o número de canais de entrada em cada camada, onde $\alpha=1$ reproduz a arquitetura MobileNet original. Por exemplo, um valor de $\alpha=0,5$ reduz pela metade o número de canais.

O hiperparâmetro multiplicador de resolução $\rho \in(0,1]$ é usado para reduzir a resolução da imagem de entrada e, conseqüentemente, de todas as camadas subseqüentes da rede. Este multiplicador, de fato, define o tamanho de entrada da rede.

Portanto, atribui-se a alteração do multiplicador de largura à alteração do número de parâmetros do modelo e do seu custo computacional, enquanto que a alteração do multiplicador de resolução reduz apenas o custo computacional. A alteração de qualquer um dos hiperparâmetros é inversamente proporcional a precisão final da Rede Neural Convolucional quanto a classificação de imagens. A Tabela 1 apresenta a arquitetura do MobileNet padrão, em que $\alpha=1$ e $\rho=1$. 
Tabela 1 - Arquitetura MobileNet padrão

\begin{tabular}{l|c|c}
\hline Type / Stride & Filter Shape & Input Size \\
\hline Conv / s2 & $3 \times 3 \times 3 \times 32$ & $224 \times 224 \times 3$ \\
\hline Conv dw / s1 & $3 \times 3 \times 32 \mathrm{dw}$ & $112 \times 112 \times 32$ \\
\hline Conv / s1 & $1 \times 1 \times 32 \times 64$ & $112 \times 112 \times 32$ \\
\hline Conv dw / s2 & $3 \times 3 \times 64 \mathrm{dw}$ & $112 \times 112 \times 64$ \\
\hline Conv / s1 & $1 \times 1 \times 64 \times 128$ & $56 \times 56 \times 64$ \\
\hline Conv dw / s1 & $3 \times 3 \times 128 \mathrm{dw}$ & $56 \times 56 \times 128$ \\
\hline Conv / s1 & $1 \times 1 \times 128 \times 128$ & $56 \times 56 \times 128$ \\
\hline Conv dw / s2 & $3 \times 3 \times 128 \mathrm{dw}$ & $56 \times 56 \times 128$ \\
\hline Conv / s1 & $1 \times 1 \times 128 \times 256$ & $28 \times 28 \times 128$ \\
\hline Conv dw / s1 & $3 \times 3 \times 256 \mathrm{dw}$ & $28 \times 28 \times 256$ \\
\hline Conv / s1 & $1 \times 1 \times 256 \times 256$ & $28 \times 28 \times 256$ \\
\hline Conv dw / s2 & $3 \times 3 \times 256 \mathrm{dw}$ & $28 \times 28 \times 256$ \\
\hline Conv / s1 & $1 \times 1 \times 256 \times 512$ & $14 \times 14 \times 256$ \\
\hline Conv dw / s1 & $3 \times 3 \times 512 \mathrm{dw}$ & $14 \times 14 \times 512$ \\
Conv / s1 & $1 \times 1 \times 512 \times 512$ & $14 \times 14 \times 512$ \\
\hline Conv dw / s2 & $3 \times 3 \times 512 \mathrm{dw}$ & $14 \times 14 \times 512$ \\
\hline Conv / s1 & $1 \times 1 \times 512 \times 1024$ & $7 \times 7 \times 512$ \\
\hline Conv dw / s2 & $3 \times 3 \times 1024 \mathrm{dw}$ & $7 \times 7 \times 1024$ \\
\hline Conv / s1 & $1 \times 1 \times 1024 \times 1024$ & $7 \times 7 \times 1024$ \\
\hline Avg Pool / s1 & Pool 7 7 & $7 \times 7 \times 1024$ \\
\hline FC / s1 & $1024 \times 1000$ & $1 \times 1 \times 1024$ \\
\hline Softmax / s1 & Classifier & $1 \times 1 \times 1000$ \\
\hline
\end{tabular}

Fonte: OLIVEIRA, Jonas H. R., et al.

Referente ao aprendizado da Rede Neural Convolucional, para alcançar um patamar considerável para detecção de objetos, é necessário o treinamento de Redes Neurais Profundas com modelos de classificação, que são aplicados sobre regiões de uma imagem.

Para detecção de objetos, aplica-se uma Rede Neural Convolucional base a fim de gerar mapas de recursos, bem como camadas convolucionais adicionais de vários tamanhos para detectar objetos em várias escalas. A detecção é realizada por meio da avaliação de várias regiões da imagem, mesmo que em diferentes escalas e proporções. O treinamento é realizado de maneira ponta a ponta e é impulsionado por técnicas como estratégias de mineração negativa forte e de aumento de dados. 
Figura 9 - Arquitetura para metodologia de detecção de objeto

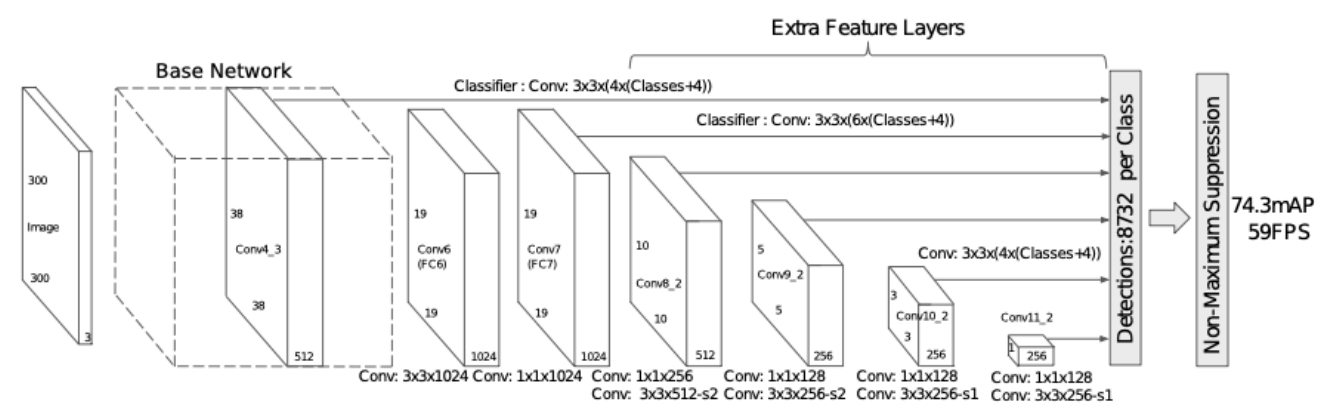

Fonte: OLIVEIRA, Jonas H. R., et al. 
Neste capítulo serão abordados outros trabalhos que exploraram o reconhecimento de padrões de imagem para referenciação de veículos de carga, ou correlatos, a fim de viabilizar a direção autônoma em ambientes externos, preferencialmente em localidades reservadas a agricultura.

Com as palavras chave: Redes Neurais Artificiais, Visão Computacional, Processamento de Imagem, Caminhões Autônomos, foram encontrados 24.700 trabalhos relacionados (Google Acadêmico, pesquisa realizada em 17/06/19 às 11:00 h.). Dos quais, 15.500 foram apresentados após o ano de 2015, 14.400 após 2018 e em 2019 foram apresentados 6.310 trabalhos relacionados.

Dos trabalhos apresentados em 2019, 976 têm relação com Caminhões Autônomos na Agricultura, principal objeto deste trabalho.

Uma análise mais profunda foi efetuada nos 100 trabalhos com maior número de citações ou patentes registradas, detalhes podem ser vistos na Tabela 2 no Apêndice C deste trabalho.

Destes 100 trabalhos pré-selecionados, 18 destes tem relação com Visão Computacional Segmentação de Imagens com aplicação em Veículos Autônomos e, 4 destes trabalhos tem correlação aplicável ao agronegócio.

YEEL e CHAKRABARTI (2019) propõem um novo algoritmo estéreo que emprega, conforme os pesquisadores, uma arquitetura de rede significativamente mais eficiente e aplicável a reconhecimento de imagem para veículos autônomos. Tal cria um volume de custo de correspondência inicial usando custos de correspondência tradicionais que são rápidos de calcular e treina uma rede para estimar a disparidade a partir desse volume, então esta nova rede proposta emprega apenas operações de convolução por pixel e bidimensional. Em suma, as informações de correspondência em cada local como um vetor de característica de baixa dimensão e para processar espacialmente esses recursos denominados de "assinatura de custo" para produzir um denso mapa de disparidade. Conforme os pesquisadores, resultados experimentais no benchmark KITTI mostram que tal método oferece precisão competitiva a velocidades significativamente maiores, a 48 quadros por segundo em uma GPU moderna. 
A abordagem de JIAO, WANG, FU, DING, TAN, CHEN e XIONG (2019), busca confrontar o desafio de minimizar correspondências incorretas de recursos no processo de reconhecimento de imagens. Para tanto, os pesquisadores, buscam derivar soluções mínimas de forma fechada para localização 3D-2D com o auxílio de medidas inerciais, usando apenas 2 pares de correspondência de pontos ou 1 par de correspondência de pontos e 1 par de correspondência de linhas. Essas soluções são utilizadas no RANSAC de 2 entidades proposto, que é mais robusto para correspondências incorretas, já que os recursos de linha e ponto podem ser usados simultaneamente e o número de correspondências necessárias para o cálculo de poses é menor. Introduziu-se então três estratégias de amostragem com diferentes vantagens, permitindo um mecanismo de seleção automática, como exemplificado na Figura 10. Com o mecanismo proposto, RANSAC de duas entidades, os pesquisadores afirmam que ele pode ser adaptável aos ambientes com diferentes distribuições de tipos de recursos em diferentes segmentos.

Figura 10 - Algoritmo para localização 3D-2D com medidas inerciais de 2 pares de correspondência de pontos ou linhas - RANSAC



Fonte: Jiao, 2019

Como importante complementação a meu trabalho, HUANG (2019) propõe uma nova forma de cinemática veicular para planejar caminhos de mudança de faixa/linha baseado em mapa de alta definição, que, conforme proposto pelo pesquisador, pode ser um tipo de controlador de mudança de pista baseado em imagem. Como resultado do trabalho, o pesquisador afirma que o modelo matemático de caminho mostrou versatilidade para diferentes condições geométricas e estados dos veículos e que o controlador baseado em 
imagem mostrou que é possível efetuarem-se manobras usando apenas uma câmera monocular como fonte geradora de imagens.

ARCLA (2019) propõe um sistema de rastreamento de veículos para reconhecer um veículo e monitorá-lo em rodovias. Tal sistema é baseado numa combinação de algoritmos bio-inspirados VOCUS2, CNN e LSTM e, conforme o pesquisador, o teste do sistema proposto com imagens reais coletadas por um robô aéreo e os resultados obtidos denotam um bom desempenho de classificação de imagens e chega até a superar outras abordagens existentes em termos de precisão. Para este trabalho, utilizar-se-ei também de conceitos abordados por este pesquisador no que tange redes neurais convolucionais e aprendizado profundo com o Modelo LeNet, porém, apesar da classificação de imagens para o meu trabalho ser mais simples do que o modelo proposto pela pesquisadora, o encadeamento do processamento de imagens é mais complexo e, provavelmente, necessário. Além do resultado necessariamente ser mais consequente e com mínimo erro, por ser aplicado em um veiculo autônomo, ao invés de apenas reconhecer e monitorar objetos em movimento.

DOSOVITSKIY, CODEVILLA e LOPEZ (2017) apresentaram o trabalho denominado CARLA e definido como um simulador de código aberto para pesquisa de condução autônoma. O CARLA foi desenvolvido desde o início para apoiar o desenvolvimento, treinamento e validação de sistemas de condução urbana autônomos, por meio de três abordagens para a direção autônoma: um pipeline modular clássico, um modelo de ponta a ponta treinado via aprendizado de imitação e um modelo de ponta a ponta treinado via aprendizado por reforço. As abordagens são avaliadas em cenários controlados de dificuldade crescente, e seu desempenho é examinado por meio de métricas fornecidas. Estas três abordagens, como pode ser visto na Figura 11, ou modalidades sensoriais desenvolvidas, primeiramente obtêm a imagem original, depois a tratam para encontrar a profundidade do solo e, por fim, faz-se a segmentação semântica do fundo da terra. Este simulador apresentase muito eficaz conforme publicação e o conceito de segmentação semântica da imagem (e seu algoritmo) podem ser de grande valia para o desenvolvimento deste trabalho. A aplicação de aprendizado profundo também faz deste modelo flexível a diferentes aplicações, porém para este trabalho, ainda é necessário evoluir para que seja possível traçar e definir linhas verticais para o correto posicionamento do veículos autônomo. 
Figura 11 - Imagem tratada para encontrar profundidade
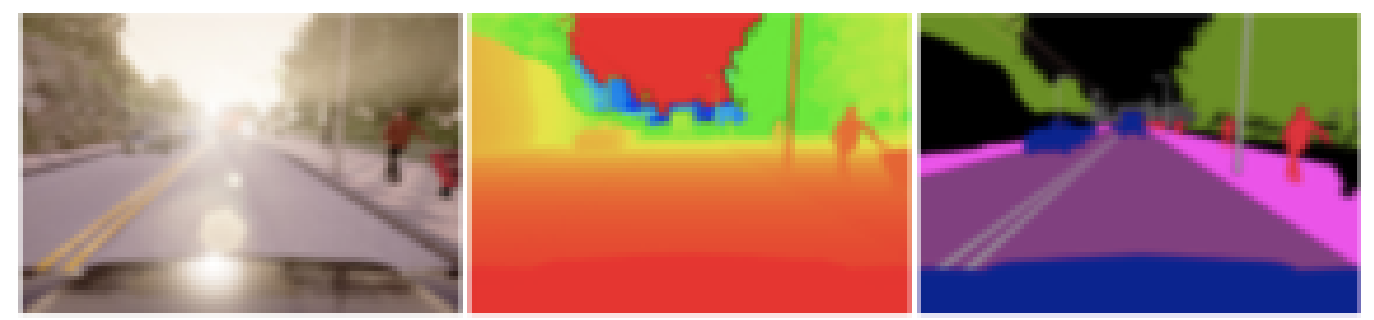

Fonte: Dosovtskiy, 2017

Um outro trabalho desenvolvido, porém, por OKSANEN, Timo e BACKMAN (2017) apresenta um algoritmo de rastreamento de trilha para um trator agrícola de quatro rodas, projetado para ser autônomo. $\mathrm{O}$ algoritmo de rastreamento de caminho utiliza o modelo cinemático e dinâmico do veículo, previsão dinâmica e leis de controle linear para direcionar os eixos dianteiro e traseiro do trator. O modelo cinemático é usado para separar o problema de controle de duas vezes em dois problemas de saída única de entrada única. Controladores lineares convencionais são usados para controle de realimentação em conjunto com a parte de alimentação direta. O sistema de orientação utiliza um receptor GPS cinemático em tempo real para posicionamento global e sensores adicionais para medir a atitude do veículo. $\mathrm{O}$ sistema de rastreamento de trilha desenvolvido foi testado em um campo agrícola com uma semeadora montada; semeando 2,4 ha de trigo no inverno e, para os pesquisadores os resultados foram satisfatórios, apesar do sinal de posicionamento GPS apresentar limites de qualidade de $15 \%$, o que incorre na interrupção do modo autônomo e, também conforme os pesquisadores, o período contínuo mais longo de sinal válido foi de dezoito minutos, o que para este trabalho em questão é inaceitável, pois a preparação do solo e colheita de cana-deaçúcar perdura por horas, durante o dia e noite, e portanto este modelo proposto pelos pesquisadores não serve para este trabalho, além de ser um dos motivos de não ter optado pelo modelo de Geo-Posicionamento.

Por meio de uma busca de trabalhos anteriores a 2015, aleatoriamente se encontrou alguns trabalhos de conteúdo relevante, como o trabalho de REINA, G. e MIELLA, A. (2012) que versa sobre detecção automática de solo aplicando visão estéreo trinocular e fazendo classificação do solo analisado por meio de coloração e geometria. Já o trabalho formulado 
por TAKAGAKI, MASUDA, LIDA, e SUGURI (2013) tem um objetivo similar ao deste trabalho, a navegação autônoma para robotizar veículos agrícolas. Para tanto, foi proposto um método de processamento de imagem para discriminar entre a região possível de atravessar (sulco) e a região não possível de atravessar em campos enrugados sem culturas e, tal método, consiste em 3 partes: primeiramente as imagens são segmentadas em imagens com ou sem sombra por meio de histogramas de nível de cinza; Então, para imagens com sombra, esta informação define a região possível de atravessar; Por fim, para região não possível de atravessar, ou seja, imagens sem sombra, faz se uma análise de textura por a variância para sua devida descrição. Este método apresentou-se eficaz conforme publicação, porém por não possuir conceitos de aprendizado de máquina pode ser de difícil replicação em diferentes ambientes e condições, bem como a extração de sinais para correto posicionamento do equipamento pode, também não ser possível. Um visão pictórica do método pode ser visto na Figura 12.

Figura 12 - Reconhecimento de linhas no solo



Fonte: Takagaki, 2013

Por meio de critérios de busca com palavras-chave fazendo referência em agronegócio e posicionamento de veículos em processos de plantio, referente a trabalhos anteriores a 2015, foi ainda possível encontrar que TAKAGAKI, MASUDA, LIDA e SUGURI (2013) propuseram um modelo de planejamento de movimento baseado em aprendizagem profunda (chamado de rede LSTM espaço-temporal), que é capaz de gerar uma reflexão em tempo real baseada na extração de informações espaço-temporais. Ou seja, o 
modelo baseado na rede LSTM espaço-temporal tem três estruturas principais, como pode ser visto na figura 3.4: Primeiramente, a Longa-Curta Memória Convolucional (Convolutional Long-Short Term Memory, em inglês e a sigla Conv-LSTM, também em inglês) que é usada para extrair recursos ocultos por meio de dados de imagens sequenciais; em seguida, a rede neural da convolução digital (3D-CNN, sigla em inglês) que é aplicada para extrair as informações espaço-temporais da informação característica do quadro múltiplo; e por fim, as redes neurais totalmente conectadas são usadas para construir um modelo de controle para o ângulo de direção do veículo autônomo.

Figura 13 - Arquitetura LSTM



Fonte: Takagaki, 2013

Existem muitas publicações para aplicação em veículos autônomos por meio de modelos diferentes do proposto neste trabalho e também dos trabalhos correlatos pesquisados aqui neste capitulo.

Como anteriormente ja citado, modelo proposto neste trabalho é baseado no reconhecimento e processamento de imagens. Outro modelo consideravelmente citado na pesquisa de trabalhos correlatos, na especificidade de veículos autônomos, é baseado na análise de sinais de sensores de análise direta, como o denominado LIDAR.

LIDAR (Light Detection and Ranging, em inglês) é uma tecnologia óptica de detecção remota que mede propriedades da luz reflectida, por meio de um feixe piscante de laser, de modo a obter a distância e/ou outra informação a respeito um determinado objecto distante. 
Por exemplo, RAMBHATLA, Sirisha, SIDIROPOULOS, Nikos D. e HAUPT, Jarvis (2019), propões uma técnica para desenvolver e localizar mapas tipológicos a partir de dados de detecção e alcance de luz por meio do LIDAR a fim de assegurar posicionamento em tempo real para um um veículo autônomo, com um modelo para desenvolver tais mapas topológicos a partir de dados LIDAR usando a decomposição ortogonal do tensor Tucker3. Conforme as avaliações experimentais relatadas pelos pesquisadores, demonstra-se que, além de atingir uma alta taxa de compressão em comparação com os dados completos, a técnica proposta, também detecta com precisão a posição do veículo em uma representação baseada em gráficos de um mapa.

Os motivos de não adotar uma modelagem com LIDAR para neste trabalho é o custo computacional como pode ser visto no trabalho de RAMBHATLA et al (2019), do ainda alto custo de aquisição do sensor LIDAR para pesquisa e também pelo alto custo de implementação em um caminhão aplicado na colheita de cana-de-açúcar, que poderia chegar até $20 \%$ do valor do próprio caminhão. 


\section{PROPOSTA}

O objetivo deste trabalho é apresentar um sistema para correto posicionamento cartográfico conforme linhas de plantio pré-estabelecidas, de caminhões escravos autônomos na colheita de cana-de-açúcar.

Para tanto, este sistema faz uso de conceitos de Visão Computacional, Processamento de Imagem e Redes Neurais Artificiais.

Para este trabalho, após a devida aplicação de técnicas de calibração de câmeras aplicadas fisicamente no caminhão escravo autônomo, foi levantado um banco de imagens com mais de 24 horas de filmagens que foram convertidas em um banco com mais de 25 mil imagens referentes ao processo de colheita de cana-de-açúcar durante a manhã, tarde e noite.

Foram avaliadas 2 hipóteses para atendimento do objetivo deste trabalho.

A primeira hipótese foi baseada numa abordagem apenas com ferramentas tradicionais de Visão Computacional. Aplicou-se primeiramente o Filtro Sobel para redução de ruído e então a Transformada de Hough.

A aplicação de visão computacional tradicional foi considerada neste trabalho em função de apresentar baixo custo de treinamento, ser mais rápida e de depender de hardware mais simples para sua execução em campo.

A segunda hipótese constituía na aplicação da Rede Neural artificial MobileNet. Para o treinamento, fizeram-se marcações manuais para identificação da pista de plantio em mais de 1.300 imagens.

\subsection{Hipótese 1}

A primeira hipótese é baseada em uma abordagem apenas com ferramentas tradicionais de Visão Computacional.

Aplica-se primeiramente o Filtro Sobel com o objetivo de calcular o gradiente da intensidade da imagem em cada ponto, apresentar a direcção da maior variação de claro para escuro e a quantidade desta variação em sua respectiva direção. Desta forma, estima-se a presença de uma transição claro-escuro e sua respectiva orientação e, então, com as fronteiras 
bem definidas entre objetos, consegue-se fazer a detecção de contornos e reduzir o ruído da imagem.

Posteriormente, aplica-se a Transformada de Hough que tem como base uma matriz bidimensional a fim de buscar uma linha reta definida por $\rho=x \cos \theta+y \sin \theta$. Esta matriz bidimensional refere-se a quantidade de parâmetros desconhecidos $(\rho$ e $\theta)$ de cada pixel em $x$ e $y$ em sua vizinhança. Para tanto, determina-se a existência de uma linha reta em um determinado pixel e então calcula-se os parâmetros $\rho$ e $\theta$. Posteriormente procura-se os valores mais altos dentro desta matriz bidimensional, por meio dos máximos locais. Ao encontrar estes máximos locais, as retas mais prováveis podem ser delineadas, assim como suas aproximada coordenadas geométricas.

Em suma, Filtro Sobel para eliminar o ruído da imagem e detectar as bordas das pistas de plantio, então aplica-se a Transformada de Hough a fim de delinear as mesmas linhas de forma a compor eventuais desvios ou pixels faltantes. Como é visto na Figura 14.

Figura 14 - Hipótese 1

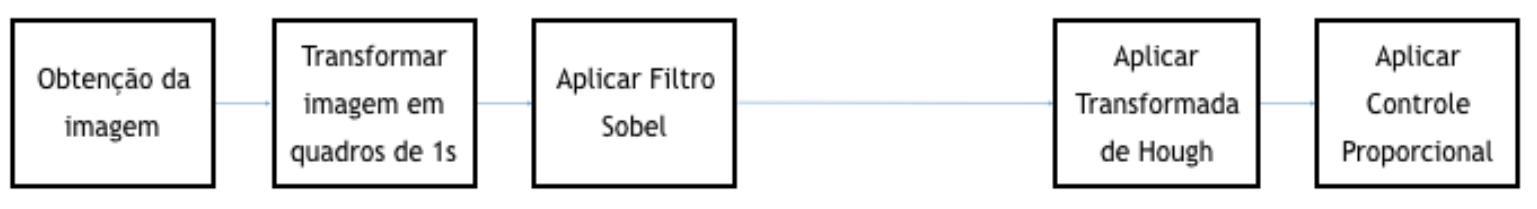

Fonte: Autor

\subsection{Hipótese 2}

A segunda hipótese baseia-se na aplicação de uma Rede Neural Artificial para detecção e classificação de regiões da imagem onde contém uma pista na área de plantio de cana-de-açúcar (como é visto na Figura 15).

Para esta hipótese aplica-se uma rede neural convolucional denominada MobileNet com uma arquitetura emprega convoluções separáveis em profundidade por meio de uma versão fatorada da operação de convolução. Desta forma reduz-se a complexidade do modelo por meio dos hiperparâmetros multiplicadores de largura e resolução. 
A escolha de uma Rede Neural Artificial MobileNet da-se em função de sua característica de modelos pequenos, de baixa latência e baixa potência, parametrizados para atender às restrições de recursos impostos a um caminhão autônomo em uma fazenda de cana-de-açúcar.

A Rede Neural Artificial MobileNet é construída, neste caso, para classificação, detecção, incorporação e segmentação semelhantes à forma de uma pista em meio a uma área de plantio de cana-de-açúcar.

O treinamento Rede Neural Artificial MobileNet usa parte das imagens contidas no banco de imagens descrito no início deste capítulo, e a análise de seu desempenho é feita com base em sua aplicação no referido banco como um todo.

Como suporte a constituição do processo de treinamento da referida rede neural artificial, utiliza-se um software para classificação manual das pistas de plantio contidas em cada imagem. Este software é denominado LabelImg.

Figura 15 - Hipótese 2

\begin{tabular}{|c|c|c|c|}
\hline $\begin{array}{c}\text { Obtençāo da } \\
\text { imagem }\end{array}$ & $\begin{array}{c}\text { Transformar } \\
\text { imagem em } \\
\text { quadros de 1s }\end{array}$ & $\begin{array}{c}\text { Aplicar Rede } \\
\text { Neural } \\
\text { Copxolucjonal }\end{array}$ & $\begin{array}{c}\text { Aplicar } \\
\text { Controle } \\
\text { Proporcional }\end{array}$ \\
\hline
\end{tabular}

Fonte: Autor 


\section{EXPERIMENTOS E RESULTADOS}

Inicialmente utilizaram-se os conceitos de calibração de câmera a fim de posicionar e aferir corretamente a câmera localizada dentro da cabina do caminhão apontada no respectivo sentido de marcha.

Utilizou-se o caminhão marca Mercedes-Benz modelo Axor 3131 modificado $8 x 4$ com bitola de eixo e suspensão adaptados para colheita de cana-de-açúcar. Altura do solo e largura da cabina são de, respectivamente, 2,992 metros e 2,57 metros conforme fabricante. Figura 16 abaixo.

Figura 16 - Caminhão marca Mercedes-Benz modelo Axor 3131 modificado 8x4

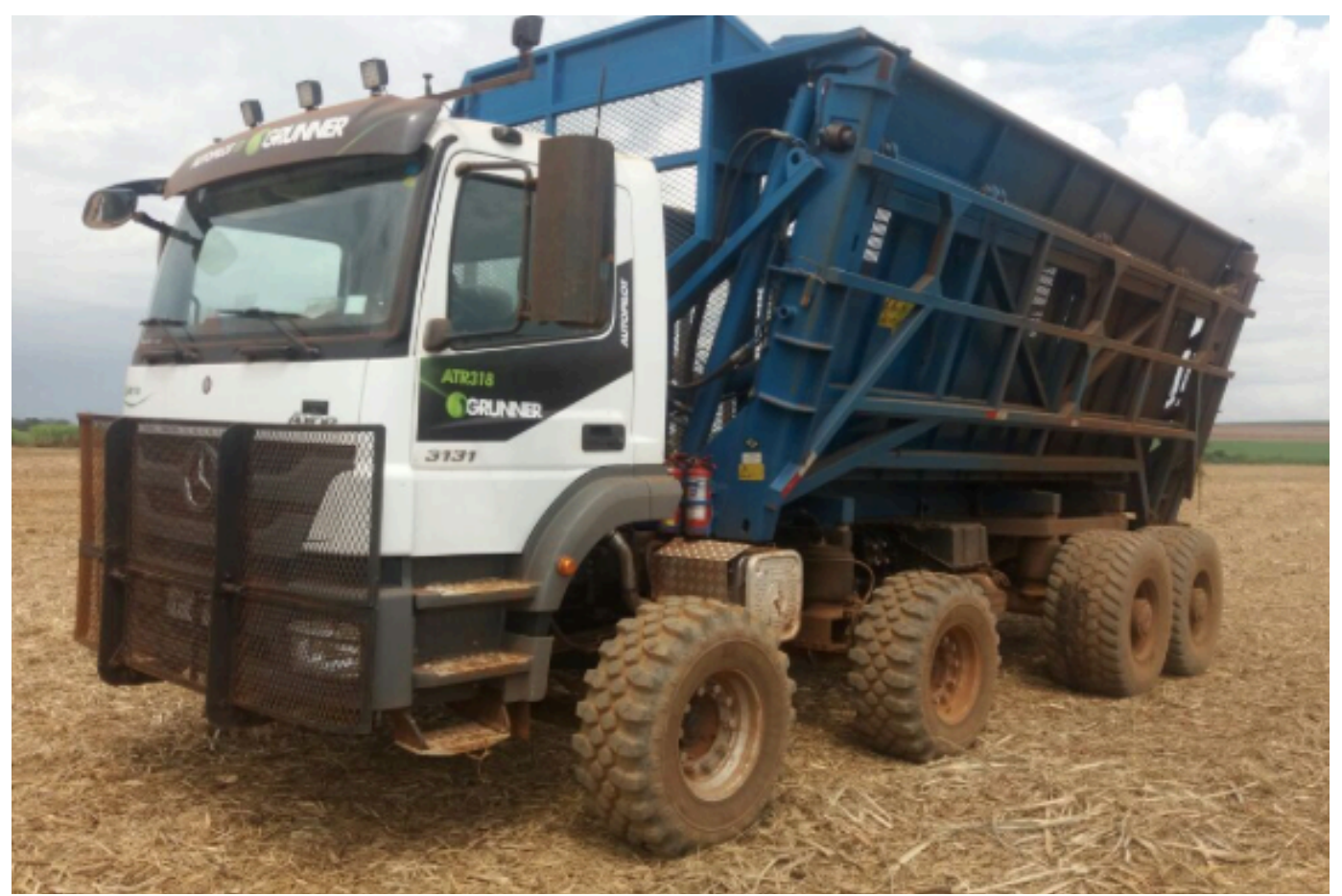

Fonte: Grunner Tec / Mercedes-Benz

O ponto de ancoragem da câmera dentro da cabina do veiculo supracitado foi definido no centro desta com 1,285 metros para cada lado horizontalmente. A altura da câmera foi definida a 2,592 metros a partir do solo e com uma inclinação vertical de 20 graus e 90 graus na posição horizontal em relação no sentido de marcha do veículo. 
A câmera utilizada foi a Clarus Carpa-1300, 1280 x 720 e resolução à 30 fps. Câmera com GPS, G-sensor e contagem de tempo integrados. Além de H.264 e compressão de vídeo em MPEG4.

Para implementação de algoritmos de processamento de imagem, bem como para treinamento e utilização da Rede Neural Artificial MobileNet, foi utilizado o equipamento Apple McBook Air com Processador Intel Core i5 dual core de 1,8 GHz (Turbo Boost de até 2,9 GHz) e 3 MB de cache L3 compartilhado e memória integrada LPDDR3 de 8 GB com $1600 \mathrm{MHz}$.

Com a aplicação da câmera no caminhão nas condições de contorno supracitados, por meio de 18 horas ininterruptas de filmagens, foram geradas 10.801 .969 .864 bytes para 462 itens/videos de base de dados para execução do trabalho em questão.

As filmagens foram executadas em uma fazenda no municipio de Lençois Paulistas no estado de São Paulo. Iniciando às 13:15:03 horas do dia 30 de março de 2019 e terminando às 7:00:04 do dia 31 de março de 2019 a fim de obter uma amostra de imagens mais heterogêneas possíveis, com imagens diurnas em diversos momentos do dia para considerar as posições de sombra. Além de imagens noturnas com iluminação artificial.

Foram selecionados e excluídos momentos de parada, troca de turnos e reparos em geral. Foram trabalhados apenas vídeos produtivos, ou seja, com o caminhão em movimento.

Posteriormente, os vídeos produtivos foram transformados em 25.904 imagens estáticas provenientes de cortes de intervalos de 1 segundo do referido vídeo com aproximadamente $300 \mathrm{~KB}$ cada.

Especificamente, para a hipótese de aplicação da Rede Neural Artificial Convolucional MobileNet, objetivando o treinamento desta, foi também formado um banco imagens com marcações manuais para para as linhas de pistas da plantação da cana-de-açúcar de 634 imagens, das quais 428 são noturnas e 206 diurnas. Estas imagens foram segregadas das 25.904 imagens provenientes do video produtivo anteriormente citados as marcações foram feitas por meio do software LabelImg.

Por fim, para detecção de linhas de pistas na plantação de cana-de-açúcar, foram testadas 2 hipóteses a fim de encontrar-se a de melhor desempenho em detectar e classificar a linha de pista de plantio de cana-de-açúcar e para a hipótese referente a Rede Neural 
Artificial, mensurar Precisão e Revocação por meio de mAP de 50 IoU e AR de 100 respectivamente no step 10.860, perfazendo 227 épocas de treinamento.

\section{$5.1 \quad$ Hipótese 1}

Antes da aplicação da hipótese 1 um tratamento de imagem foi necessário. Com a obtenção das imagens provenientes de cortes sequenciais de 1 segundo, a fim de se reduzir o custo computacional e apenas processar especificamente o segmento necessário da imagem, e para tanto aplicaram-se um recorte longitudinal e outro horizontal na referida imagem, por meio da biblioteca disponível no OPENCV do Python com o denominado "crop", como pode ser visto na Figura 17 e Figura 18. Desta forma aplicou-se o Filtro Sobel exatamente no quadrante da imagem onde se fazia necessária a detecção de pista de plantio de cana-deaçúcar.

Figura 17 - Demonstração de recorte de imagem em quadrantes - "Crop"



Fonte: Autor

Figura 18 - Recorte (Crop) do quadrante 0,2 descrito na Figura 18, anteriormente

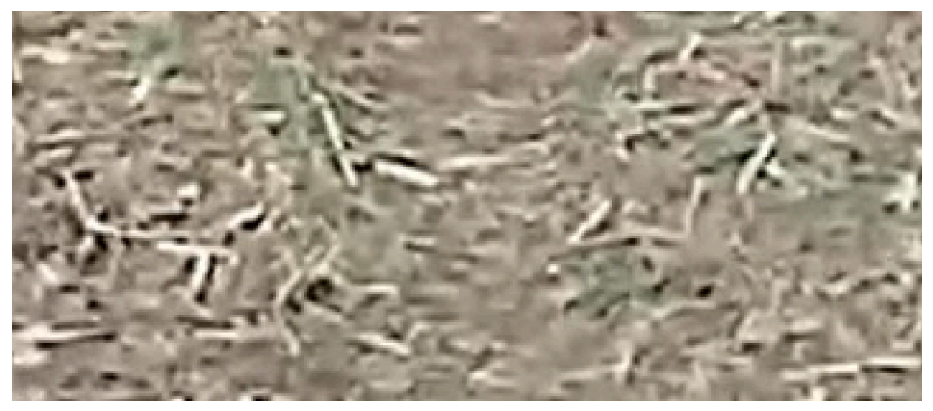

Fonte: Autor 
A aplicação do Filtro Sobel apresentou ótima supressão de ruídos, como preconizado na referência bibliográfica deste trabalho, como ser visto na Figura 19. Porém, também conforme a encontrado na referência bibliográfica aqui presente, a operação de gradientes do Filtro Sobel por meio de quadrados e raizes geraram um custo computacional relativamente alto, dependendo da imagem processada, chegou até cerca de 5 segundos para o processamento no equipamento descrito no capítulo anterior.

Figura 19 - Aplicação do Filtro Sobel na imagem da Figura 18

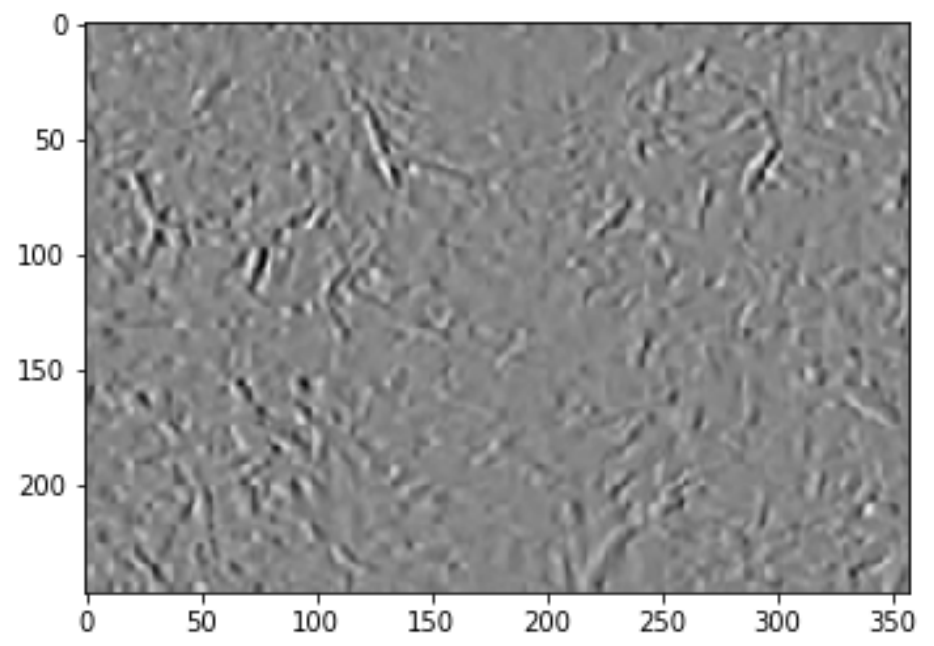

Fonte: Autor

Visualmente pode-se notar, bem no meio da Figura 20, uma leve transição nas tonalidades de cinza indicando algo como que um abaulamento da imagem. Tal posição é a pista de plantio de cana-de-açúcar que o pneu do caminhão deve permanecer constantemente.

Como próxima etapa na hipótese 1, aplicou-se a Transformada de Hough.

Como tratado na referência bibliográfica deste trabalho, a Transformada de Hough só é eficiente se um grande número de votos cair na posição correta, de modo que a região possa ser facilmente detectada em meio ao ruído de fundo, portanto, a efetividade da Transformada de Hough depende da qualidade dos dados de entrada, seu uso em imagens ruidosas não é eficaz, portanto um estágio anterior de tratamento da imagem é necessário. 
Porém, mesmo com a aplicação anterior do Filtro Sobel, o resultado obtido com a aplicação da Transformada de Hough não foi satisfatório e inviabilizou o modelo tratado na hipótese 1. A imagem resultante foi um emaranhado de linhas em sentidos aleatórios, isto em função da quantidade de votos do algoritmo ter ocorrido de forma aleatória em toda a imagem em função da própria característica da imagem que, mesmo com filtro de ruído, não é homogênea o suficiente.

O ruído contido nas imagens é proveniente do próprio contexto em que esta inserido a coleta de imagens, devido a complexidade imposta a imagens provenientes de áreas de colheita de cana-de-açúcar como o grande volume de transição de texturas no solo e plantação de cana-de-açúcar, além da própria sujeira recuperada na imagem em função da movimentação de máquinas.

Diante disto, a hipótese 1 não logrou hesito da forma inicialmente concebida. Alternativamente, omitiu-se a aplicação da Transformada de Hough e buscou-se encontrar a pista de posicionamento para colheita por meio da variação média de pixels. Pois, como pôde ser observado na Figura 20, se esta variação de tonalidade é observada a olho nu, também sua detecção é possível por meio da variação da quantidade de pixels.

Aplicou-se então o Filtro Sobel em x e y, posteriormente fez-se um histograma com a contagem da concentração de pixels do quadro da imagem segmentada e calculou-se a maior concentração de pixels. Uma maior concentração de pixels é obtida após a aplicação do Filtro Sobel em x e outra em y. Cada uma destas concentrações e pixels é classificada como linha de plantio de cana-de-açúcar a ser preservada e a média entre esta duas concentrações de pixels é a pista onde deve ser posicionada a roda do caminhão. 
Figura 20 - Histograma e concentração de pixels

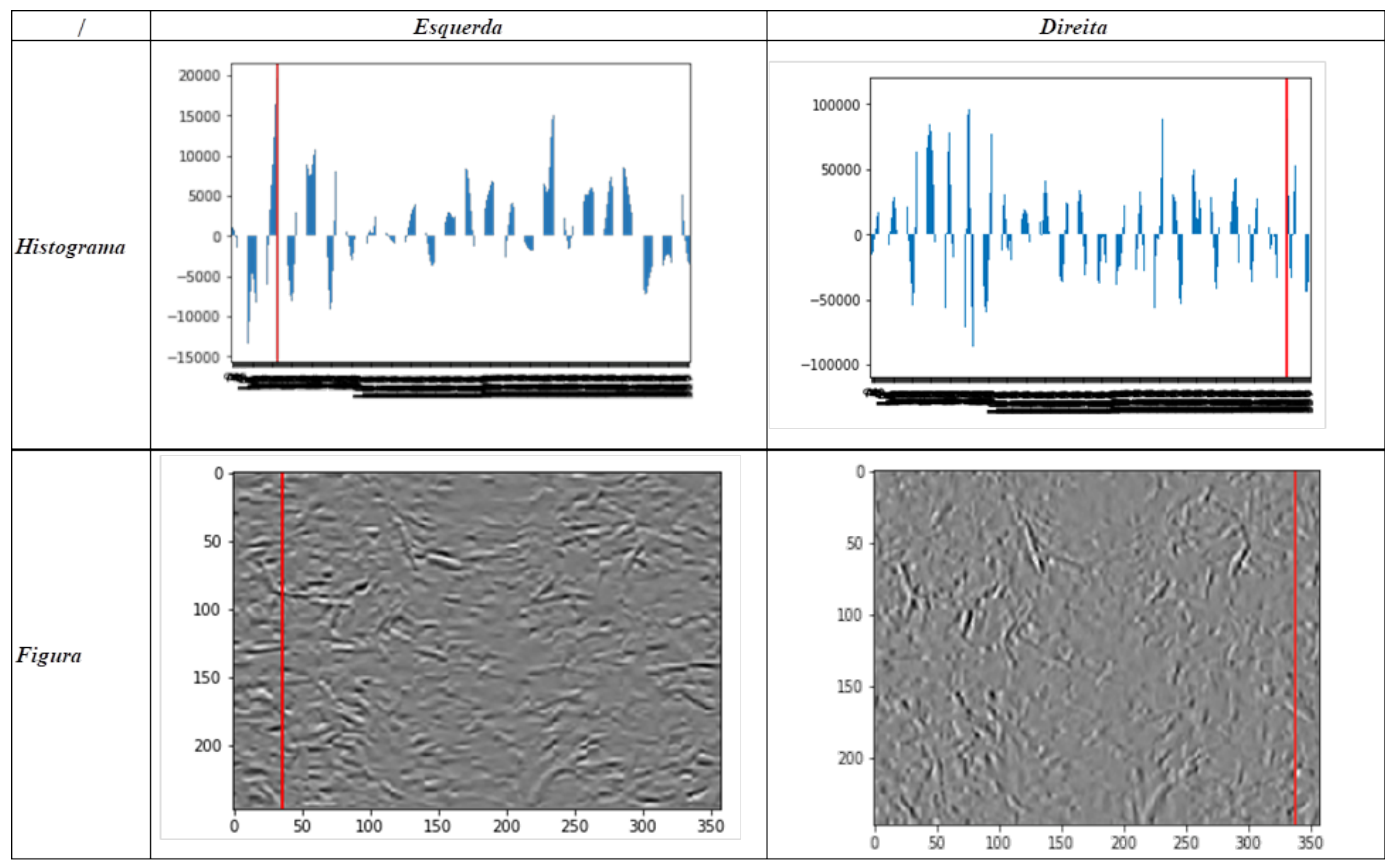

Fonte: Autor

Figura 21 - Cálculo da média de pixels - Pista

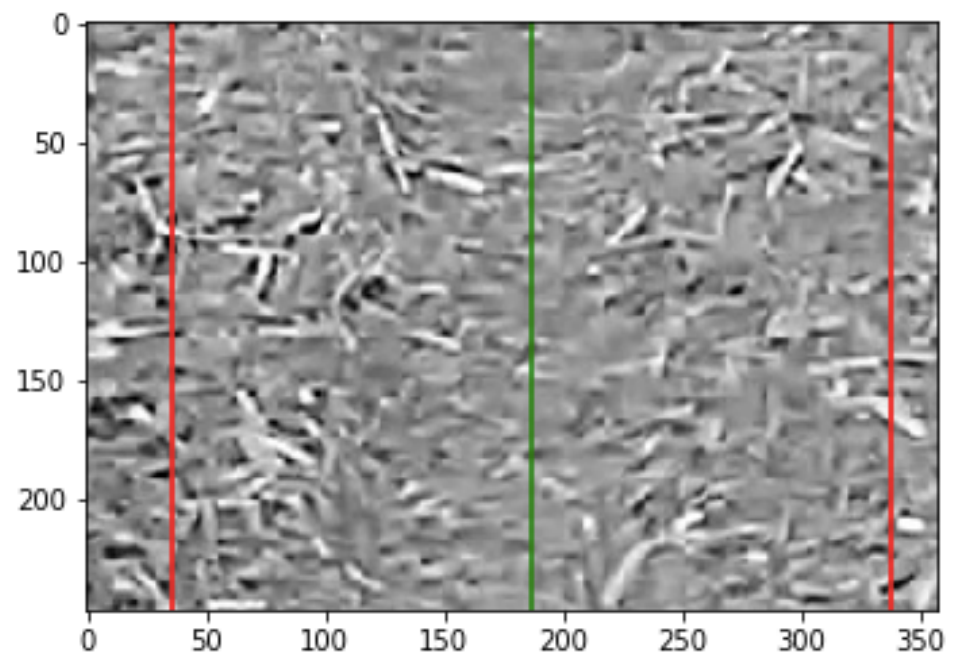

Fonte: Autor 
Esta forma alternativa apresenta-se eficaz em condições muito específicas, como quando a linha de plantio está exatamente perpendicular ao sentido de marcha do caminhão, caso contrário, este modelo alternativo não funciona como pode ser visto na Figura 24.

Figura 22 - Exemplo de linha de plantio não perpendicular ao sentido de marcha

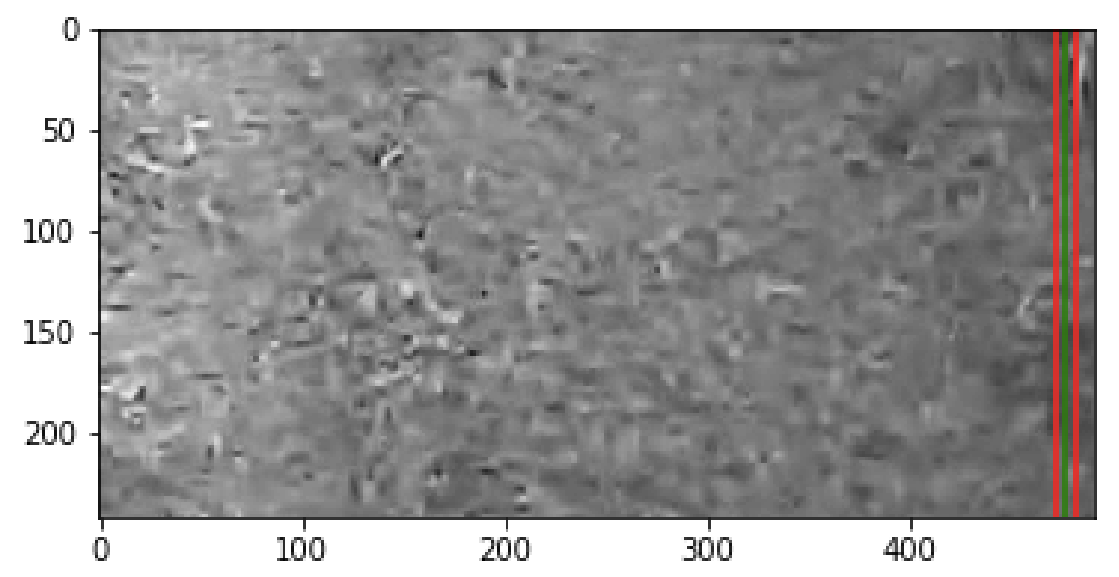

Fonte: Autor

\subsection{Hipótese 2}

As MobileNet aplicada com característica preconizada de baixa latência e baixa potência, parametrizada para atender às restrições de recursos impostas ao processamento dentro da cabine de um caminhão.

Ela foi aplicada para classificação, detecção, incorporação e segmentação semelhantes à pista onde deve-se posicionar a roda do caminhão.

O aprendizado da Rede Neural Convolucional em questão, para alcançar um patamar considerável para detecção de objetos, é necessário o treinamento de Redes Neurais Profundas com modelos de classificação, que foram aplicados sobre regiões de uma imagem.

A fase de de treinamento é executada em iterações de 48 imagens por step de treinamento, sendo estes 1.000 steps, perfazendo 21 épocas.

O treinamento foi feito em duas etapas distintas com imagens com luz natural e sem luz natural. 
Como citado no capítulo anterior, foi formado um banco imagens com marcações manuais para para as linhas de pistas da plantação da cana-de-açúcar de 634 imagens sendo 428 noturnas e 206 diurnas. Estas imagens foram segregadas de 25.904 imagens provenientes do video produtivo também descrito no capitulo anterior. As marcações foram feitas por meio do software LabelImg, como pode ser visto na Figura 23 abaixo.

Foram testadas 2 formas de marcação de imagens por meio do programa LabelImg utilizado para marcação de imagens para treinamento:

a) marcação retangular exatamente dentro da pista de plantio de cana-de-açúcar e ;

b) marcação retangular abrangendo também a transição entre borda e pista de plantio, a qual a curva de aprendizado alcançou uma convergência mínima no milésimo step de treinamento deste trabalho.

Figura 23 - Exemplo da marcação de imagem e sua descrição no arquivo texto.

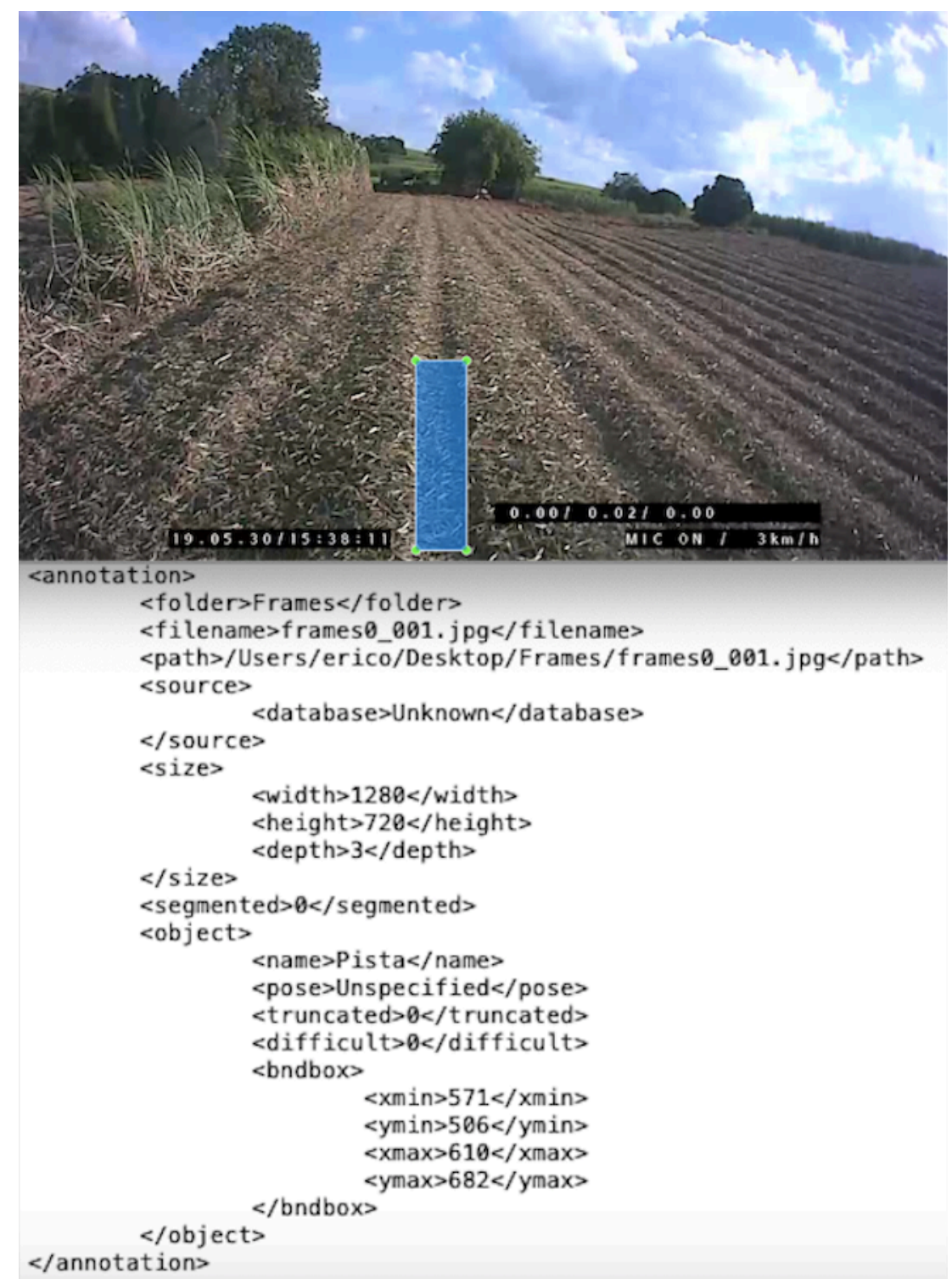


As curvas de aprendizado da Rede Neural MobileNet podem ser vistas no gráfico da Figura 24.

Figura 24 - Curva de Aprendizado MobileNet

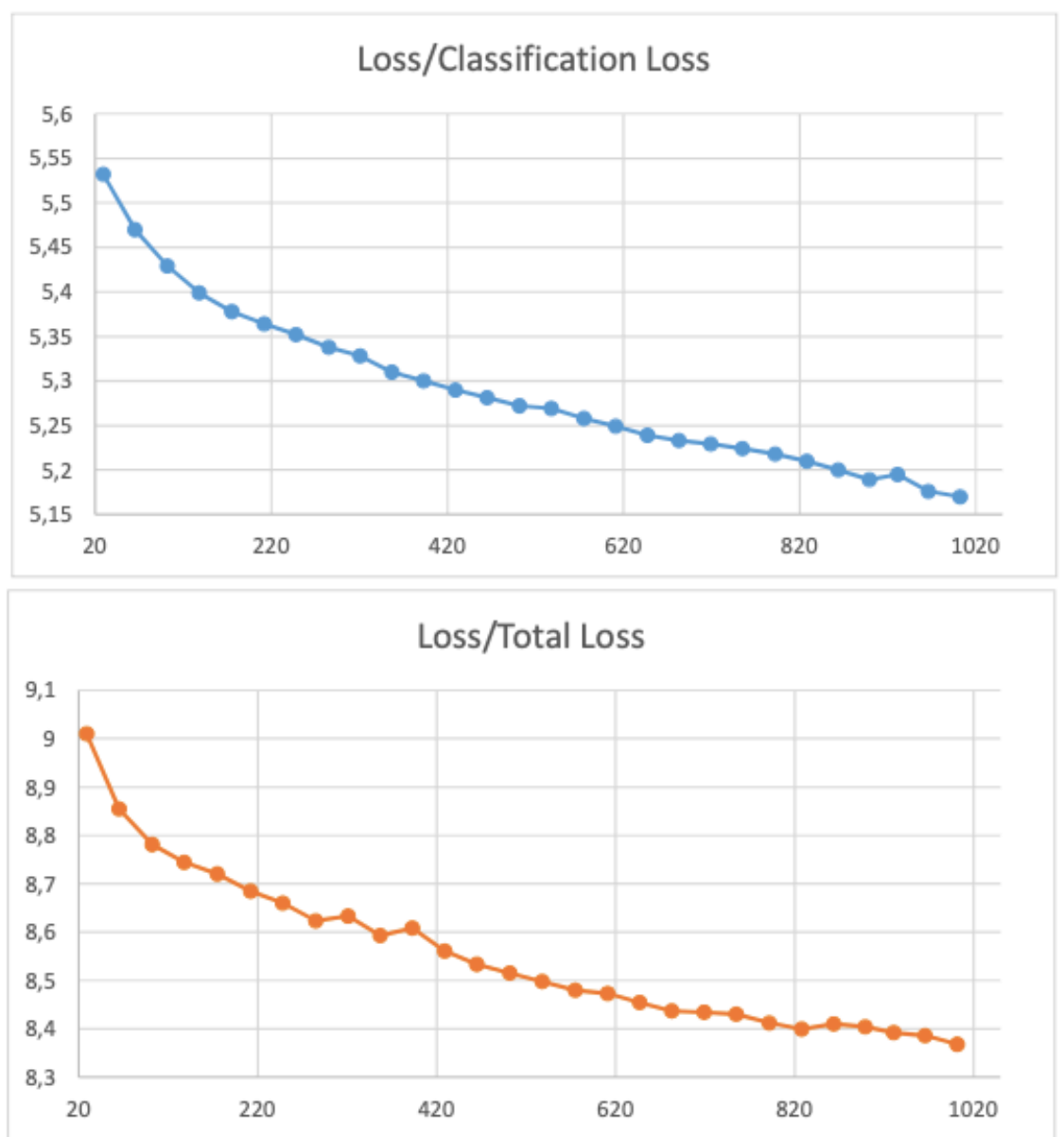

Fonte: Autor

O treinamento para reconhecimento de imagem classificação da pista de plantio ocorreu de forma convergente até o milésimo step de treinamento e 21 épocas, e pode ser visto na Figura 24 e um exemplo de detecção de pista de plantio pela rede neural treinada em um ambiente extremo na ausência de luz natural, pode ser visto na Figura 25 abaixo. 
Figura 25 - Exemplo de reconhecimento de imagem classificação da pista de plantio.

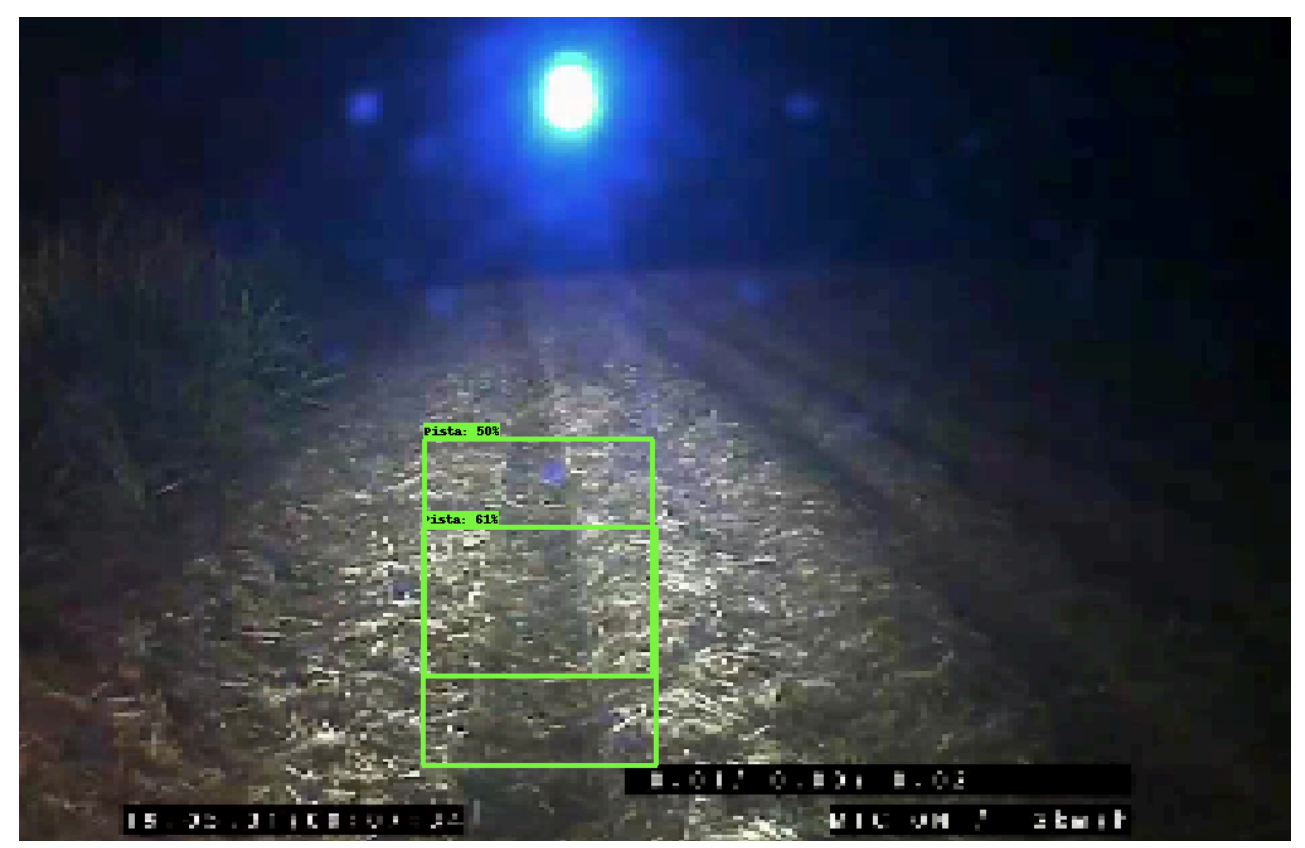

Fonte: Autor

Para análise do resultado do treinamento da Rede Neural aplicou-se o conceito de Precisão que é o número de imagens corretamente classificados como da classe Pista de Plantio dividido pelo número total de imagens classificados como da Pista de Plantio: Precision $=\frac{\text { TotalDePositivos }}{\text { TotalDePositivos }+ \text { FalsosPositivos }}$.

O conceito de Revocação também foi utilizado a fim de avaliar o desempenho da RNA MobileNet V2, definido como a fração de imagens corretamente classificadas como pista de plantio de cana-de-açúcar (Verdadeiro Positivo) pela soma destas com imagens de pista de cana-de-açúcar não classificadas (Verdadeiro Positivo + Falso Negativo): Recall $=\frac{\text { TotalDePositivos }}{\text { TotalDePositivos }+ \text { FalsosNegativos }}$.

O sistema métrico aplicado para análise dos resultados provenientes MobileNet V2 é denominado COCO (sigla em inglês para Objetos Comuns em Contexto) obtidos por meio do TensorFlow Board em Python (LIN, MAIRE, et al, 2015). 
A métrica COCO apresenta diversos indicadores para mensuração de Precisão e Revocação baseados em AP (sigla em inglês para Precisão Média) e AR ( Sigla em inglês para Revocação Média).

Os AP e AR são calculados sobre vários valores de Intersecção sobre União (IoU, sigla em inglês). Aplicam-se especificamente 10 limites de IoU entre 0,5 e 0,95. A média de IoUs recompensa os detectores com melhor localização.

Tradicionalmente a métrica COCO aplica a "precisão média média" (mAP), como mAP (e também AR e mAR).

O AP (calculado em média em todos os 10 limites de IoU e em todas as 80 categorias) determinará o vencedor do desafio. Essa deve ser considerada a métrica mais importante ao considerar o desempenho no COCO.

O AR é dado um número fixo de detecções por imagem, com média de categorias e IoUs e é calculado por categoria, permitindo no máximo 100 detecções com a melhor pontuação por imagem (em todas as categorias).

Neste este trabalho, para aferição da Precisão e Revocação, foram utilizados mAP de $50 \mathrm{IoU}$ e AR de 100 respectivamente no step 10.860, perfazendo 227 épocas de treinamento.

O resultado de Precisão em 227 épocas foi de 57,22\% (step 10,86 k, DetectionBoxes_Precision/mAP@.50IOU)

Figura 26 - Curva Precisão

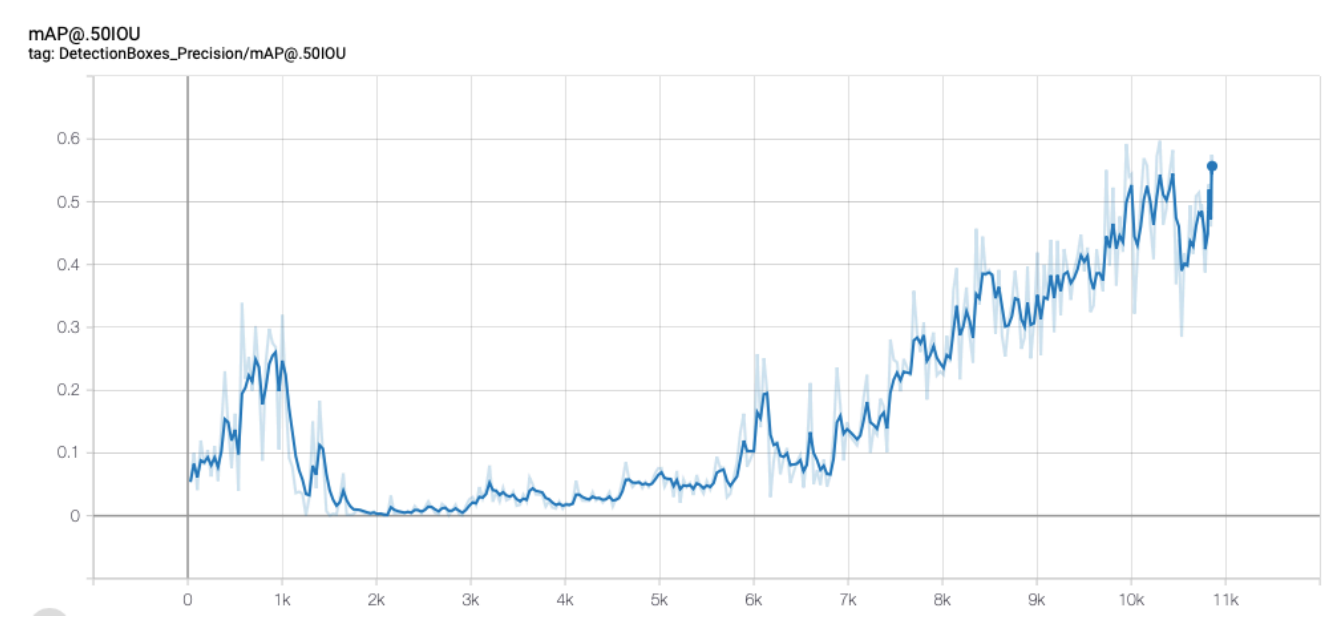

Fonte: Autor 
O resultado da Revocação foi de 28,84\% (step 10,86 k, DetectionBoxes_Recall) AR@100).

Figura 27 - Curva Revocação

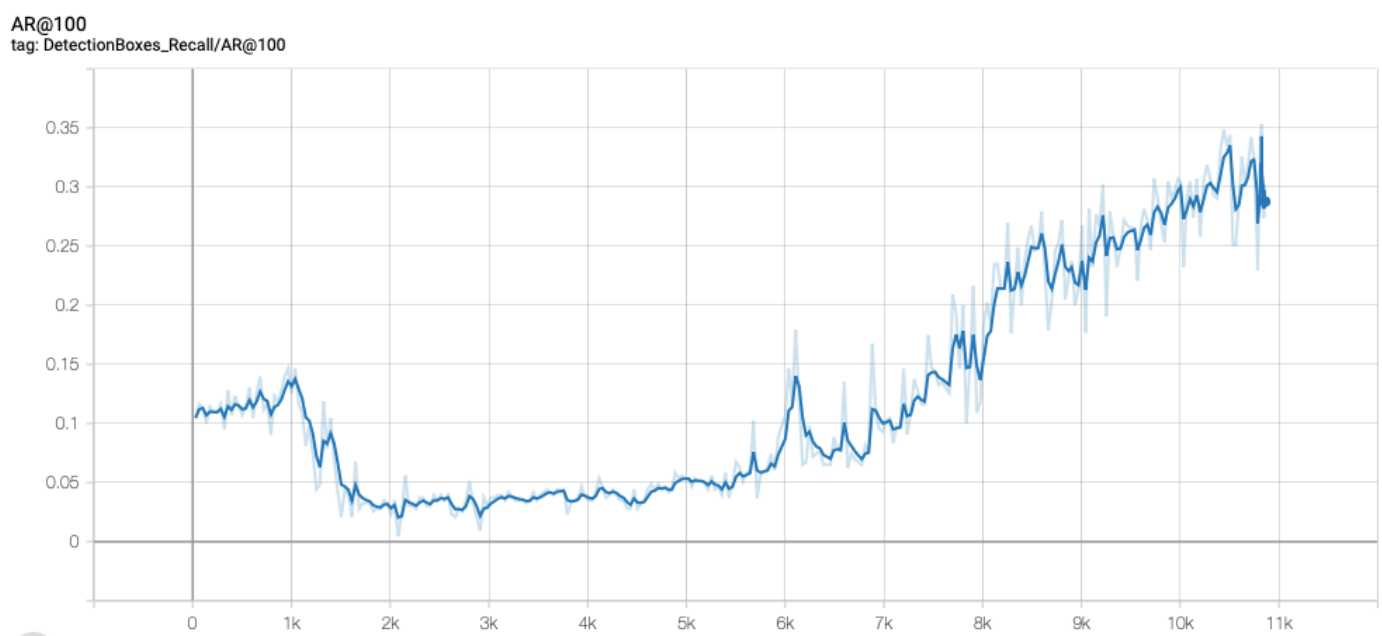

Fonte: Autor 


\section{DISCUSSÃO}

A comparação entre as hipóteses descritas no capítulo anterior não foi completamente possível em função da impossibilidade de detecção de linhas de plantio de cana-de-açúcar aplicando Filtro Sobel e Transformada de Hough preconizados na hipótese 1.

A grande quantidade de ruído proveniente de uma imagem de um processo de colheita de cana-de-açúcar não permitiu que a Transformada de Hough encontrasse e determinasse a correta posição das linhas de plantio.

O ruído contido nas imagens é proveniente do próprio contexto em que esta inserido a coleta de imagens, devido a complexidade imposta a imagens provenientes de áreas de colheita de cana-de-açúcar como o grande volume de transição de texturas no solo e plantação de cana-de-açúcar, além da própria sujeira recuperada na imagem em função da movimentação de máquinas.

Alternativamente, à hipótese 1 , tentou-se também eliminar a aplicação da Transformada Hough e buscar a linha de plantio por meio da variação média de pixels da imagem. O que apresentou êxito apenas em imagens cuja a linha de plantio esta perfeitamente perpendicular ao sentido de marcha do caminhão, ou seja, em imagens onde esta se fazendo uma curva, mesmo que pouco acentuada, a detecção da linha de plantio é falsa.

Para hipótese 2, do banco de 25.904 imagens foram utilizadas 1.338 destas para treinamento da Rede Neural com 1.000 steps para melhor convergência da curva de aprendizado Loss, vide Figura 24.

Para 227 épocas e 10.860 steps a Precisão foi de 57,22\% conforme métrica de Objetos Comuns em Contexto (COCO, sigla em inglês) baseado na média da média da Precisão (mAP, sigla em inglês) e métrica de acuracidade de valores de Intersecção sobre União (IoU, sigla em inglês) de 0,5 (LIN, MAIRE, et al, 2015).

Também para 227 épocas e 10.860 steps a Revocação foi de $28,84 \%$ conforme métrica de Objetos Comuns em Contexto (COCO, sigla em inglês) baseado na Revocação média (AR, sigla em inglês) por meio de no máximo 100 detecções com melhor pontuação por imagem (LIN, MAIRE, et al, 2015). 
Para realizar uma comparação, os trabalhos que utilizaram a mesma Rede Neural MobileNet V2, como (OLIVEIRA, 2019) e (ABREU, 2019) alcançaram valores inferiores a $50 \%$ de mAP para 2.000 steps de treinamento até valores superiores a $90 \%$ para mais de 10.000 steps de treinamento e AR mínimo de 61,6\% até mais de 90\%. Ambos trabalhos aqui citados tem como objetivo a detecção de bola de futebol de robôs, o que imprime teoricamente uma complexidade de contexto inferior a necessidade de detecção de linhas de plantio de cana-de-açúcar em um contexto mais complexo imposto a um ambiente ruidoso e volátil como uma plantação de cana-de-açúcar.

Diante disto o valor de Precisão de 57,22\% alcançado neste trabalho, frente a referência ponderada e citada anteriormente entre 50\% e 90\% apresenta-se em conformidade para o atendimento do objetivo deste trabalho e corrobora com a confirmação da hipótese 2 .

O valor de Revocação de 28,84\% alcançado neste trabalho, frente a referência mínima ponderada e citada anteriormente de $61,6 \%$, por sua vez, apresenta-se em um patamar inferior, o que não é bom, porém e a seguir neste capítulo apresenta-se uma hipótese para explicar tal desempenho.

O valor de convergência da curva de treinamento apresentada na Figura 24 apresenta um valor de Loss acima de 8 pontos. Enquanto que nas referências citadas nos trabalhos de (OLIVEIRA, 2019) e (ABREU, 2019) este valor aproxima-se de uma convergência de treinamento de Loss 1 - 2 pontos.

Como hipótese para os valores alcançados de Loss, Precisão e Revocação com suas respectivas referências é que a característica e complexidade do contexto para reconhecimento de imagem, bem como a marcação de imagens referência para treinamento, exercem grande influência no resultado obtido conforme métricas Objetos Comuns em Contexto (COCO, sigla em inglês).

Como pode ser visto na Figura 23, é feita uma marcação de referência por imagem por meio do LabelImg, esta marcação pode ser feita de diversas formas e a Rede Neural é treinada com base nesta marcação. Posteriormente, a Rede Neural testa o treinamento proveniente das marcações em imagens do banco de imagens. Como pode ser visto no exemplo da Figura 25, onde a Rede Neural me questão identificou mais do que uma área de marcação verdadeira para pista. Ambas estavam certas. 
Como hipótese, diante do descrito acima, é possível que quando a Rede Neural quando faça o reconhecimento de uma segunda marcação na mesma imagem, ou em outro local do preconizado nas notações de marcação para treinamento, mesmo sendo verdadeiro como exemplo na Figura 25, pode-se registrar na métrica de Objetos Comuns em Contexto como falso e influenciar na curva de treinamento Loss e Revocação.

O sistema proposto na hipótese 2 apresenta-se superior quando comparado a outra hipótese presente neste trabalho. Ou seja, para detecção de pista de plantio de cana-de-açúcar uma abordagem com Rede Neural Convolucional apresenta-se mais adequada do que uma abordagem tradicional de Visão Computacional com processamento de imagens. 
Diante da constante evolução tecnológica e consolidação como preponderante agente do Produto Interno Bruto brasileiro, o agronegócio alcançou um espaço importante na sociedade brasileira e tem como relevante protagonista, a cana-de-açúcar, que é grande fonte de energia renovável, além de ser foco constante de evoluções tecnológicas em seu ciclo produtivo.

As hipóteses apresentadas neste trabalho tiveram como finalidade apresentar um sistema para correto posicionamento de caminhões autônomos no processo de colheita de cana-de-açúcar, conforme linhas de plantio pré-estabelecidas.

A finalidade do correto posicionamento cartográfico é o aumento da produtividade no ciclo da cana-de-açúcar. Pois com a manutenção do caminhão corretamente posicionado na pista traçada anteriormente durante o plantio, não há ocorrência de atropelamento do broto da cana-de-açúcar durante o processo de colheita, ficando assim broto desta intacto plantado e pronto para próxima brotação e subsequente colheita. Quanto mais vezes puder se fazer a colheita sem um novo plantio, ou seja, apenas se valendo do broto remanescente da colheita anterior, maior a produtividade no ciclo desta monocultura.

A hipótese com aplicação da Rede Neural artificial MobileNet apresentou melhor resultado ao determinar as linhas de plantio de cana-de-açúcar a partir de um treinamento da Rede Neural Artificial Convolucional MobileNet V2 com iteração em 227 épocas resultando uma Precisão de 57,22\% (step 10,86 k, DetectionBoxes_Precision/mAP@.50IOU) e Revocação foi de 28,84\% (step 10,86 k, DetectionBoxes_Recall/AR@100).

Para a aplicação no trabalho em questão, a Rede Neural Artificial Convolucional MobileNet V2 apresentou-se capaz de alcançar o objetivo inicialmente definido de detecção da pista para posicionamento do caminhão autônomo.

As métricas aplicadas conforme Objetos Comuns em Contexto (COCO, sigla em inglês) para mensuração dos resultados provenientes da Rede Neural também apresentaramse adequado e viabilizaram a comparação com outros trabalhos relativos ao tema.

A complexidade de contexto e a preparação para o treinamento da Rede Neural é preponderante para o resultado, principalmente no que tange a construção das marcações e notações de imagens para treinamento. 
Uma forma de aprimoramento do sistema aqui proposto na hipótese 2 com aplicação de Rede Neural Artificial Convolucional seria a execução de um extenso trabalho que seja capaz de determinar um processo robusto de marcações e notações para um contexto complexo como a plantação de cana-de-açúcar, bem como a aplicação de uma Rede Neural Artificial Convolucional mais profundo que a MobileNet V2 aplicada neste trabalho.

A eficiência da substituição da iteração humana para o correto posicionamento de um caminhão nas pistas de plantio de cana-de-açúcar pelo modelo descrito na hipótese 2 , é complexo de se comprovar e pode ser também objeto de trabalho futuro. Porém empiricamente é razoável inferir que frente as suscetibilidades de um humano, como cansaço, distração, alterações de humor, etc. o sistema proposto na hipótese 2 deste trabalho tende a ser mais eficiente que a iteração humana na direção do caminhão. 


\section{REFERÊNCIAS}

ABREU, Lucas Ribeiro de, BIANCHI, Reinaldo Augusto da Costa: Real-time Ball Detection for Robocup Soccer Using Convolutional Neural Networks, 2019

ANG, K.H. and CHONG, G.C.Y. and LI, Y. (2005) PID control system analysis, design, and technology. IEEE Transactions on Control Systems Technology 13(4):pp. 559-576.

BALLARD, D.H. Generalizing the Hough Transform to Detect Arbitrary Shapes. Patterns Recognition, 1981

BAI, Zhengwei, CAI, Baigen, SHANGGUAN, Wei ShangGuan, CHAI, Linguo: Deep Learning Based Motion Planning For Autonomous Vehicle Using Spatiotemporal LSTM Network, 2019

BRAGA, A. P, LUdERMiR, T. B. e CARVAlHO, A. C. P. L. F.. Redes Neurais Artificiais, Teoria e Aplicações, LTC - Livros Técnicos e Científicos Editora S.A., 2000

CARLA, Ludwin Lope: Recognition and tracking of vehicles in highways using deep learning, 2019

DOSOVITSKIY, Alexey, ROS, German, CODEVILLA e LOPEZ, Antonio: CARLA: An Open Urban Driving Simulator, 2017

DUDA, R. O. e HART, P.E. Use of the Hough Transformation to Detect Lines and Curves in Pictures, Comm ACM, 15 ed., 1972

FERNANDES, L.A.F. e OLIVEIRA, M.. Real Tome Detection through na improved Hough transform voting scheme. Pattern Recognition, 2008

GLOROT, Xavier, BORDES, Antoine, BENGIO, Yoshua: Deep Sparse Rectifier Neural Networks, 2011

GONZALEZ, R.C e WOODS, R.E., Digital Image Processing. 3 ed., 2007

GOODFELLOW, I., BENGIO, Y. e COURVILE, A., Deep Learning, MIT PRESS, 2016

HAYKIN, S. Neural Networks: A Comprehensive Foundation, 2 ed, 1998 
HOUGH, Paul V.C.: Method and means for recognizing complex patterns, 1962

HOWARD, Andrew G., et al: MobileNets: Efficient Convolutional Neural Networks for Mobile Vision Applications, 2017

HUANG, Yunlong: A Lane-Change Path Planner and its application with a monocular camera, 2019

JARRETT, Kevin, KAVUKCUOGLU, Koray, RANZATO, Marc'Aurelio e LECUN: What is the Best Multi-Stage Architecture for Object Recognition?, 2009

JIAO, Yanmei, WANG, Yue, FU, Bo, DING, Xiaqing, TAN, Qimeng, CHEN, Lei e XIONG, Rong: Entity RANSAC for robust visual localization in changing environment, 2019

LECUN, Yann.: LeNet-5, convolutional neural networks, 2013

LIMBERGER, F.A e OLIVEIRA, M.M. Real Time Detection of Planar Regions in Unorganized Point Clouds. Pattern Recognition, 2015

LIN, Tsung-Yi, MAIRE, Michael, et al: Microsoft COCO: Common Objects in Context V3, 2015

LISA Lab.: Convolutional Neural Networks (LeNet) - DeepLearning documentatio, 2018

MCCULLOCH, W. S. e PITTS, W. A Logical Calculus of Ideas Immanent in Nervous Activity. Bulletin of Mathematical Biophysics, 1943.

NAIR, Vinod e HILTON, Geoffrey E.: Rectified Linear Units Improve Restricted Boltzmann Machines, 2010

OLIVEIRA, Jonas H. R., et al: Object detection under constrained hardware scenarios: a comparative study of reduced convolutional network architectures, 2019

OKSANEN, Timo e BACKMAN: Guidance system for agricultural tractor with four wheel steering, 2017 
RAMBHATLA, Sirisha, SIDIROPOULOS, Nikos D. e HAUPT, Jarvis: Tensormap: LIDAR-based topological mapping and localization via tensor decompositions, 2019

RUMELHARD, D.E., HILTON, G.E. e WILLIAM, R.J.: Learning representations by error propagation, 1986

SHAPIRO, Linda e STOCKMAN, George. Computer Vision, Pretice-Hall, 2001

SOBEL, Irvin: An Isotropic 3x3 Image Gradient Operator, 2014

SOBEL, Irvin: Sobel operator, 1968

TAKAGAKI, Akane, MASUDA, Ryohei, LIDA, Michihisa e SUGURI, Masahiko: Image Processing for Ridge/Furrow Discrimination for Autonomous Agricultural Vehicles Navigation, 2013

YEEL, Kyle e CHAKRABARTI, Ayan: Fast Deep Stereo with 2D Convolutional Processing of Cost Signatures, 2019 
Apêndice A

\section{CONCEITO DE CAMINHÃO AUTÔNOMO}

Atualmente pode-se encontrar tecnologia de veículos autônomos ja aplicada parcialmente em veículos que transitam nas estradas brasileiras, o que levou a normatização dos níveis de automação pela SAE ( Associação de Engenheiros Automotivos, sigla em inglês).

O nível de automação SAE 0, sem automação, são basicamente a esmagadora maioria do que vimos em toda a história dos carros até hoje. Ou seja, o veiculo depende de um humano, desde sua aceleração e direção, monitoramento do ambiente, respostas dinâmicas à situações de risco, além da ausência de modos de condução distintos.

O nível de automação SAE 1, de assistência ao condutor, é primeiro nível de automação e o sistema consegue ajudar o condutor com algumas atividades simples, como na manutenção de aceleração por meio de funções não-adaptativas, que ainda exige que o motorista direcione o veículo e freie quando necessário. Neste nível existem também os modos de condução distintos que podem ser escolhidos manualmente para se adaptar a uma situação especifica.

Ja o nível de automação SAE 2, apresenta uma automação parcial podemos encontrar tal tecnologia atualmente. O sistema é capaz de efetuar por conta própria algumas funções do veículo, como acelerar e frear de acordo com o limite estipulado pelo condutor, por meio doe funções adaptativos. Pode também direcionar ou ajudar o motorista a manter sua direção, mas é necessário um humano para assumir o controle em caso de situações de risco. Geralmente reservado para o uso em estradas. Para tanto, os veículos atuais vêm equipados com um conjunto de radares e sensores que fazem um mapeamento de objetos em torno do veículo para um monitoramento passivo, ou seja, que não é capaz de reagir.

Para o nível SAE 3, denominado de automação condicional, previsto por especialistas para até 2021, os veículos ja podem se movimentar por conta própria tanto na parte de aceleração e direção quanto no monitoramento ativo do ambiente. Isso permite que o motorista foque completamente em outras atividades, mas eventualmente terá que assumir o 
controle em situações de risco. Neste caso, os especialistas da SAE já postulam que ha a exigência de um conjunto mais robusto de sensores, como scanners a laser, sensores ultrassônicos e sistemas de radar, como os LIDARs, citados anteriormente neste trabalho. Tais sensores devem monitorar e reproduzir o ambiente ao redor do veículo para que o sistema consiga tomar decisões mais complexas de condução. Para este nível de automação, o proposto neste trabalho para o nicho de aplicação selecionado, apresenta como alternativa o reconhecimento e processamento de imagens través de MLP ( Multi Layer Perceptron), Deep Learning e, principalmente, Redes Neurais Convolucionais, bem como o domínio da frequência de imagens com filtros Sobel e Transformada de Hough.

No nível de automação SAE 4, automação Alta, prevista também pelos especialistas da SAE para a partir de 2021, a expectativa é que o motorista possa até dormir ao longo do trajeto até o destino, já que praticamente todas as atividades serão feitas pelo sistema autônomo do veículo, inclusive habilidades reativas em situações de risco mesmo quando o motorista humano não for capaz de responder à solicitação para assumir o comando do automóvel. Neste nível, a expectativa é que todos os sensores e câmeras já sejam capazes de fornecer dados muito mais precisos e o sistema também contará com informações fornecidas pelos serviços de navegação para definição de rotas e de manobras de condução, o que exigirá um altíssimo nível de conectividade constante do veículo e comunicações do tipo V2V (Vehicle-To-Vehicle) e V2I (Vehicle-To-Infrastructure). Neste nível de automação cabe também um relevante trabalho de Doutorado, talvez como evolução deste mesmo.

O último nível, SAE 5 de automação completa, extingue definitivamente a necessidade de um condutor humano, com absolutamente todos os controles e responsabilidade pela direção sendo feitos pelo sistema autônomo do veículo. O motorista se torna mais um passageiro e pode dedicar todo o seu tempo dentro do carro para fazer outras atividades. É difícil especificar quais são as reais exigências do nível SAE 5 em termos de estrutura veicular, mas o que se espera é que a parte de sensores esteja extremamente avançada e que a conectividade já tenha se tornado parte indivisível da sociedade. 


\section{Apêndice B}

\section{CONTROLE PROPORCIONAL}

Para uma devida manobra de correção de rota e uma aproximação suave do trajeto objetivo, é necessário tratar o sinal proveniente da nova direção e sentido determinada. Um modelo para o tratamento do referido sinal é o Controle Proporcional.

O modelo de Controle proporcional ou controlador proporcional integral derivativo (controlador PID), é baseado no controle de processos de ações derivativa, integral e proporcional para minimização do sinal de erro de forma não abrupta.

Um controlador PID pode ser considerado como uma forma extrema de um compensador atraso-avanço de fase com um polo na origem e outro no infinito (Compensador que permite conjugar as qualidades dos compensadores de avanço e atraso, introduzindo dois novos polos e dois novos zeros e em geral aumenta a ordem do sistema). Um controlador PID é, também, conhecido como controlador de "três termos", cuja função de transferência é geralmente escrita na "forma paralela" dada pela Equação 2.7.2 e a "forma ideal” pela Equação 2.7.3 (Ang, K.H., et al, 2005), tais equações são provenientes de uma forma original descrita na Equação 2.7.1 onde os termos em questão estão claramente descritos em suas respectivas operação de derivação ou integração e, então, aplica-se a transformada de Laplace.

$$
\begin{aligned}
& \mathrm{u}(t)=K_{p} e(t)+K_{i} \int_{0}^{t} e(\tau) d \tau+K_{d} \frac{d e(t)}{d t} \\
& G(s)=K_{p}+K_{I} \frac{1}{s}+K_{D^{s}} \\
& G(s)=K_{p}\left(1+\frac{1}{T_{I^{s}}}+T_{D^{s}}\right)
\end{aligned}
$$

Sendo: $K_{p}$ é o ganho proporcional, $K_{I}$ o ganho integral, $K_{D}$ o ganho derivativo, $T_{I}$ a constante de tempo integral e $T_{D}$ a constante de tempo derivativo. 
Os "três termos" são definidos pelo termo proporcional que fornece uma ação de controle geral proporcional ao sinal de erro por meio do fator de ganho de passagem, o termo integral -que reduz erros de estado estável por meio de compensação de baixa frequência por um integrador e o termo derivativo que melhora a resposta transiente por meio de compensação de alta frequência por um diferenciador. (Ang, K.H., et al, 2005).

Neste capítulo foram abordadas metodologias que vão desde a calibração de câmeras para uma adequada obtenção e referenciação de imagens, então transcorre-se por conceitos de visão computacional e processamento de imagem para o devido tratamento das imagens obtidas e, por fim, abordou-se o controle proporcional para tratar o sinal resultante de uma modelo de aproximação de um objetivo espacial.

Para o próximo capítulo, aborda-se trabalhos existentes e correlatos aos conceitos apresentados neste capitulo atual. 
Apêndice C

PESQUISA DE TRABALHOS CORRELATOS

Tabela 2 - Pesquisa de trabalhos correlatos

\section{Trabalhos Correlatos}

\begin{tabular}{|c|c|c|c|c|}
\hline Titulo & Autor & Objeto & Relevante & Motivo \\
\hline $\begin{array}{l}\text { Safety system for } \\
\text { autonomous operation of off- } \\
\text { road and agricultural vehicles } \\
\text { using machine learning for } \\
\text { detection and identification of } \\
\text { obstacles }\end{array}$ & $\begin{array}{l}\text { CJ Hurd, R Ramakrishnan, } \\
\text { MW Barglof...- US Patent } \\
\text { App. } 16 \ldots, 2019 \text { - Google } \\
\text { Patents }\end{array}$ & $\begin{array}{l}\text {... Similarly, the safety framework } 100 \text { may be utilized with any } \\
\text { type of off-road vehicle or machine, regardless of the industrial } \\
\text { or commercial application thereof ... The image and wave } \\
\text { processing component } 126 \text { produces output data } 140 \text { that } \\
\text { is indicative of whether an object... }\end{array}$ & Sim & $\begin{array}{l}\text { Detecção de obstáculos em } \\
\text { ambientes não urbanos }\end{array}$ \\
\hline $\begin{array}{l}\text { Monitoring one or more } \\
\text { articles on a support surface }\end{array}$ & $\begin{array}{l}\text { D Theobald - US Patent App. } \\
13 / 678,193,2019 \text { - } \\
\text { freepatentsonline.com }\end{array}$ & $\begin{array}{l}\text {... and Dynamics of Multiple Mobile Manipulators Handling Non- } \\
\text { Rigid Materials, Computers and Electronics ... Machine } \\
\text { Vision defined by Wikipedia archived Jan ... Mcllraith, S., } \\
\text { CSC2542 Representations for (Classical) Planning problem, } \\
\text { Department of Computer Science University ... }\end{array}$ & Não & $\begin{array}{l}\text { Não se refere ao objeto de } \\
\text { busca }\end{array}$ \\
\hline $\begin{array}{l}\text { Deep Learning for Driverless } \\
\text { Vehicles }\end{array}$ & $\begin{array}{l}\text { C Hodges, } \underline{S \text { An }}, \underline{\text { HRahmani, }} \\
\frac{\text { M Bennamoun }}{\text { Deep Learning }} \text { Handbook of } \\
\text { Springer }\end{array}$ & $\begin{array}{l}\ldots 3 \text { Visual representation ROI proposals for classification } \\
\text { [37 ... While traditional analytical control systems and } \\
\text { computer vision techniques have in the past been adequate } \\
\text { for the fundamental ... D. Pomerleau, T. Jochem, Rapidly } \\
\text { adapting machine vision for automated vehicle steering ... }\end{array}$ & Sim & Aprendizado de máquina \\
\hline Agricultural Robotics & $\begin{array}{l}\text { SG Vougioukas - ... Review } \\
\text { of Control, Robotics, and } \\
\text { Autonomous ..., 2019 - } \\
\text { annualreviews.org }\end{array}$ & $\begin{array}{l}\text {... Drexl (33) reviewed similar problems in transportation } \\
\text { science ... Essentially, accurate vehicle positioning with } \\
\text { respect to the crop is established through absolute machine } \\
\text { positioning on the map ... Monocular vision has been used for } \\
\text { guidance in orchards (87) ... }\end{array}$ & Não & Conceito genérico \\
\hline $\begin{array}{l}\text { WoodScape: A multi-task, } \\
\text { multi-camera fisheye dataset } \\
\text { for autonomous driving }\end{array}$ & $\begin{array}{l}\text { S Yogamani, C Hughes, J } \\
\text { Horgan, } \frac{G \text { Sistu.... - arXiv }}{\text { preprint arXiv ..., } 2019 \text { - }} \\
\text { arxiv.org }\end{array}$ & $\begin{array}{l}\text {... Standard computer vision models do not generalize easily } \\
\text { to fisheye cameras because of large ... Multi-task: } \\
\text { Autonomous driving has various vision tasks and most of the } \\
\text { work has ... How- ever, such methods are unacceptable for } \\
\text { machine learning or image processing algorithms ... }\end{array}$ & Sim & $\begin{array}{l}\text { Processamento de Imagem e } \\
\text { calibração de câmeras }\end{array}$ \\
\hline $\begin{array}{l}\text { Cognitive Systems and } \\
\underline{\text { Robotics }}\end{array}$ & $\begin{array}{l}\text { C Bauckhage, T Bauernhansl, } \\
\text { J Beyerer, J Garcke - Digital } \\
\text { Transformation, } 2019 \text { - } \\
\text { Springer }\end{array}$ & $\begin{array}{l}\ldots \text { In the era of big data and powerful, inexpensive computers/ } \\
\text { cloud solutions, however, both ... fundamental technical and } \\
\text { physical processes are calculated in advance on computer } \\
\text { systems using ... In order to analyze this large amount of } \\
\text { complex data, we use machine learning (ML ... }\end{array}$ & Não & $\begin{array}{l}\text { Não se refere ao objeto de } \\
\text { busca }\end{array}$ \\
\hline $\begin{array}{l}\text { [LIVRO] Autonomous } \\
\text { Technologies in Agricultural } \\
\text { Equipment: A Review of the } \\
\text { State of the Art }\end{array}$ & $\begin{array}{l}\text { JA Thomasson, CP Baillie, DL } \\
\text { Antille, CR Lobsey... - } 2019 \text { - } \\
\text { elibrary.asabe.org }\end{array}$ & $\begin{array}{l}\ldots \text { This system runs automated image analysis and generates } \\
\text { an alert via iMonitor if a person ... over-come these limitations } \\
\text { as well as alternative approaches in- volving stereo vision have } \\
\text { been ... is processing the infor- mation in a timely manner for } \\
\text { an autonomous machine to react ... }\end{array}$ & Sim & Análise de imagem \\
\hline $\begin{array}{l}\text { [PDF] COMPUTER } \\
\text { TECHNOLOGY AND } \\
\text { UNMANNED VEHICLES }\end{array}$ & $\begin{array}{l}\text { A Ivanko, M Ivanko, O } \\
\text { Kolesnikova...- } \\
\text { AGRICULTURAL ..., } 2019 \text { - } \\
\text { european-science.org }\end{array}$ & $\begin{array}{l}\text {... The era of high technology and automation of many } \\
\text { activities, computers began to do a ... In fact, his system was a } \\
\text { machine learning model capable of adequately assessing } \\
\text { the ... Sidhart Lakshmanan, an engineer who spe- cializes in } \\
\text { image processing and computer vision of un ... }\end{array}$ & Sim & $\begin{array}{l}\text { Processamento de imagens } \\
\text { para veículos autônomos }\end{array}$ \\
\hline $\begin{array}{l}\text { Deep learning for critical } \\
\text { infrastructure resilience }\end{array}$ & $\begin{array}{l}\text { K Dick, L Russell, Y Souley } \\
\text { Dosso... - Journal of ..., } 2019 \\
\text { - ascelibrary.org }\end{array}$ & $\begin{array}{l}\ldots . \text { and ac- tionable information returned; or (2) real-time, on-site } \\
\text { deployment of computer vision models (on the "edge"), known } \\
\text { as "Embedded Vision." These two ... In the Cloud: Offline } \\
\text { Image Analysis Machine vision models are currently most } \\
\text { often deployed on large computation ... }\end{array}$ & Não & $\begin{array}{l}\text { Não se refere ao objeto de } \\
\text { busca }\end{array}$ \\
\hline $\begin{array}{l}\text { Assisted Perception For } \\
\text { Autonomous Vehicles }\end{array}$ & $\begin{array}{l}\text { DI Ferguson, WY Lo, } \underline{N} \\
\text { Fairfield - US Patent App. } \\
16 / 111,860,2019 \text { - Google } \\
\text { Patents }\end{array}$ & $\begin{array}{l}\text {... of Global Positioning System } 122 \text { and the features } \\
\text { recognized by the computer vision system } 140 \text { may ... system } \\
\text { may combine data from both radar information and a captured } \\
\text { image to determine ... While operating in the autonomous } \\
\text { mode, the vehicle may use a computer system to ... }\end{array}$ & Sim & $\begin{array}{l}\text { Processamento de imagens } \\
\text { para veiculos autônomos }\end{array}$ \\
\hline $\begin{array}{l}\text { Technology Scouting and } \\
\text { Inventions Patenting With } \\
\text { Impact on the Agrifood } \\
\text { Future: INACO-Institutional } \\
\text { Innovation for } \\
\text { Competitiveness in Romania }\end{array}$ & $\begin{array}{l}\text { A Paul - Agrifood Economics } \\
\text { and Sustainable Development } \\
\text { in ..., } 2019 \text { - igi-global.com }\end{array}$ & $\begin{array}{l}\text {... Today, } 3 \mathrm{D} \text { is being "printed" in very fast-moving machine } \\
\text { parts or airplanes with ... Contemporary technological } \\
\text { developments have created computers with artificial intelligence } \\
\text { (Al) that go beyond ... The computer - which has made physical } \\
\text { work unnecessary in many areas - has ... }\end{array}$ & Não & $\begin{array}{l}\text { Não se refere ao objeto de } \\
\text { busca }\end{array}$ \\
\hline $\begin{array}{l}\text { Artificial intelligence and } \\
\text { policy: quo vadis? }\end{array}$ & $\begin{array}{l}\text { A Lauterbach - Digital Policy, } \\
\text { Regulation and Governance, } \\
2019 \text { - emeraldinsight.com }\end{array}$ & $\begin{array}{l}\text {... Computer vision, radars and sensors, cheap batteries enable } \\
\text { cars to see, and trust } 3 D \text { navigation tools and pre-collision ... } \\
\text { Machine learning is no substitute for a doctor's experience and } \\
\text { intuition. MIT computer scientists have analyzed written notes } \\
\text { by doctors on ICU patients ... }\end{array}$ & Não & $\begin{array}{l}\text { Não se refere ao objeto de } \\
\text { busca }\end{array}$ \\
\hline
\end{tabular}




\begin{tabular}{|c|c|c|c|c|}
\hline $\begin{array}{l}\text { Deep memory and prediction } \\
\text { neural network for video } \\
\text { prediction }\end{array}$ & $\begin{array}{l}\text { Z Liu, X Chai, X Chen - } \\
\text { Neurocomputing, } 2019 \text { - } \\
\text { Elsevier }\end{array}$ & $\begin{array}{l}\ldots \text { partially supported by } 973 \text { Program under contract No } \\
2015 \text { CB351802, Natural Science Foundation of ... for event } \\
\text { prediction, in: Proceedings of the European Conference on } \\
\text { Computer Vision, } 2010 \ldots \text {.. K. Wong, W.-c. Woo, Convolutional } \\
\text { LSTM network: a machine learning approach ... }\end{array}$ & Não & $\begin{array}{l}\text { Não se refere ao objeto de } \\
\text { busca }\end{array}$ \\
\hline $\begin{array}{l}\text { Autonomous mobile platform } \\
\text { and variable rate irrigation } \\
\text { method for preventing frost } \\
\text { damage }\end{array}$ & $\begin{array}{l}\text { SAB Rodriguez, L Klein, AG } \\
\text { Schrott... - US Patent App. } 16 \\
\text {.., } 2019 \text { - Google Patents }\end{array}$ & $\begin{array}{l}\text {... purpose computer, or other programmable data processing } \\
\text { apparatus to produce a machine, such that the ... The } \\
\text { computers } 16 \text { and } 18 \text { may include peripherals, displays, } \\
\text { interfaces (mouse, keyboard, etc ... loop with the cognitive } \\
\text { computing platform } 40 \text { on the central computer } 16 \text { for ... }\end{array}$ & Não & $\begin{array}{l}\text { Não se refere ao objeto de } \\
\text { busca }\end{array}$ \\
\hline $\begin{array}{l}\text { Numerical Analysis of Tractor } \\
\text { Accidents using Driving } \\
\text { Simulator for Autonomous } \\
\text { Driving Tractor }\end{array}$ & $\begin{array}{l}\text { M Watanabe, K Sakai - } \\
\text { Proceedings of the 5th } \\
\text { International Conference ..., } \\
2019 \text { - dl.acm.org }\end{array}$ & $\begin{array}{l}\text {... Human detection for a robot tractor using omni-directional } \\
\text { stereo vision. Computers and Electronics in Agriculture, } 89, \\
116-125 \ldots \text {... Computers and Electronics in Agriculture, } 142, \\
79-90 \ldots \text {. Real-time detection system of driver distraction using } \\
\text { machine learning ... }\end{array}$ & Não & $\begin{array}{l}\text { Não se refere ao objeto de } \\
\text { busca }\end{array}$ \\
\hline $\begin{array}{l}\text { Detecting Motion of an } \\
\text { Autonomous Vehicle Using } \\
\text { Radar Technology }\end{array}$ & $\begin{array}{l}\text { T Campbell, LD Smith - US } \\
\text { Patent App. 15/713,500, } 2019 \\
\text { - Google Patents }\end{array}$ & $\begin{array}{l}\ldots 9 \text { depicts a schematic diagram of an example computer } \\
\text { program ....As a result, the radar system may enable a vehicle } \\
\text { to operate in a partial or fully autonomous mode ... For } \\
\text { example, a coherent processing interval (CPI) may be } \\
\text { compared with another } \mathrm{CP} i \text { (where } \mathrm{i} \text { is the size of the } \ldots\end{array}$ & Não & $\begin{array}{l}\text { Não se refere ao objeto de } \\
\text { busca }\end{array}$ \\
\hline $\begin{array}{l}\text { Robust aerial image } \\
\text { mosaicing algorithm based on } \\
\text { fuzzy outliers rejection }\end{array}$ & $\begin{array}{l}\text { A Lati, M Belhocine, N Achour } \\
\text { - Evolving Systems, } 2019 \text { - } \\
\text { Springer }\end{array}$ & $\begin{array}{l}\text {... such as interference, weather, and mission objectives, in that } \\
\text { case; visual self-localization ... features between overlapped } \\
\text { images; inevitably produces some out- liers, computer vision } \\
\text { researchers typically ... } 1 \text { and } 2 \text {, SIFT detector locates interest } \\
\text { points in each image, then, biinary ... }\end{array}$ & Não & $\begin{array}{l}\text { Não se refere ao objeto de } \\
\text { busca }\end{array}$ \\
\hline $\begin{array}{l}\text { Calculating Velocity of an } \\
\text { Autonomous Vehicle Using } \\
\text { Radar Technology }\end{array}$ & $\begin{array}{l}\text { LD Smith, T Campbell - US } \\
\text { Patent App. 15/713,499, } 2019 \\
\text { - Google Patents }\end{array}$ & $\begin{array}{l}\text {... Control of position, course or altitude of land, water, air, or } \\
\text { space vehicles, eg automatic pilot characterized by the } \\
\text { autonomous decision making ... G05D2201/00 - Application; } \\
\text { G05D2201/02-Control of position of land vehicles; } \\
\text { G05D2201/0213-Road vehicle, eg car or truck ... }\end{array}$ & Não & $\begin{array}{l}\text { Não se refere ao objeto de } \\
\text { busca }\end{array}$ \\
\hline $\begin{array}{l}\text { State-of-the-art and adoption } \\
\text { of artificial intelligence in } \\
\text { retailing }\end{array}$ & $\begin{array}{l}\text { FD Weber, R Schütte - Digital } \\
\text { Policy, Regulation and ..., } \\
2019 \text { - emeraldinsight.com }\end{array}$ & $\begin{array}{l}\ldots \text { and Norvig (2016) will be followed: Al is the science, which } \\
\text { teaches computers and machines ... and the hardware provider } \\
\text { "Sensape" use large displays with a computer system with ... } \\
\text { The machine automatically searches for empty spaces or } \\
\text { incorrectly stored products and travels ... }\end{array}$ & Não & $\begin{array}{l}\text { Não se refere ao objeto de } \\
\text { busca }\end{array}$ \\
\hline $\begin{array}{l}\text { Person classification from } \\
\text { aerial imagery using local } \\
\text { convolutional neural network } \\
\text { features }\end{array}$ & $\begin{array}{l}\text { T Marasović, V Papić - } \\
\text { International Journal of } \\
\text { Remote Sensing, } 2019 \text { - } \\
\text { Taylor \& Francis }\end{array}$ & $\begin{array}{l}\ldots \text {.. doi:10.1023/B:VISI.0000029664.99615.94. [Crossref], [Web } \\
\text { of Science } ₫] \text {, [Google Scholar]) are ... state-of-the-art } \\
\text { performances in a wide range of computer vision tasks, such as } \\
\ldots \text { with Region Proposal Networks." "EEE Transactions on } \\
\text { Pattern Analysis and Machine Intelligence } 39 . . .\end{array}$ & Não & $\begin{array}{l}\text { Não se refere ao objeto de } \\
\text { busca }\end{array}$ \\
\hline $\begin{array}{l}\text { Biometric Security and } \\
\text { Internet of Things (IoT) }\end{array}$ & $\begin{array}{l}\text { MS Obaidat, SP Rana, T } \\
\text { Maitra, D Giri... - Biometric- } \\
\text { Based Physical ..., } 2019 \text { - } \\
\text { Springer }\end{array}$ & $\begin{array}{l}\ldots \text { among various smart devices in the house, like medical } \\
\text { devices, computers, mobiles, TVs ... There are two types of } \\
\text { feature extraction methods in computer vision: low-level and } \\
\text { high-level ... so on, whereas high-level algorithms are typically } \\
\text { associated with the machine learning field ... }\end{array}$ & Não & $\begin{array}{l}\text { Não se refere ao objeto de } \\
\text { busca }\end{array}$ \\
\hline $\begin{array}{l}\text { System and method for } \\
\text { predicting and responding to } \\
\text { soft underfoot conditions }\end{array}$ & $\begin{array}{l}\text { A Chrungoo, S Gowda, AP } \\
\text { Kini... - US Patent App. } 15 \text {..., } \\
2019 \text { - Google Patents }\end{array}$ & $\begin{array}{l}\ldots \text { The computer-readable medium includes computer- } \\
\text { executable instructions for performing a method for ... } \\
\text { feedback) through various controls and/or an operator seat, } \\
\text { visual feedback, auditory ... predicted locations based on an } \\
\text { analysis of real time machine operational parameters ... }\end{array}$ & Não & $\begin{array}{l}\text { Não se refere ao objeto de } \\
\text { busca }\end{array}$ \\
\hline $\begin{array}{l}\text { Digitization in wood supply-A } \\
\text { review on how Industry } 4.0 \\
\text { will change the forest value } \\
\text { chain }\end{array}$ & $\begin{array}{l}\text { F Müller, D Jaeger, M } \\
\text { Hanewinkel - Computers and } \\
\text { Electronics in ..., } 2019 \text { - } \\
\text { Elsevier }\end{array}$ & $\begin{array}{l}\text {... Volume } 162 \text {, July } 2019, \text { Pages 206-218. Computers and } \\
\text { Electronics in Agriculture, . I I } 4.0 \text { describes a vision on how } \\
\text { industry and society may look like in the future before the ... } \\
\text { Human-machine interaction: As humans will still be an important } \\
\text { part of the Smart Factory (Zuehlke, } 2010 \ldots\end{array}$ & Não & $\begin{array}{l}\text { Não se refere ao objeto de } \\
\text { busca }\end{array}$ \\
\hline $\begin{array}{l}\text { A detailed comparative study } \\
\text { of open source deep learning } \\
\text { frameworks }\end{array}$ & $\begin{array}{l}\text { G Al-Bdour, R Al-Qurran, M } \\
\text { Al-Ayyoub... - arXiv preprint } \\
\text { arXiv ..., 2019 - arxiv.org }\end{array}$ & $\begin{array}{l}\text {... field of DL occurred when more people started to use the } \\
\text { graphics processing units (GPUs ... of deep neural network } \\
\text { models, and it is used for deploying machine learning systems } \\
\text { into production for different fields including speech recognition, } \\
\text { NLP, computer vision, robotics, and ... }\end{array}$ & Não & $\begin{array}{l}\text { Não se refere ao objeto de } \\
\text { busca }\end{array}$ \\
\hline $\begin{array}{l}\text { Detecting uncut crop edge } \\
\text { with convolutional neural } \\
\text { networks }\end{array}$ & $\begin{array}{l}\text { D Protasov - ... and Practical } \\
\text { Conference "Digital } \\
\text { agriculture ..., } 2019 \text { - atlantis- } \\
\text { press.com }\end{array}$ & $\begin{array}{l}\text {... transfer of data on the position of the border to the main } \\
\text { control computer ... [4] V. Subramanian, TF Burks, and A. } \\
\text { Arroyo, "Development of machine vision and laser radar based } \\
\text { autonomous vehicle guidance systems for citrus grove } \\
\text { navigation," Computers and Electronics ... }\end{array}$ & Sim & $\begin{array}{l}\text { Processamento de imagens } \\
\text { para localização }\end{array}$ \\
\hline Deeper in BLUE & $\begin{array}{l}\text { I del Pino, MÁ Muñoz- } \\
\text { Bañon...- Journal of } \\
\text { Intelligent \& ..., } 2019 \text { - } \\
\text { Springer }\end{array}$ & $\begin{array}{l}\ldots \text { used a central process that managed the information flow } \\
\text { between several asynchronous subsystems that ran in parallel } \\
\text { in different computers ... Computer No Yes Yes Yes ... As a } \\
\text { downside, the traction system does not have encoders, so the } \\
\text { original machine does not provide any ... }\end{array}$ & Não & $\begin{array}{l}\text { Não se refere ao objeto de } \\
\text { busca }\end{array}$ \\
\hline $\begin{array}{l}\text { Recognizing assigned } \\
\text { passengers for autonomous } \\
\text { vehicles }\end{array}$ & $\begin{array}{l}\text { JW Dyer, L Torres, M } \\
\text { Epstein... - US Patent App. } \\
15 / 679,485,2019 \text { - Google } \\
\text { Patents }\end{array}$ & $\begin{array}{l}\text {... Recognizing assigned passengers for autonomous vehicles. } \\
\text { Download PDF Info ... DATA PROCESSING; G06F21/00_- } \\
\text { Security arrangements for protecting computers, components } \\
\text { thereof ... detection systems using field detection presence } \\
\text { sensors for image processing, eg cameras ... }\end{array}$ & Não & $\begin{array}{l}\text { Não se refere ao objeto de } \\
\text { busca }\end{array}$ \\
\hline $\begin{array}{l}\text { User interface for displaying } \\
\text { object-based indications in an } \\
\text { autonomous driving system }\end{array}$ & $\begin{array}{l}\text { RCE Mariet, MC Clement, P } \\
\text { Nemec... - US Patent App. } 15 \\
\ldots, 2019 \text { - } \\
\text { freepatentsonline.com }\end{array}$ & $\begin{array}{l}\text {... 20110285717, METHOD FOR GENERATING MANOEUVRE } \\
\text { GRAPHICS IN ANAVIGATION DEVICE, November ... } \\
\text { 20110071818, MAN-MACHINE INTERFACE FOR REAL-TIME } \\
\text { FORECASTING USER' INPUT, March ... D438874, Computer } \\
\text { icon for a display panel, March, 2001, Flamini ... }\end{array}$ & Não & $\begin{array}{l}\text { Não se refere ao objeto de } \\
\text { busca }\end{array}$ \\
\hline $\begin{array}{l}\text { Fusion of radar and vision } \\
\text { sensor systems }\end{array}$ & $\begin{array}{l}\text { S Zeng, I Bilik, S Villeval, Y } \\
\text { Hu - US Patent App. } \\
\text { 15/683,144, } 2019 \text { - Google } \\
\text { Patents }\end{array}$ & $\begin{array}{l}\ldots \text { to claim } 13, \text { wherein the controller is further configured to } \\
\text { obtain the visual feature map based ... en), } 2017-08-22 \text {, } \\
2018-08-21, \text { Fusion of radar and image sensor systems ... } \\
\text { US7366325B2 (en), 2008-04-29, Moving object detection using } \\
\text { low illumination depth capable computer vision ... }\end{array}$ & Sim & $\begin{array}{l}\text { Processamento de imagens } \\
\text { para veículos autônomos }\end{array}$ \\
\hline $\begin{array}{l}\text { Methods and apparatus for } \\
\text { early sensory integration and } \\
\text { robust acquisition of real } \\
\text { world knowledge }\end{array}$ & $\begin{array}{l}\text { A Gorshechnikov, M } \\
\text { Versace... - US Patent App. } \\
\text { 10/300,603, } 2019 \text { - Google } \\
\text { Patents }\end{array}$ & $\begin{array}{l}\text { US10300603B2 - Methods and apparatus for early sensory } \\
\text { integration and robust acquisition of real world knowledge - } \\
\text { Google Patents. Methods and apparatus for early sensory } \\
\text { integration and robust acquisition of real world knowledge. } \\
\text { Download PDF Info ... }\end{array}$ & Sim & $\begin{array}{l}\text { Processamento de imagens } \\
\text { para veículos autônomos }\end{array}$ \\
\hline
\end{tabular}




\begin{tabular}{|c|c|c|c|c|}
\hline $\begin{array}{l}\text { System and method for object } \\
\text { detection }\end{array}$ & $\begin{array}{l}\text { LA Mianzo, M Hoffelder, JT } \\
\text { Stringer - US Patent App. } \\
15 / 723,293,2019 \text { - Google } \\
\text { Patents }\end{array}$ & $\begin{array}{l}\text {... image including a } 360 \text {-degree view of the environment of the } \\
\text { machine } 100 \ldots \text { capturing device } 120 \text { may comprise a smart } \\
\text { camera or a smart vision system having a ... by programmable } \\
\text { state array (FPGA), digital signal processor (DSP), general } \\
\text { purpose graphics processing unit (GP ... }\end{array}$ & Não & $\begin{array}{l}\text { Não se refere ao objeto de } \\
\text { busca }\end{array}$ \\
\hline $\begin{array}{l}\text { System and method for } \\
\text { autonomous vehicle control to } \\
\text { minimize energy cost }\end{array}$ & $\begin{array}{l}\text { X Sun, LIN Wutu, L Liu, MA } \\
\text { Kai-Chieh... - US Patent App. } \\
15 \text {..., } 2019 \text { - Google Patents }\end{array}$ & $\begin{array}{l}\ldots \text { within which a set of instructions when executed may cause } \\
\text { the machine to perform ... assistants (PDA's), MP3 players, } \\
\text { tablet computing devices (eg, iPad }{ }^{T M} \text { ), laptop computers, CD } \\
\text { players ... that executes processing instructions stored in a } \\
\text { non-transitory computer readable medium ... }\end{array}$ & Não & $\begin{array}{l}\text { Não se refere ao objeto de } \\
\text { busca }\end{array}$ \\
\hline $\begin{array}{l}\text { [PDF] THE ADVANCEMENT } \\
\text { OF TECHNOLOGIES IN } \\
\text { INFORMATICS }\end{array}$ & $\begin{array}{l}\text { N Qasim, MQ Rind - 17th, } \\
2019 \text { - researchgate.net }\end{array}$ & $\begin{array}{l}\text {... A quantum Turing machine is a theoretical model of such a } \\
\text { computer and is also known as the universal quantum computer } \\
\ldots \text { https://bigthink. com/philip-perry/microsoft-plans-to-have-a- } \\
\text { dna-based-computer-by- } 2020,25 \text { November, } 2017 \ldots \text { org/ } \\
\text { computers/quantumcomputers ... }\end{array}$ & Não & $\begin{array}{l}\text { Não se refere ao objeto de } \\
\text { busca }\end{array}$ \\
\hline $\begin{array}{l}\text { Applicability of Wireless } \\
\text { Sensor Networks in Precision } \\
\text { Agriculture: A Review }\end{array}$ & $\begin{array}{l}\text { D Thakur, Y Kumar, A Kumar, } \\
\text { PK Singh - Wireless Personal } \\
\ldots, 2019 \text { - Springer }\end{array}$ & $\begin{array}{l}\text {.. } 3 \text { Precision Agriculture Springer } 114 \text { Computers and } \\
\text { Electronics in Agriculture Elsevier } 185 \text { Computer Standards \& } \\
\text { Interfaces Elsevier } 36 \text { Frontiers of Forestry in China Springer } 1 \\
\ldots 30 \text { Remote Sensing of Environment Elsevier } 131 \text { Frontiers } \\
\text { of Earth Science Springer } 1 \ldots\end{array}$ & Não & $\begin{array}{l}\text { Não se refere ao objeto de } \\
\text { busca }\end{array}$ \\
\hline $\begin{array}{l}\text { Approximate cross-check for } \\
\text { real-time feature matching }\end{array}$ & $\begin{array}{l}\text { LD Kohn, G Rapaport - US } \\
\text { Patent App. 15/590,251, } 2019 \\
\text { - freepatentsonline.com }\end{array}$ & $\begin{array}{l}\ldots \text { The circuit(s) } 432 \text { may implement one or more computer } \\
\text { vision coprocessor circuits ... be a wireless interface for } \\
\text { communicating with a user device (eg, a smart phone, a } \\
\text { computer, a tablet ... } 436 \text { may implement a direct memory } \\
\text { access (DMA) engine and/or a graphics direct memory ... }\end{array}$ & Não & $\begin{array}{l}\text { Não se refere ao objeto de } \\
\text { busca }\end{array}$ \\
\hline $\begin{array}{l}\text { Vr-proud: Vehicle re- } \\
\text { identification using } \\
\text { progressive unsupervised } \\
\text { deep architecture }\end{array}$ & $\begin{array}{l}\text { RMS Bashir, M Shahzad, MM } \\
\text { Fraz - Pattern Recognition, } \\
2019 \text { - Elsevier }\end{array}$ & $\begin{array}{l}\ldots \text {... aforementioned approaches relying on conventional } \\
\text { supervised and unsupervised machine learning performs ... } \\
\text { when it comes to process images for diverse computer vision } \\
\text { related applications ... that won the ILSVRC-2012 (ImageNet } \\
\text { Large-Scale Visual Recognition Challenge ... }\end{array}$ & Sim & $\begin{array}{l}\text { Processamento de imagens } \\
\text { para veiculos autônomos }\end{array}$ \\
\hline $\begin{array}{l}\text { [PDF] PREPAREDNESS OF } \\
\text { GHANAIAN MINE } \\
\text { STAKEHOLDERS FOR THE } \\
\text { ADOPPION OF } \\
\text { AUTONOMOUS SURFACE } \\
\text { MINING SYSTEMS }\end{array}$ & $\begin{array}{l}\text { BA Kansake, FA Kaba, NK } \\
\text { Dumakor-Dupey, CK Arthur - } \\
\text { researchgate.net }\end{array}$ & $\begin{array}{l}\text {... Advanced computing skills include skills in computer } \\
\text { programming, machine learning, artificial intelligence and } \\
\text { simulation of mining systems using computers ... Simulation } \\
\text { Model of Human Drivers to Study Autonomous Haulage } \\
\text { Trucks", Procedia Computer Science, } 6, \mathrm{pp} . .\end{array}$ & Não & $\begin{array}{l}\text { Não se refere ao objeto de } \\
\text { busca }\end{array}$ \\
\hline $\begin{array}{l}\text { System and method for } \\
\text { providing multiple agents for } \\
\text { decision making, trajectory } \\
\text { planning, and control for } \\
\text { autonomous vehicles }\end{array}$ & $\begin{array}{l}\text { X Sun, Y Zhao, LIN Wutu, X } \\
\text { Zijie, L Liu.... - US Patent App. } \\
15 \text {..., } 2019 \text { - Google Patents }\end{array}$ & $\begin{array}{l}\ldots \text { within which a set of instructions when executed may cause } \\
\text { the machine to perform ... assistants (PDA's), MP3 players, } \\
\text { tablet computing devices (eg, iPad } \mathrm{P} \text { ), laptop computers, CD } \\
\text { players ... between the vehicle } 105 \text { and external sensors, other } \\
\text { vehicles, other computer systems, and ... }\end{array}$ & Não & $\begin{array}{l}\text { Não se refere ao objeto de } \\
\text { busca }\end{array}$ \\
\hline $\begin{array}{l}\text { Evaluating the effect of MIPM } \\
\text { on vehicle detection } \\
\text { performance }\end{array}$ & $\begin{array}{l}\text { N Yaghoobi Ershadi, JM } \\
\text { Menéndez... - Transportation } \\
\text {..., } 2019 \text { - Taylor \& Francis }\end{array}$ & $\begin{array}{l}\text {... A Gaussian Mixture Model and Support Vector Machine } \\
\text { Approach to ... a Survey on Vehicle Detection Techniques in } \\
\text { Aerial Surveillance." International Journal Of Computer } \\
\text { Applications } 55 . . . \text { Handling, Tracking, and OC-SVM } \\
\text { Classification: A High Performance Vision-Based System ... }\end{array}$ & Não & $\begin{array}{l}\text { Não se refere ao objeto de } \\
\text { busca }\end{array}$ \\
\hline $\begin{array}{l}\text { Artificial intelligence and } \\
\text { contemporary Japanese } \\
\text { architecture-any relationship? }\end{array}$ & $\begin{array}{l}\text { D Ahmed - Intelligent } \\
\text { Buildings International, } 2019 \text { - } \\
\text { Taylor \& Francis }\end{array}$ & $\begin{array}{l}\text {... In the information society 'the information utility (a computer- } \\
\text { based public infrastructure)', consisting of ... the knowledge- } \\
\text { intensive industries of the industrial age which were fed by } \\
\text { science (Leadbeater } 2004 \ldots \text {... architecture of wind', he compares } \\
\text { it with the idea of a 'machine' in order ... }\end{array}$ & Não & $\begin{array}{l}\text { Não se refere ao objeto de } \\
\text { busca }\end{array}$ \\
\hline $\begin{array}{l}\text { System and method for } \\
\text { vehicle occlusion detection }\end{array}$ & $\begin{array}{l}\text { YU Hongkai, Z Yan, P Wang, } \\
\text { P Chen - US Patent App. } \\
\text { 15/796,769, } 2019 \text { - Google } \\
\text { Patents }\end{array}$ & $\begin{array}{l}\ldots \text { within which a set of instructions when executed may cause } \\
\text { the machine to perform ... assistants (PDA's), MP3 players, } \\
\text { tablet computing devices (eg, iPad }{ }^{\mathrm{TM}} \text { ), laptop computers, CD } \\
\text { players ... between the vehicle } 105 \text { and external sensors, other } \\
\text { vehicles, other computer systems, and ... }\end{array}$ & Não & $\begin{array}{l}\text { Não se refere ao objeto de } \\
\text { busca }\end{array}$ \\
\hline $\begin{array}{l}\text { System and method for } \\
\text { evaluating the perception } \\
\text { system of an autonomous } \\
\text { vehicle }\end{array}$ & $\begin{array}{l}\text { J Zhu, CP Urmson, D } \\
\text { Haehnel.... - US Patent App. } \\
15 \ldots, 2019 \text { - } \\
\text { freepatentsonline.com }\end{array}$ & $\begin{array}{l}\ldots .20050131645, \text { Machine having automatic transport with } \\
\text { scanning and GPS functions, June ... READABLE DATA ... } \\
4970653 \text {, Vision method of detecting lane boundaries and } \\
\text { obstacles, November ... }\end{array}$ & Sim & $\begin{array}{l}\text { Processamento de imagens } \\
\text { para veiculos autônomos }\end{array}$ \\
\hline $\begin{array}{l}\text { Determining drivability of } \\
\text { objects for autonomous } \\
\text { vehicles }\end{array}$ & $\begin{array}{l}\text { DIF Ferguson, A WENDEL, } Z \\
\text { Xu, DH Silver.... - US Patent } \\
\text { App. } 10 \ldots, 2019 \text { - Google } \\
\text { Patents }\end{array}$ & $\begin{array}{l}\text {... optical position detecting means using a video camera in } \\
\text { combination with image processing means ... The vehicle's } \\
\text { computer systems may include a classifier trained to classify } \\
\text { detected objects ... Using machine learning techniques, over } \\
\text { time, the more information provided to the ... }\end{array}$ & Sim & $\begin{array}{l}\text { Processamento de imagens } \\
\text { para veiculos autônomos }\end{array}$ \\
\hline $\begin{array}{l}\text { Vison-Based Object Detection } \\
\text { Using a Polar Grid }\end{array}$ & $\begin{array}{l}\text { WY Lo, DIF Ferguson, A } \\
\text { Ogale - US Patent App. } \\
16 / 191,835,2019 \text { - Google } \\
\text { Patents }\end{array}$ & $\begin{array}{l}\ldots .3 \text { is a flow chart of a method for vision-based object } \\
\text { detection using a polar ... } 11 \text { is a schematic illustrating a } \\
\text { conceptual partial view of a computer program, in accordance } \\
\text { with ... bins across multiple images, the computing device may } \\
\text { determine whether a given image portion within ... }\end{array}$ & Não & Apenas detecção de objetos \\
\hline $\begin{array}{l}\text { Object detection and } \\
\text { passenger notification }\end{array}$ & $\begin{array}{l}\text { CJ Stoffel, TD Kentley-klay - } \\
\text { US Patent App. 15/486,559, } \\
2019 \text { - freepatentsonline.com }\end{array}$ & $\begin{array}{l}\text {... personal items, such as, for example, cell phones, } \\
\text { briefcases, and computers, which can ... may be performed by } \\
\text { various computer vision algorithms, such as machine learning } \\
\text { using a ... device } 400 \text { can comprise memory } 402 \text { configured to } \\
\text { include computer-executable instructions ... }\end{array}$ & Não & $\begin{array}{l}\text { Apenas detecção de objetos } \\
\text { pessoais }\end{array}$ \\
\hline $\begin{array}{l}\text { [PDF] Automatic Detection } \\
\text { Method of Picture-based } \\
\text { Lingwu Long Jujubes }\end{array}$ & $\begin{array}{l}\text { S Pang, J Kan, Y Wang - icj- } \\
\text { e.org }\end{array}$ & $\begin{array}{l}\ldots \text { Object detection is an important topic in the field of computer } \\
\text { vision and its main ... a basic and general data set for image } \\
\text { recognition in machine learning, including ... MATLAB, the } \\
\text { computer visual toolbox, provides an average precision } \\
\text { evaluationDetectionPrecision function and a ... }\end{array}$ & Não & Apenas detecção de objetos \\
\hline $\begin{array}{l}\text { Methods and Systems for } \\
\text { Vehicle Occupancy } \\
\text { Confirmation }\end{array}$ & $\begin{array}{l}\text { J Herbach - US Patent App. } \\
\text { 15/681,041, } 2019 \text { - Google } \\
\text { Patents }\end{array}$ & $\begin{array}{l}\text {... Additionally, the combination of GPS } 122 \text { and the features } \\
\text { recognized by computer vision system } 140 \ldots \text { interface, and } \\
\text { graphical display } 360 \text { may be configured to provide a visual } \\
\text { depiction of ... For example, computer storage media may take } \\
\text { the form of RAM, ROM, EEPROM, flash ... }\end{array}$ & Não & Apenas detecção de objetos \\
\hline $\begin{array}{l}\text { A systematic review of } \\
\text { perception system and } \\
\text { simulators for autonomous } \\
\text { vehicles research }\end{array}$ & $\begin{array}{l}\text { F Rosique, PJ Navarro, C } \\
\text { Fernández, A Padilla - } \\
\text { Sensors, } 2019 \text { - mdpi.com }\end{array}$ & $\begin{array}{l}\ldots \text { and communications technology (leading to miniaturization } \\
\text { and improvement of computers, sensors and ... can vary from } \\
\text { operational tests to a fully computer-generated representation } \\
\ldots \text { ie, Bayes theorem), and ( } 3 \text { ) artificial intelligence methods } \\
\text { based on machine learning algorithms ... }\end{array}$ & Não & $\begin{array}{l}\text { Não usa processamento de } \\
\text { imagens }\end{array}$ \\
\hline
\end{tabular}




\begin{tabular}{|c|c|c|c|c|}
\hline $\begin{array}{l}\text { The future of mining in } \\
\text { Ghana: Are stakeholders } \\
\text { prepared for the adoption of } \\
\text { autonomous mining systems? }\end{array}$ & $\begin{array}{l}\text { BA Kansake, FA Kaba, NK } \\
\text { Dumakor-Dupey, CK Arthur - } \\
\text { Resources Policy, } 2019 \text { - } \\
\text { Elsevier }\end{array}$ & $\begin{array}{l}\text {... Accidents can also dent the image of mining companies, } \\
\text { which can have devastating ... other tertiary educational } \\
\text { institutions in Ghana, including Kwame Nkrumah University of } \\
\text { Science and Technology ... forms were downloaded in.csv file } \\
\text { formats for further processing and analysis ... }\end{array}$ & Não & Conceito genérico \\
\hline $\begin{array}{l}\text { Applications of Digital } \\
\text { Technologies in Sustainable } \\
\text { Logistics and Supply Chain } \\
\text { Management }\end{array}$ & $\begin{array}{l}\text { F Wei, C Alias, B Noche - } \\
\text { Innovative Logistics Services } \\
\text { and Sustainable ..., } 2019 \text { - } \\
\text { Springer }\end{array}$ & $\begin{array}{l}\text {... It reflects the manual operation on a computer using } \\
\text { spreadsheets and forms as a ... improvement is mapped into a } \\
\text { third solution type where process and machine data are ... } \\
\text { Computers and Information in Engineering Conference 2014: } \\
\text { Volume } 1 \mathrm{~B}: 34 \text { th Computers and Information ... }\end{array}$ & Não & Conceito genérico \\
\hline $\begin{array}{l}\text { Computational Methods of } \\
\text { Acquisition and Processing of } \\
\text { 3D Point Cloud Data for } \\
\text { Construction Applications }\end{array}$ & $\begin{array}{l}\text { Q Wang, Y Tan, Z Mei - } \\
\text { Archives of Computational } \\
\text { Methods in ..., 2019 - } \\
\text { Springer }\end{array}$ & $\begin{array}{l}\text {... cloud data were used to evaluate the building design } \\
\text { regarding the visual harmony, aesthetics ... and Remote } \\
\text { Sensing (ASPRS), photogrammetry is defined as the art, } \\
\text { science, and technology of ... case for Stereo camera, in which } \\
\text { only the Bumblebee } \text { XB3 } \text { stereo vision system is ... }\end{array}$ & Não & $\begin{array}{l}\text { Não se refere ao objeto de } \\
\text { busca }\end{array}$ \\
\hline $\begin{array}{l}\text { Data-driven prediction-based } \\
\text { system and method for } \\
\text { trajectory planning of } \\
\text { autonomous vehicles }\end{array}$ & $\begin{array}{l}\text { X Sun, LIN Wutu, L Liu, MA } \\
\text { Kai-Chieh... - US Patent App. } \\
15 \text {..., } 2019 \text { - Google Patents }\end{array}$ & $\begin{array}{l}\text {... PDA's), MP3 players, tablet computing devices (eg, iPad }{ }^{\top M} \text { ), } \\
\text { laptop computers, CD players, and ... that executes processing } \\
\text { instructions stored in a non-transitory computer readable } \\
\text { medium ... the prediction-based trajectory planning system } 202 \\
\text { can use the machine learning training ... }\end{array}$ & Não & $\begin{array}{l}\text { Não usa processamento de } \\
\text { imagens }\end{array}$ \\
\hline $\begin{array}{l}\text { Encoding lidar signals to } \\
\text { avoid interference }\end{array}$ & $\begin{array}{l}\text { W Xu - US Patent App. } \\
\text { 15/855,479, } 2019 \text { - Google } \\
\text { Patents }\end{array}$ & $\begin{array}{l}\text {... Also, encode logic } 206 \text { and/or decode logic } 220 \text { may utilize } \\
\text { machine learning/deep ... device, a smartphone, tablet, UMPC } \\
\text { (Ultra-Mobile Personal Computer), laptop computer, } \\
\text { Ultrabook } \\
\text { and one or momputing ... includes one or more processors } 902 \\
\text { incs processors } 908 \ldots\end{array}$ & Não & $\begin{array}{l}\text { Não usa processamento de } \\
\text { imagens }\end{array}$ \\
\hline $\begin{array}{l}\text { Witness of Things: } \\
\text { Blockchain-based distributed } \\
\text { decision record-keeping } \\
\text { system for autonomous } \\
\text { vehicles }\end{array}$ & $\begin{array}{l}\text { S Ayvaz, SC Cetin - } \\
\text { International Journal of } \\
\text { Intelligent ..., 2019- } \\
\text { emeraldinsight.com }\end{array}$ & $\begin{array}{l}\text {... services, payments, cybersecurity, education, voting } \\
\text { systems, supply chain management,agriculture, forecasting, } \\
\text { healthcare ... human operator errors by replacing human } \\
\text { drivers with intelligent computer systems ... US consumers } \\
\text { report that they could trust the autonomous vehicle ... }\end{array}$ & Não & $\begin{array}{l}\text { Não se refere ao objeto de } \\
\text { busca }\end{array}$ \\
\hline $\begin{array}{l}\text { [HTML] Voice-driven fleet } \\
\text { management system for } \\
\text { agricultural operations }\end{array}$ & $\begin{array}{l}\text { C Achillas, D Bochtis, D } \\
\text { Aidonis, V Marinoudi... - } \\
\text { Information Processing ..., } \\
2019 \text { - Elsevier }\end{array}$ & $\begin{array}{l}\text {... For the latter, visual and textual elements were considered in } \\
\text { order to ensure ... technical improvements in the interface and } \\
\text { improvements in the human-machine interaction present a ... } \\
\text { International Conference on Robotics and Automation, } \\
\text { Workshop on Robotic Vision and Action ... }\end{array}$ & Não & $\begin{array}{l}\text { Não usa processamento de } \\
\text { imagens }\end{array}$ \\
\hline $\begin{array}{l}\text { Valuing Cyber-Physical } \\
\text { Bridging Intensity of Drone }\end{array}$ & $\begin{array}{l}\text { JS Um - Drones as Cyber- } \\
\text { Physical Systems, } 2019 \text { - } \\
\text { Springer }\end{array}$ & $\begin{array}{l}\text {... The drones are SMM (Smart Mobile Machine) equipped with } \\
\text { artificial intelligence along with the ... Vision sensors (eg, such } \\
\text { as camera, hyper-spectral sensors, laser scanners etc.) can be } \\
\ldots . \text { A high-precision navigation system, using a computer and a } \\
\text { sensor, Automatically fly along ... }\end{array}$ & Não & $\begin{array}{l}\text { Aplicação para imagens } \\
\text { externas (Drones) }\end{array}$ \\
\hline $\begin{array}{l}\text { System and method for } \\
\text { sensing an edge }\end{array}$ & $\begin{array}{l}\text { JE Slichter, AJ Pierson, DM } \\
\text { Stotz... - US Patent App. } 10 \\
\text {..., } 2019 \text { - Google Patents }\end{array}$ & $\begin{array}{l}\text {... provide a high throughput of data that saturates the } \\
\text { processing power of most field computers ... In still other } \\
\text { examples, color based machine vision is used to detect and } \\
\text { identify terrain features (eg ... configured to operate on its own } \\
\text { or in communication with the field computer of the ... }\end{array}$ & Não & $\begin{array}{l}\text { Não se refere ao objeto de } \\
\text { busca }\end{array}$ \\
\hline $\begin{array}{l}\text { Unmanned Aerial Vehicles } \\
\text { (UAVs): A Survey on Civil } \\
\text { Applications and Key } \\
\text { Research Challenges }\end{array}$ & $\begin{array}{l}\text { H Shakhatreh, AH Sawalmeh, } \\
\text { A Al-Fuqaha... - IEEE ..., } \\
2019 \text { - ieeexplore.ieee.org }\end{array}$ & $\begin{array}{l}\text {... Heights, Newark, NJ 07102, USA 10Department of Electrical } \\
\text { and Computer Engineering, University of ... of analyzing, } \\
\text { communicating, planning and decision making using on-board } \\
\text { computers, as well as ... In [57], the authors propose machine } \\
\text { learning techniques applied to images ... }\end{array}$ & Não & $\begin{array}{l}\text { Não se refere ao objeto de } \\
\text { busca }\end{array}$ \\
\hline $\begin{array}{l}\text { System and method for } \\
\text { semantic segmentation using } \\
\text { hybrid dilated convolution } \\
\text { (hdc) }\end{array}$ & $\begin{array}{l}\text { Z Huang, P Chen, P Wang - } \\
\text { US Patent App. 16/209,262, } \\
2019 \text { - Google Patents }\end{array}$ & $\begin{array}{l}\ldots \text { within which a set of instructions when executed may cause } \\
\text { the machine to perform ... assistants (PDA's), MP3 players, } \\
\text { tablet computing devices (eg, iPad }{ }^{\text {TM }} \text { ), laptop computers, CD } \\
\text { players ... that executes processing instructions stored in a } \\
\text { non-transitory computer readable medium ... }\end{array}$ & Sim & Segmentação de imagens \\
\hline $\begin{array}{l}\text { Tracking vehicles in a } \\
\text { warehouse environment }\end{array}$ & $\begin{array}{l}\text { CF Eckman - US Patent App. } \\
\text { 10/242,273, } 2019 \text { - Google } \\
\text { Patents }\end{array}$ & $\begin{array}{l}\ldots 700 \text { is intended to represent various forms of digital } \\
\text { computers, such as laptops, desktops, workstations, personal } \\
\text { digital assistants, servers, blade servers, mainframes, and other } \\
\text { appropriate computers ... The information carrier is a computer- } \\
\text { or machine-readable medium ... }\end{array}$ & Não & Apenas detecção de objetos \\
\hline $\begin{array}{l}\text { Vison-based object detection } \\
\text { using a polar grid }\end{array}$ & $\begin{array}{l}\text { W Lo, DIF Ferguson, A Ogale } \\
\text { - US Patent App. 15/671,316, } \\
2019 \text { - freepatentsonline.com }\end{array}$ & $\begin{array}{l}\ldots 3 \text { is a flow chart of a method } 300 \text { for vision-based object } \\
\text { detection using a polar grid, in ... In some embodiments, the } \\
\text { disclosed methods may be implemented as computer program } \\
\text { instructions encoded on a computer-readable storage media in } \\
\text { a machine-readable format ... }\end{array}$ & Não & Apenas detecção de objetos \\
\hline $\begin{array}{l}\text { Benefits of real-time } \\
\text { monitoring and process } \\
\text { mining in a digitized } \\
\text { construction supply chain }\end{array}$ & $\begin{array}{l}\text { AJ Spengler, C Alias, EGC } \\
\text { Magallanes... - Mobilität in } \\
\text { Zeiten der ..., } 2019 \text { - Springer }\end{array}$ & $\begin{array}{l}\ldots \text { work leads to a lack of transparency during the realization of } \\
\text { the owner's vision and the ... In the given reference process, } \\
\text { the building model, sensor data, application data, profiles, } \\
\text { machine data etc ... N . Teizer J (eds) (2014) Passive RFID and } \\
\text { BIM for Real-Time Visual- ization and ... }\end{array}$ & Não & Conceito genérico \\
\hline The Ethics of Biosurveillance & $\begin{array}{l}\text { SK Devitt, PWJ Baxter, G } \\
\text { Hamilton - ... Agricultural and } \\
\text { Environmental Ethics, } 2019 \text { - } \\
\text { Springer }\end{array}$ & $\begin{array}{l}\text {... explanation of: Sampling procedures (eg attractant trapping, } \\
\text { whole plant sampling, visual inspection, sample ... of German } \\
\text { census data in } 1933 \text { collected on IBM computers enabled Nazis } \\
\ldots . \text { Given its advantages to agricultural productivity and food and } \\
\text { environmental security, what ... }\end{array}$ & Não & Conceito genérico \\
\hline $\begin{array}{l}\text { Drones for conservation in } \\
\text { protected areas: Present and } \\
\text { future }\end{array}$ & $\begin{array}{l}\text { J Jiménez López, M Mulero- } \\
\text { Pázmány - Drones, } 2019 \text { - } \\
\text { mdpi.com }\end{array}$ & $\begin{array}{l}\text {... ecological process at regional scale [107], validate } \\
\text { vegetation maps from drone image interpretation [108 ... live } \\
\text { streaming visible and thermal camera systems with real time } \\
\text { vision processing techniques ... The flight rules often limit flying } \\
\text { drones beyond the visual line of sight ... }\end{array}$ & Não & $\begin{array}{l}\text { Aplicação para imagens } \\
\text { externas (Drones) }\end{array}$ \\
\hline $\begin{array}{l}\text { [PDF] National Science } \\
\text { Foundation Workshop Report }\end{array}$ & $\begin{array}{l}\text { V Green, EH Branch - } \\
\text { researchgate.net }\end{array}$ & $\begin{array}{l}\ldots \text { Need a clear vision of the ... Ethics of ADSs We need to } \\
\text { develop a new paradigm about how we educate engineers and } \\
\text { computer scientists who ... side issues From a tech industry } \\
\text { demand perspective, firms are interested in the continued } \\
\text { development of machine learning methods ... }\end{array}$ & Não & Conceito genérico \\
\hline $\begin{array}{l}\text { Autonomous vehicle path } \\
\text { coordination }\end{array}$ & $\begin{array}{l}\text { B Konrardy, ST } \\
\text { Christensen.... - US Patent } \\
\text { App. } 15 \ldots ., 2019 \text { - } \\
\text { freepatentsonline.com }\end{array}$ & $\begin{array}{l}\text {... Real-Time Driver Gaze Location Determination and Analysis } \\
\text { Utilizing Computer Vision Technology, } 2014 \text {... } 8040247 \text {, } \\
\text { System for rapid detection of drowsiness in a machine operator, } \\
2011 \ldots 7719431 \text {, Systems, methods and computer products for } \\
\text { drowsy driver detection and response ... }\end{array}$ & Não & Sistemas de segurança ativa \\
\hline
\end{tabular}




\begin{tabular}{|c|c|c|c|c|}
\hline $\begin{array}{l}\text { [PDF] Application of artificial } \\
\text { intelligence in the trucking } \\
\text { industry }\end{array}$ & $\begin{array}{l}\text { JP Rubocki - } 2019 \text { - } \\
\text { minds.wisconsin.edu }\end{array}$ & $\begin{array}{l}\text {... While originally designed to support computer gaming } \\
\text { graphics, GPUs } \ldots \text { computing is enabling massive data sets to } \\
\text { be processed by powerful central computers which is ... } \\
\text { General Al, or artificial general intelligence }(\mathrm{AGI}) \text {, is a } \\
\text { technology that seeks to develop a machine that can ... }\end{array}$ & Não & $\begin{array}{l}\text { Não se refere ao objeto de } \\
\text { busca }\end{array}$ \\
\hline $\begin{array}{l}\text { [PDF] Green Wave } \\
\text { Technologies }\end{array}$ & $\begin{array}{l}\text { S Farm - } 2019 \text { - } \\
\text { cloudfront.escholarship.org }\end{array}$ & $\begin{array}{l}\ldots \text { to grow at a rate that is far quicker than one our agricultural } \\
\text { practices and } \ldots \text {. We also integrated computer vision to monitor } \\
\text { the health of the strawberries, and reinforced our wired sensor } \\
\ldots \text { floors; Floor } 1 \text { is a designated loading zone, while Floor } 2 \\
\text { contain processing and packaging ... }\end{array}$ & Não & $\begin{array}{l}\text { Não se refere ao objeto de } \\
\text { busca }\end{array}$ \\
\hline $\begin{array}{l}\text { Method and system for } \\
\text { vehicle localization }\end{array}$ & $\begin{array}{l}\text { M Rohani, S Zhang - US } \\
\text { Patent App. 15/655,349, } 2019 \\
\text { - Google Patents }\end{array}$ & $\begin{array}{l}\ldots \text { code executable by the processor } 120 \text { to perform the method } \\
500 \text { may be stored in a non-transitory machine readable } \\
\text { medium ... The present disclosure teaches methods and } \\
\text { systems for using computer vision based on sensed data to } \\
\text { generate a top view image, and using the ... }\end{array}$ & Não & $\begin{array}{l}\text { Não se refere ao objeto de } \\
\text { busca }\end{array}$ \\
\hline $\begin{array}{l}\text { System and method for using } \\
\text { human driving patterns to } \\
\text { detect and correct abnormal } \\
\text { driving behaviors of } \\
\text { autonomous vehicles }\end{array}$ & $\begin{array}{l}\text { LIN Wutu, L Liu, X Sun - US } \\
\text { Patent App. } 15 / 6405212019 \\
\text { - Google Patents }\end{array}$ & $\begin{array}{l}\text {... client devices may also include other computing devices } \\
\text { such as personal computers (PCs) multiprocessor ... The } \\
\text { machine may be a personal computer }(\mathrm{PC}) \text { a laptop computer a } \\
\text { tablet computing ... Further while only a single machine is } \\
\text { illustrated the term "machine" can also be ... }\end{array}$ & Não & $\begin{array}{l}\text { Não usa processamento de } \\
\text { imagens }\end{array}$ \\
\hline $\begin{array}{l}\text { Autonomous vehicle support } \\
\text { for secondary vehicle }\end{array}$ & $\begin{array}{l}\text { RB TOWAL, AK Konertz, J } \\
\text { Golston - US Patent App. } \\
15 / 7005682019 \text { - Google } \\
\text { Patents }\end{array}$ & $\begin{array}{l}\text { US20190079525A1 - Autonomous vehicle support for } \\
\text { secondary vehicle - Google Patents. Autonomous vehicle } \\
\text { support for secondary vehicle. Download PDF Info. Publication } \\
\text { number US20190079525A1. US20190079525A1 ... }\end{array}$ & Não & $\begin{array}{l}\text { Não se refere ao objeto de } \\
\text { busca }\end{array}$ \\
\hline $\begin{array}{l}\text { System and method for using } \\
\text { triplet loss for proposal free } \\
\text { instance-wise semantic } \\
\text { segmentation for lane } \\
\text { detection }\end{array}$ & $\begin{array}{l}\text { Z Huang, P Wang, P Chen, T } \\
\text { Li - US Patent App. 15/684 } \\
7912019 \text { - Google Patents }\end{array}$ & $\begin{array}{l}\ldots \text {. PDA's) MP3 players tablet computing devices (eg } \mathrm{iPad}^{\mathrm{TM}} \text { ) } \\
\text { laptop computers CD players ... that executes processing } \\
\text { instructions stored in a non-transitory computer readable } \\
\text { medium ... device } 172 \text { may store data such as image } \\
\text { processing parameters machine learning training } . . .\end{array}$ & Sim & Segmentação de imagens \\
\hline $\begin{array}{l}\text { Thermal imaging drift sensor } \\
\text { for agricultural spraying }\end{array}$ & $\begin{array}{l}\text { A Paralikar, ME Barker, RA } \\
\text { Humpal, J Desai...- US } \\
\text { Patent App. } 16 \ldots 2019 \text { - } \\
\text { Google Patents }\end{array}$ & $\begin{array}{l}\text { US20190116726A1 - Thermal imaging drift sensor for } \\
\text { agricultural spraying - Google Patents. Thermal imaging drift } \\
\text { sensor for agricultural spraying. Download PDF Info. Publication } \\
\text { number US20190116726A1. US20190116726A1 ... }\end{array}$ & Não & Imagens térmicas \\
\hline $\begin{array}{l}\text { Object detection and } \\
\text { passenger notification }\end{array}$ & $\begin{array}{l}\text { CJ Stoffel TD Kentley-Klay - } \\
\text { US Patent App. 10/303 } 961 \\
2019 \text { - Google Patents }\end{array}$ & $\begin{array}{l}\text { US10303961B1 - Object detection and passenger notification - } \\
\text { Google Patents. Object detection and passenger notification. } \\
\text { Download PDF Info. Publication number US10303961B1. } \\
\text { US10303961B1 US } 15 / 486559 \text { US201715486559A ... }\end{array}$ & Não & Apenas detecção de objetos \\
\hline $\begin{array}{l}\text { Accuracy Analysis of a 3D } \\
\text { Model of Excavation Created } \\
\text { from Images Acquired with an } \\
\text { Action Camera from Low } \\
\text { Altitudes }\end{array}$ & $\begin{array}{l}\text { D Wierzbicki, M Nienaltowski } \\
\text { - ISPRS International Journal } \\
\text { of Geo ... } 2019 \text { - } \underline{\text { mdpi.com }}\end{array}$ & $\begin{array}{l}\text {... It is a mini computer on board of the UAV in the form of a } \\
\text { control board which with the help of pre... The calibration } \\
\text { parameters of the camera are: calibrated focal length- }-\mathrm{k} \text {; the } \\
\text { projection centres in relation to the pictures determined by } x 0 \\
\text { and y } 0 \text { - image coordinates of ... }\end{array}$ & Não & $\begin{array}{l}\text { Aplicação para imagens } \\
\text { externas (Drones) }\end{array}$ \\
\hline Physical Systems & $\begin{array}{l}\text { JS Um - Drones as Cyber- } \\
\text { Physical Systems } 2019 \text { - } \\
\text { Springer }\end{array}$ & $\begin{array}{l}\text {... linguistics which clarify the nature and thinking process of } \\
\text { human intelligence using computers ... In unsupervised } \\
\text { learning computer concerns the identification of obscure } \\
\text { structures or patterns } \ldots \text { In the future thanks to rapidly } \\
\text { developing machine learning techniques applied to ... }\end{array}$ & Não & $\begin{array}{l}\text { Aplicação para imagens } \\
\text { externas (Drones) }\end{array}$ \\
\hline $\begin{array}{l}\text { Prediction-based system and } \\
\text { method for trajectory planning } \\
\text { of autonomous vehicles }\end{array}$ & $\begin{array}{l}\text { X Zhang, Y Chen, LI } \\
\text { Guangyu, X Sun...-US } \\
\text { Patent App. } 15 \ldots 2019 \text { - } \\
\text { Google Patents }\end{array}$ & $\begin{array}{l}\ldots \text { within which a set of instructions when executed may cause } \\
\text { the machine to perform ... assistants (PDA's) MP3 players } \\
\text { tablet computing devices (eg iPad }{ }^{T M} \text { ) laptop computers CD } \\
\text { players ... between the vehicle } 105 \text { and external sensors other } \\
\text { vehicles other computer systems and } \ldots\end{array}$ & Não & $\begin{array}{l}\text { Não usa processamento de } \\
\text { imagens }\end{array}$ \\
\hline Big Data in loT Systems & $\begin{array}{l}\text { F Aziz, SK Chalup, J Juniper - } \\
\text { arXiv preprint } \\
\text { arXiv:1905.00490 } 2019 \text { - } \\
\text { arxiv.org }\end{array}$ & $\begin{array}{l}\text {... 2.4.3 Machine-to-Machine Communications Machine-to- } \\
\text { machine communications (M2M) represent a ... access to a } \\
\text { shared pool of configurable resources (eg computers, networks, } \\
\text { servers ... servers and many kinds of terminals connected by } \\
\text { distributed computer networks etc.; and ... }\end{array}$ & Não & $\begin{array}{l}\text { Não se refere ao objeto de } \\
\text { busca }\end{array}$ \\
\hline $\begin{array}{l}\text { System and method for } \\
\text { controlling an unmanned } \\
\text { vehicle and releasing a } \\
\text { payload from the same }\end{array}$ & $\begin{array}{l}\text { CM Yong, JJ Ong, JJNE Hon, } \\
\text { JJ Chen... - US Patent App. } \\
16 \text {..., } 2019 \text { - Google Patents }\end{array}$ & $\begin{array}{l}\text {... the processor is operable to obtain the plurality of captured } \\
\text { images from the image capturing device ... available, the } \\
\text { processor is operable to generate a feature model using a } \\
\text { computer vision algorithm and ... to use a subset of the plurality } \\
\text { of captured images for machine learning ... }\end{array}$ & Não & $\begin{array}{l}\text { Não usa processamento de } \\
\text { imagens }\end{array}$ \\
\hline $\begin{array}{l}\text { Work site monitoring system } \\
\text { and method }\end{array}$ & $\begin{array}{l}\text { MG Kean - US Patent App. } \\
15 / 825,583,2019 \text { - Google } \\
\text { Patents }\end{array}$ & $\begin{array}{l}\text {... controller, the work site map by layering the object } \\
\text { symbology onto the scene image ... associated with a speech } \\
\text { recognition system, or various other human-machine interface } \\
\text { devices ... the applicable sensors described below (or other } \\
\text { sources) or undergo some processing in the ... }\end{array}$ & Não & $\begin{array}{l}\text { Não se refere ao objeto de } \\
\text { busca }\end{array}$ \\
\hline $\begin{array}{l}\text { Agricultural drone for use in } \\
\text { livestock feeding }\end{array}$ & $\begin{array}{l}\text { CV Horton, SR Vorpahl - US } \\
\text { Patent App. 16/262,035, } 2019 \\
\text { - Google Patents }\end{array}$ & $\begin{array}{l}\ldots 1 \text { and/or agricultural drone } 610-2 \text { may be programmed (via } \\
\text { camera and vision unit } 465 \ldots \text { and so executed by a computer, } \\
\text { machine or processor, whether or not such computer, machine } \\
\text { or processor ... a high level representation of some of the } \\
\text { components of such a computer is for ... }\end{array}$ & Não & $\begin{array}{l}\text { Aplicação para imagens } \\
\text { externas (Drones) }\end{array}$ \\
\hline $\begin{array}{l}\text { System and method for } \\
\text { automated lane change } \\
\text { control for autonomous } \\
\text { vehicles }\end{array}$ & $\begin{array}{l}\text { MA Kai-Chieh, X Sun - US } \\
\text { Patent App. 15/946,195, } 2019 \\
\text { - Google Patents }\end{array}$ & $\begin{array}{l}\ldots \text { within which a set of instructions when executed may cause } \\
\text { the machine to perform ... assistants (PDA's), MP3 players, } \\
\left.\text { tablet computing devices (eg, iPad }{ }^{T M}\right) \text {, laptop computers, CD } \\
\text { players ... between the vehicle } 105 \text { and external sensors, other } \\
\text { vehicles, other computer systems, and ... }\end{array}$ & Não & $\begin{array}{l}\text { Não se refere ao objeto de } \\
\text { busca }\end{array}$ \\
\hline Rearview device & $\begin{array}{l}\text { ES Sloterbeek - US Patent } \\
\text { App. 29/559,838, 2019 - } \\
\text { Google Patents }\end{array}$ & $\begin{array}{l}\text { USD845851S1 - Rearview device - Google Patents. Rearview } \\
\text { device. Download PDF Info. Publication number } \\
\text { USD845851S1. USD845851S1 US29/559,838 } \\
\text { US201629559838F USD845851S US D845851 S1 USD845851 } \\
\ldots\end{array}$ & Não & $\begin{array}{l}\text { Não se refere ao objeto de } \\
\text { busca }\end{array}$ \\
\hline $\begin{array}{l}\text { Autonomous communication } \\
\text { feature use }\end{array}$ & $\begin{array}{l}\text { B Konrardy, ST } \\
\text { Christensen.... US Patent } \\
\text { App. } 14 \ldots, 2019 \text { - } \\
\text { freepatentsonline.com }\end{array}$ & $\begin{array}{l}\text {... Time Driver Gaze Location Determination and Analysis } \\
\text { Utilizing Computer Vision Technology, 2014-06 ... System for } \\
\text { rapid detection of drowsiness in a machine operator, } 2011 \ldots \\
20080061953 \text {... }\end{array}$ & Não & $\begin{array}{l}\text { Não se refere ao objeto de } \\
\text { busca }\end{array}$ \\
\hline
\end{tabular}




\begin{tabular}{|c|c|c|c|c|}
\hline Static obstacle detection & $\begin{array}{l}\text { DH Silver, JB Dowdall, DI } \\
\text { Ferguson - US Patent App. } \\
\text { 10/204,278, } 2019 \text { - Google } \\
\text { Patents }\end{array}$ & $\begin{array}{l}\ldots \text {.. G05D2201/02-Control of position of land vehicles; } \\
\text { G05D2201/0213 - Road vehicle, eg car or truck ... an } \\
\text { environment, and the vehicle may be configured to operate in } \\
\text { an autonomous mode in ... The computer system may also be } \\
\text { configured to compare a first respective frame of the ... }\end{array}$ & Não & Apenas detecção de objetos \\
\hline $\begin{array}{l}\text { Accident fault determination } \\
\text { for autonomous vehicles }\end{array}$ & $\begin{array}{l}\text { B Konrardy, ST } \\
\text { Christensen.... - US Patent } \\
\text { App. } 14 \ldots ., 2019 \text { - } \\
\text { freepatentsonline.com }\end{array}$ & $\begin{array}{l}\ldots \text { for Real-Time Driver Gaze Location Determination and } \\
\text { Analysis Utilizing Computer Vision Technology, } 2014-06 \text {... } \\
20130237194, \text { Method, cell phone and system for accessing a } \\
\text { computer resource over a ... System and method for accident } \\
\text { logging in an automated machine, } 2013-06 \text {... }\end{array}$ & Não & Apenas detecção de objetos \\
\hline $\begin{array}{l}\text { Pose determination from } \\
\text { contact points }\end{array}$ & $\begin{array}{l}\text { V Karasev, J Kangaspunta... } \\
\text { - US Patent App. 15/814,870, } \\
2019 \text { - Google Patents }\end{array}$ & $\begin{array}{l}\text {... Such machine vision systems often use cameras to capture } \\
\text { a two-dimensional representation of an ... FIG. } 9 \text { depicts a } \\
\text { block diagram of an example computer system for implementing } \\
\text { the ... For example, the object contact point component can } \\
\text { include a machine learning algorithm ... }\end{array}$ & Não & $\begin{array}{l}\text { Não se refere ao objeto de } \\
\text { busca }\end{array}$ \\
\hline $\begin{array}{l}\text { Automated vehicle traffic } \\
\text { control tower-the bridge to } \\
\text { next level automation }\end{array}$ & $\begin{array}{l}\text { X Zhao, R Darwish, A } \\
\text { Perneståll - } 2019 \text { - diva- } \\
\text { portal.org }\end{array}$ & $\begin{array}{l}\ldots \text { to look around, determine the best course of action, and } \\
\text { issue fresh instructions to the computer onboard the car ... } \\
\text { Image sensing, 3D map, vision could be delayed in the } \\
\text { transmission, this could lead to decisions made in AVTCT ... } \\
\text { Machine Systems } 1982 \text { (pp. 129-135) ... }\end{array}$ & Não & $\begin{array}{l}\text { Não se refere ao objeto de } \\
\text { busca }\end{array}$ \\
\hline $\begin{array}{l}\text { [PDF] Energy Consumption } \\
\text { Prediction Using Machine } \\
\text { Learning; A Review }\end{array}$ & $\begin{array}{l}\text { A Mosavi, A Bahmani - } 2019 \text { - } \\
\text { researchgate.net }\end{array}$ & $\begin{array}{l}\ldots \text { learning; a review } 3 \text { Amir Mosavi } 1,2,3^{*} \text {, Abdullah Bahmani } 1 \text {, } \\
41 \text { Department of Computer Science, Norwegian University of } \\
\text { Science and Technology, Trondheim ...653. Machine learning } \\
\text { models } 66 \text { Here comes the taxonomy chart and one paragraph } \\
\text { explanation ... }\end{array}$ & Não & $\begin{array}{l}\text { Não se refere ao objeto de } \\
\text { busca }\end{array}$ \\
\hline $\begin{array}{l}\text { Infrastructure monitoring } \\
\text { system on autonomous } \\
\text { vehicles }\end{array}$ & $\begin{array}{l}\text { D Ferguson, J Zhu, C } \\
\text { Leipold... - US Patent App. } 16 \\
\text {..., } 2019 \text { - Google Patents }\end{array}$ & $\begin{array}{l}\text {... G06F15/18-Digital computers in general; Data processing } \\
\text { equipment in general in which a ... recognition algorithm and } \\
\text { the infrastructure assessment algorithm comprises a machine } \\
\text { learning algorithm ... computer; a desktop computer; a laptop } \\
\text { computer; a tablet computer; and/or a ... }\end{array}$ & Não & $\begin{array}{l}\text { Não se refere ao objeto de } \\
\text { busca }\end{array}$ \\
\hline Autonomous police vehicle & $\begin{array}{l}\text { M Ahmad, H Banvait, AM } \\
\text { Gurghian... - US Patent App. } \\
10 \text {.., } 2019 \text { - Google Patents }\end{array}$ & $\begin{array}{l}\ldots \text { for image analysis or image enhancement; G06T2207/30- } \\
\text { Subject of image; Context of image processing; ...110 may } \\
\text { analyze the one or more images based on machine learning } \\
\text { and ... Alternatively or additionally, autonomous police vehicle } \\
110 \text { may receive an image of the ... }\end{array}$ & Não & $\begin{array}{l}\text { Não se refere ao objeto de } \\
\text { busca }\end{array}$ \\
\hline $\begin{array}{l}\text { Site scanning using a work } \\
\text { machine with a camera }\end{array}$ & $\begin{array}{l}\text { MG Kean - US Patent App. } \\
\text { 15/693,818, } 2019 \text { - Google } \\
\text { Patents }\end{array}$ & $\begin{array}{l}\text {... A visual odometry calculation } 320 \text {, for example, may be } \\
\text { performed by the controller as part of ... In one example of this } \\
\text { process, the field data database } 402 \text { or vision processing } \\
\text { algorithm that may ... For example, if the robot or machine } \\
\text { encounters a bump on the road, this may affect ... }\end{array}$ & Sim & $\begin{array}{l}\text { Processamento de imagens } \\
\text { para localização }\end{array}$ \\
\hline $\begin{array}{l}\text { Robotic agricultural system } \\
\text { and method }\end{array}$ & $\begin{array}{l}\text { DC Crinklaw, C Schapansky, } \\
\text { R Vaccari... - US Patent App. } \\
16 \text {..., } 2019 \text { - Google Patents }\end{array}$ & $\begin{array}{l}\text {... Publication date 2019-03-28 2018-11-28 Application filed by } \\
\text { Crinklaw Farm Services Inc filed Critical Crinklaw Farm } \\
\text { Services Inc ...A01B-SOIL WORKING IN AGRIIULTURE OR } \\
\text { FORESTRY; PART, DETALS, OR ACCESSORIES OF } \\
\text { AGRICULTURAL MACHINES OR ... }\end{array}$ & Não & $\begin{array}{l}\text { Não usa processamento de } \\
\text { imagens }\end{array}$ \\
\hline $\begin{array}{l}\text { Vehicle and trailer maneuver } \\
\text { assist system }\end{array}$ & $\begin{array}{l}\text { JP Gali, RC Bozich, N Gupta, } \\
\text { DW Hodgman... - US Patent } \\
\text { App. } 16 \ldots, 2019 \text { - Google } \\
\text { Patents }\end{array}$ & $\begin{array}{l}\ldots . . \text { at a data processor using machine vision techniques, such } \\
\text { as known machine vision techniques ... The system is also } \\
\text { suitable for trailers used in the agricultural Industry, used on ... } \\
\text { that includes the imaging sensor array and associated circuitry } \\
\text { and image processing circuitry and ... }\end{array}$ & Não & $\begin{array}{l}\text { Não se refere ao objeto de } \\
\text { busca }\end{array}$ \\
\hline $\begin{array}{l}\text { System and method for } \\
\text { detecting taillight signals of a } \\
\text { vehicle }\end{array}$ & $\begin{array}{l}\text { Y Wang, ZHU Ligeng, P } \\
\text { Wang... - US Patent App. } \\
\text { 15/709,832, } 2019 \text { - Google } \\
\text { Patents }\end{array}$ & $\begin{array}{l}\ldots \text { within which a set of instructions when executed may cause } \\
\text { the machine to perform ... assistants (PDA's), MP3 players, } \\
\text { tablet computing devices (eg, iPad }{ }^{\text {TM }} \text { ), laptop computers, CD } \\
\text { players ... that executes processing instructions stored in a } \\
\text { non-transitory computer readable medium ... }\end{array}$ & Não & $\begin{array}{l}\text { Não usa processamento de } \\
\text { imagens }\end{array}$ \\
\hline $\begin{array}{l}\text { Apparatuses And Methods } \\
\text { For Bio-Sensing Using } \\
\text { Unmanned Aerial Vehicles }\end{array}$ & $\begin{array}{l}\text { V Pluvinage - US Patent App. } \\
\text { 16/201,727, } 2019 \text { - Google } \\
\text { Patents }\end{array}$ & $\begin{array}{l}\text {... could be sent to various computers } 120 \text { (eg, hand held } \\
\text { devices } 120 \text {, fog computers } 120 \text {, or ... This could be a standard } \\
\text { filter, a simple machine learning algorithm, or other computation } \\
\ldots \text { of useful information that can be sent on the UAV radio-link } \\
\text { to the flight monitoring computer ... }\end{array}$ & Não & $\begin{array}{l}\text { Aplicação para imagens } \\
\text { externas (Drones) }\end{array}$ \\
\hline $\begin{array}{l}\text { [PDF] Fast Instance and } \\
\text { Semantic Segmentation } \\
\text { Exploiting Local Connectivity, } \\
\text { Metric Learning, and One- } \\
\text { Shot Detection for Robotics }\end{array}$ & $\begin{array}{l}\text { A Milioto, L Mandtler, C } \\
\text { Stachniss - ipb.uni-bonn.de }\end{array}$ & $\begin{array}{l}\ldots \text { This is inconvenient for robotic tasks where the location of } \\
\text { each object is of interest, for example, to be used as a visual } \\
\text { landmark, for object manipulation ... on Pattern Analalysis and } \\
\text { Machine Intelligence (TPAMI), } 2017 \ldots \text { on Computer Vision and } \\
\text { Pattern Recognition (CVPR), } 2018 \ldots\end{array}$ & Sim & Segmentação de imagens \\
\hline $\begin{array}{l}\text { System and method for } \\
\text { occluding contour detection }\end{array}$ & $\begin{array}{l}\text { P Wang, P Chen, Z Huang - } \\
\text { US Patent App. 16/159,060, } \\
2019 \text { - Google Patents }\end{array}$ & $\begin{array}{l}\text {... a diagrammatic representation of machine in the example } \\
\text { form of a computer system within which a set of instructions } \\
\text { when executed may cause the machine to perform .... } \\
\text { assistants (PDA's), MP3 players, tablet computing devices (eg, } \\
\left.\text { (Pad }{ }^{T M}\right) \text {, laptop computers, CD players ... }\end{array}$ & Sim & $\begin{array}{l}\text { Processamento de imagens } \\
\text { para veiculos autônomos }\end{array}$ \\
\hline $\begin{array}{l}\text { A cascading fuzzy logic with } \\
\text { image processing algorithm- } \\
\text { based defect detection for } \\
\text { automatic visual inspection of } \\
\text { industrial cylindrical object's } \\
\text { surface }\end{array}$ & $\begin{array}{l}\text { MAH Ali, AK Lun - The } \\
\text { International Journal of } \\
\text { Advanced Manufacturing ..., } \\
2019 \text { - Springer }\end{array}$ & $\begin{array}{l}\ldots \text { on flabbiness, shape, size, and intensity of the fruit [9]. } \\
\text { Computer vision techniques are ... For advanced color sorting } \\
\text { and classifying, Anvarkhah proposed a machine vision } \\
\text { algorithm for ... fuzzy logic, artificial neural network, genetic } \\
\text { algorithm, support vector machine, and decision ... }\end{array}$ & Não & $\begin{array}{l}\text { Não se refere ao objeto de } \\
\text { busca }\end{array}$ \\
\hline $\begin{array}{l}\text { [LIVRO] Artificial Intelligence: } \\
\text { Rise of the Lightspeed } \\
\text { Learners }\end{array}$ & $\begin{array}{l}\text { C Jennings - } 2019 \text { - } \\
\text { books.google.com }\end{array}$ & $\begin{array}{l}\text {... employment is down } 99 \text { percent since } 2010 \text { and where Als } \\
\text { and computers now do ... of Earth." He dubbed this new } \\
\text { species Machina sapiens the thinking machine. } 13 \text { Twenty ... } \\
\text { explained that he was helping a Caltech professor } \\
\text { commercialize Al computer vision intellectual property ... }\end{array}$ & Não & $\begin{array}{l}\text { Não se refere ao objeto de } \\
\text { busca }\end{array}$ \\
\hline
\end{tabular}




\section{Apêndice D}

\section{APRENDIZADO DE MÁQUINA}

O aprendizado de máquina é fundamental para viabilizar de forma algébrica os algoritmos de aprendizado em cada camada da rede profunda. Os principais avaliados foram:

\section{Regressão Linear}

Mais simples usada forma linear de projeção de valores de uma determinada variável y, a partir de valores condicionais uma outra variável. Matematicamente representada como uma equação de uma reta e sua respectiva inclinação por $y_{i}=\alpha+\beta X_{i}+\varepsilon_{i}$. Sendo $y_{i}$ a variável a ser prevista pelo modelo, $\alpha$ uma constante que determina a interceção da reta com o eixo $y, \beta$ refere-se a inclinação da reta, $X_{i}$ é a outra variável condicional para projeção de $y_{i}$ e, por fim, o $\varepsilon_{i}$ representa os demais potencias erros da base de dados.

\section{Método dos Minimos Quadrados}

Conforme debatido em aula do curso de Mestrado em Engenharia Elétrica, o Método dos Mínimos Quadrados (MMQ), é uma técnica de otimização matemática que procura encontrar o melhor ajuste para um conjunto de dados tentando minimizar a soma dos quadrados das diferenças entre o valor estimado e os dados observados (tais diferenças são chamadas resíduos).

É a forma de estimar mais comumente utilizada na econometria. Consiste em uma estimativa que minimiza a soma dos quadrados dos resíduos da regressão, de forma a maximizar o grau de ajuste do modelo aos dados observados. Um requisito para o método dos mínimos quadrados é que o fator imprevisível (erro) seja distribuído aleatoriamente e essa distribuição seja normal. O Teorema Gauss-Markov garante (embora indiretamente) que o estimador de mínimos quadrados é o estimador não-enviesado de mínima variância linear na variável resposta. 
Outro requisito é que o modelo é linear nos parâmetros, ou seja, as variáveis apresentam uma relação linear entre si. Caso contrário, deveria ser usado um modelo de regressão não-linear.

O método dos mínimos é descrito da seguinte forma:

Dado um vetor de entrada $X^{T}=\left(X_{1}, X_{2}, \ldots, X_{p}\right)$, é possível estimar a saída Y por meio do modelo: $Y=\beta_{0}+\sum_{j=1}^{p} X_{j} \beta_{j}$, onde o termo $\beta_{0}$ é conhecido como "intercept" ou bias no conceito de aprendizado de máquina.

Para o método dos mínimos, deve se utilizar os valores de Beta para minimizar a soma residual dos quadrados: $\operatorname{RSSB}(\beta)=\sum_{i=1}^{N}\left(y_{i}-x_{i}^{T} \beta\right)^{2}$. $\operatorname{RSS}($ Beta $)$ é uma função quadrática e apesar de seu mínimo sempre existir, pode não ser o único. A solução é utilizar a notação de matriz.

Fazendo a derivada de acordo com Beta, assumindo que $\mathrm{X}$ é completo de dados e XTX é singular, obtem-se por meio de igualar a tal derivada a zero, a respectiva solução para $\beta=\left(X^{T} X\right)^{-1} X^{T} y$

Outros métodos lineares seriam Weighted Linear Leats Squares e Robust Least squares. Onde o primeiro consiste em atribuir pesos no processo de aderência da da reta por meio de sua divisão pelo desvio padrão respectivo. Ja o segundo consiste em desconsiderar valores que tem seu desvio de aderência muito grande comparado ao método linear.

Análise do Componente Principal (PCA, sigla em inglês)

A Principal Component Analysis (sigla PCA em inglês) é um procedimento matemático que utiliza uma transformação ortogonal (ortogonalização de vetores) para converter um conjunto de observações de variáveis possivelmente correlacionadas num conjunto de valores de variáveis linearmente não correlacionadas chamadas de componentes principais. $\mathrm{O}$ número de componentes principais é menor ou igual ao número de variáveis originais. Esta transformação é definida de forma que o primeiro componente principal tem a maior variância possível (ou seja, é responsável pelo máximo de variabilidade nos dados), e 
cada componente seguinte, por sua vez, tem a máxima variância sob a restrição de ser ortogonal a dos componentes anteriores. Os componentes principais são independentes apenas se os dados forem normalmente distribuídos (conjuntamente). O PCA é sensível à escala relativa das variáveis originais. Dependendo da área de aplicação, o PCA é também conhecido como transformada de Karhunen-Loève (KLT) discreta, transformada de Hotelling ou decomposição ortogonal própria (POD).

O PCA é a mais simples das verdadeiras análises multivariadas por autovetores. Com frequência, sua operação pode ser tomada como sendo reveladora da estrutura interna dos dados, de uma forma que melhor explica a variância nos dados. Se visualizarmos um conjunto de dados multivariados em um espaço de alta dimensão, com 1 eixo por variável, o PCA pode ser usado para fornecer uma visualização em dimensões mais baixas dos mesmos dados, uma verdadeira "sombra" do objeto original quando visto de seu ponto mais informativo. Isto é feito usando-se apenas os primeiros componentes principais, de forma que a dimensionalidade dos dados transformados é reduzida.

Seja a matriz de dados, XT, com média empírica nula, onde cada uma das n linhas representa uma repetição diferente do experimento, e cada uma das $m$ colunas dá um tipo particular de dado. A decomposição em valores singulares de $\mathbf{X}$ é $\mathbf{X}=\mathbf{W} \mathbf{\Sigma V T}$, onde a matriz $m \times m \mathbf{W}$ é a matriz de autovetores da matriz de covariância XXT, a matriz $\Sigma$ é $m \times n$ e é uma matriz diagonal retangular com números reais não negativos na diagonal, e a matriz $n \times$ $n \mathbf{V}$ é a matriz de autovetores de XTX. V não é definida unicamente no caso usual de $m<n$ - 1, porém $\mathbf{Y}$ deve ser. Como $\mathbf{W}$ é uma matriz ortogonal, e cada linha de $\mathbf{Y T}$ é simplesmente uma rotação da linha correspondente de XT. A primeira coluna de YT é feita das "pontuações" dos casos relativamente ao componente "principal", a próxima coluna tem a pontuação relativamente ao segundo componente "principal", e assim por diante.

Para uma representação de dimensionalidade reduzida, pode-se projetar $\mathbf{X}$ ao espaço a matriz identidade retangular, ja a matriz $\mathbf{W}$ de vetores singulares de $\mathbf{X}$ é equivalentemente a matriz $\mathbf{W}$ de autovetores da matriz de covariâncias $\mathbf{C}=\mathbf{X} \mathbf{X T}$.

Para um conjunto de pontos no espaço euclidiano, o primeiro componente principal corresponde a uma linha que passa por meio da média multidimensional e minimiza a soma dos quadrados das distâncias dos pontos à linha. $O$ segundo componente principal corresponde ao mesmo conceito, depois de subtrair-se toda a correlação com o primeiro 
componente principal dos pontos. Os valores singulares (em $\Sigma$ ) são as raízes quadradas dos autovalores da matriz XXT. Cada autovalor é proporcional à porção de "variância" que tem relação com cada autovetor. A soma de todos os autovalores é igual à soma dos quadrados dos pontos à média multidimensional dos mesmos. O PCA essencialmente rotaciona $\mathrm{o}$ conjunto de pontos em torno da média de forma a alinhá-los com os componentes principais. Isto move o máximo possível de variância (usando uma transformação ortogonal) a algumas das primeiras dimensões. Os valores nas dimensões restantes, portanto, tendem a serem pequenos e podem ser descartados com o mínimo de perda de informação.

Análise Discriminante Linear (LDA, sigla em inglês)

Análise discriminante linear é uma generalização do discriminante linear de Fisher, um método usado em estatística, para reconhecimento de padrões e para encontrar uma combinação linear de características que determinam ou separam duas ou mais classes de objetos ou eventos. A combinação resultante pode ser usada como um classificador linear ou, mais comumente, para redução de dimensionalidade antes de uma classificação posterior.

A LDA está relacionada à análise de variância e de regressão, que determinam também uma variável dependente como uma combinação linear de outras características ou medidas. No entanto, a análise de variância usa variáveis independentes categóricas e uma variável dependente contínua, enquanto a análise discriminante tem variáveis independentes contínuas e uma variável dependente categórica, ou seja, a respectiva denominação da classe. A regressão logística, por exemplo, é mais semelhantes ao LDA do que, no caso, a análise de variância supracitada, pois também corresponde a uma variável categórica pelos valores das variáveis independentes contínuas. Esse outro método é preferível em aplicações em que não é razoável assumir que as variáveis independentes são normalmente distribuídas, o que é uma suposição fundamental do método LDA.

A LDA também está intimamente relacionado à análise de componentes principais (PCA, sigla em inglês), na medida em que ambos buscam combinações lineares de variáveis que melhor expliquem os dados. Enquanto a LDA modela a diferença entre as classes de dados, o PCA não leva em consideração nenhuma diferença na classe, e a análise fatorial determina as combinações de recursos com base nas diferenças, e não nas semelhanças. 
A LDA funciona quando as medições feitas em variáveis independentes para cada observação são quantidades contínuas. Ao lidar com variáveis independentes categóricas, a técnica equivalente é a análise de correspondência discriminante, que é usada quando os grupos são previamente conhecidos e cada caso deve ter uma pontuação em uma ou mais medidas preditivas e uma pontuação em uma medida em grupo.

\section{K-Means}

O K-Means tem como finalidade particionar $\mathrm{n}$ observações dentre $\mathrm{k}$ grupos onde cada observação pertence ao grupo mais próximo da média. Isso resulta em uma divisão do espaço de dados em um Diagrama de Voronoi. Ele usa o centro de clusters para modelar dados, no entanto, este agrupamento tende a encontrar clusters de extensão espacial comparáveis .

O K-Means é definido a partir de uma quantidade inicial aleatória de centroides (centros) de uma base de dados calculados conforme a distância euclidiana entre eles. Desta forma o algoritmo alterna em dois passos principais: para cada centro é identificado um subgrupo de pontos (cluster) que é o mais próximo que qualquer outro centro; A média de cada ponto em cada agrupamento é novamente calculada ou computada, e para o vetor médio resultante é atribuído o novo centro do respectivo agrupamento/cluster. Para os dois passos principais do algoritmo em questão são feitas iterações até que haja a convergência.

Para um conjunto de ocorrências $(x 1, x 2, \ldots, x n)$, onde cada ocorrência é um vetor real d-dimensional, o K-Mean deve particionar as n ocorrências em $k(\leq n)$ conjuntos $S=\{S 1, S 2$, ..., $S k\}$ para minimizar a soma de quadrados dentro do cluster, ou seja, formalmente: $\underset{\mathbf{S}}{\arg \min } \sum_{i=1}^{k} \sum_{\mathbf{x} \in S_{i}}\left\|\mathbf{x}-\boldsymbol{\mu}_{i}\right\|^{2}=\underset{\mathbf{S}}{\arg \min } \sum_{i=1}^{k}\left|S_{i}\right| \operatorname{Var} S_{i}$

Onde $\mu i$ é a média de pontos em Si. Isso equivale a minimizar os pares de desvios de pontos no mesmo cluster, ou seja, $\underset{\mathbf{S}}{\arg \min } \sum_{i=1}^{k} \frac{1}{2\left|S_{i}\right|} \sum_{\mathbf{x}, \mathbf{y} \in S_{i}}\|\mathbf{x}-\mathbf{y}\|^{2}$. Deduzindo da identidade: $\sum_{\mathbf{x} \in S_{i}}\left\|\mathbf{x}-\boldsymbol{\mu}_{i}\right\|^{2}=\sum_{\mathbf{x} \neq \mathbf{y} \in S_{i}}\left(\mathbf{x}-\boldsymbol{\mu}_{i}\right)\left(\boldsymbol{\mu}_{i}-\mathbf{y}\right)$ 
Sendo a variância constante, isto equivale a maximizar a soma dos desvios quadrados entre os pontos nos diferentes agrupamentos.

\section{Naïve Bayes}

Naive Bayes é uma técnica simples para a construção de classificadores. Modelos que atribuem rótulos de classes a instâncias de problemas, representados como vetores de valores de recursos, em que os rótulos de classes são extraídos de um conjunto finito. Não existe um algoritmo único para treinar esses classificadores, mas uma família de algoritmos baseada em um princípio comum: todos os classificadores Bayes ingênuos assumem que o valor de uma característica particular é independente do valor de qualquer outra característica, dada a variável de classe. Por exemplo, uma fruta pode ser considerada uma maçã se for vermelha, redonda e com cerca de $10 \mathrm{~cm}$ de diâmetro. Um classificador de Bayes ingênuo considera que cada uma dessas características contribui independentemente para a probabilidade de que essa fruta seja uma maçã, independentemente de quaisquer possíveis correlações entre as características de cor, redondeza e diâmetro.

Para alguns tipos de modelos de probabilidade, os classificadores ingênuos de Bayes podem ser treinados de forma muito eficiente em um ambiente de aprendizado supervisionado. Em muitas aplicações práticas, a estimação de parâmetros para modelos ingênuos de Bayes usa o método da máxima probabilidade; em outras palavras, pode-se trabalhar com o modelo ingênuo de Bayes sem aceitar a probabilidade bayesiana ou usando quaisquer métodos bayesianos.

No aprendizado de máquina, os classificadores ingênuos de Bayes é uma família de classificadores probabilísticos simples baseados na aplicação do teorema de Bayes com pressupostos de independência entre os recursos, dai a denominação de classificadores ingênuos.

Os classificadores Naive Bayes são altamente escalonáveis, exigindo um número de parâmetros lineares no número de variáveis (recursos / preditores) em um problema de aprendizado. 
O treinamento de máxima probabilidade pode ser feito por meio da avaliação de uma expressão de forma fechada, que leva tempo linear, ao invés de uma aproximação iterativa cara como é usada para muitos outros tipos de classificadores.

Nas estatísticas e na literatura da ciência da computação, modelos ingênuos de Bayes são conhecidos sob uma variedade de nomes, incluindo Bayes simples e Bayes da independência.

Uma vantagem dos Bayes ingênuos é que requer apenas um pequeno número de dados de treinamento para estimar os parâmetros necessários para a classificação.

Resumidamente, Naive Bayes ingênuo é um modelo de probabilidade condicional, ou seja, dada uma instância de problema a ser classificada, representada por um vetor $x=(x 1, \ldots$ , xn) representando alguns $\mathrm{n}$ recursos (variáveis independentes), atribui a esta instância probabilidades: $p(C k \mid x 1, \ldots, x n)$ para cada um dos possíveis resultados de $K$ ou classes.

O problema com a formulação acima é que, se o número de recursos $\mathrm{n}$ for grande ou se um recurso puder assumir um grande número de valores, basear esse modelo em tabelas de probabilidade será inviável. Portanto, o modelo foi reformulado para torná-lo mais tratável. Usando o teorema de Bayes, a probabilidade condicional pode ser decomposta como : $p(C k \mid$ $x)=p(C k) p(x \mid C k) / p(x)$, ou seja, posterior $=$ anterior $\mathrm{x}$ probabilidade $/$ evidencia.

Na prática, apenas o numerador dessa fração é importante, pois o denominador não depende de $\mathrm{C}$ e os valores das características xi são dados, de modo que o denominador é efetivamente constante. O numerador é equivalente ao modelo de probabilidade conjunto.

Definiu-se então, até agora, modelo de recursos independente, isto é, o modelo de probabilidade ingênuo de Bayes. $O$ classificador Bayes ingênuo combina esse modelo com uma regra de decisão. Uma regra comum é escolher a hipótese mais provável; isto é conhecido como a máxima regra de decisão a posteriori ou MAP. O classificador correspondente, um classificador de Bayes, é a função que atribui um rótulo de classe.

Ao lidar com dados contínuos, uma suposição típica é que os valores contínuos associados a cada classe são distribuídos de acordo com uma distribuição gaussiana: $p\left(x=v \mid C_{k}\right)=\frac{1}{\sqrt{2 \pi \sigma_{k}^{2}}} e^{-\frac{\left(v-\mu_{k}\right)^{2}}{2 \sigma_{k}^{2}}}$ 